\title{
Anais do I Congresso Interdisciplinar da Área Médica (I C.I.A.M.)
}

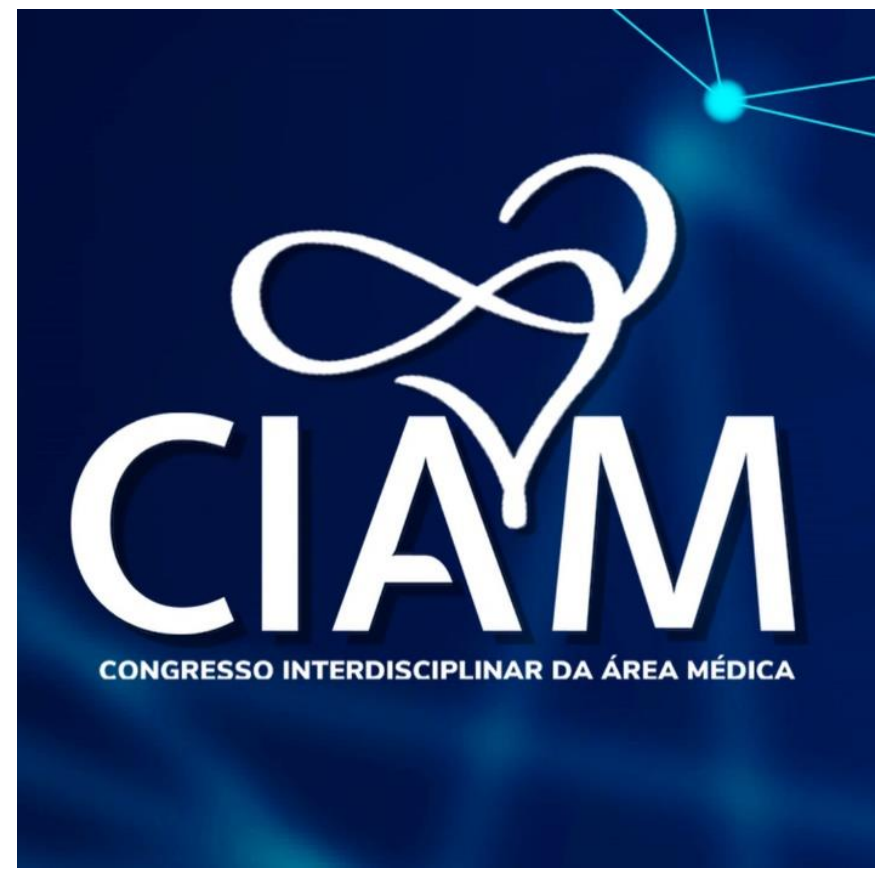

\section{Apoio:}

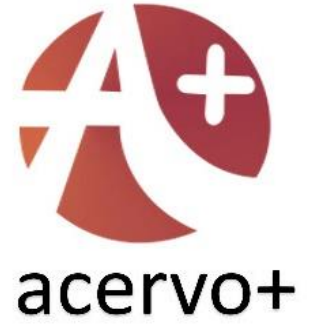

Eventos

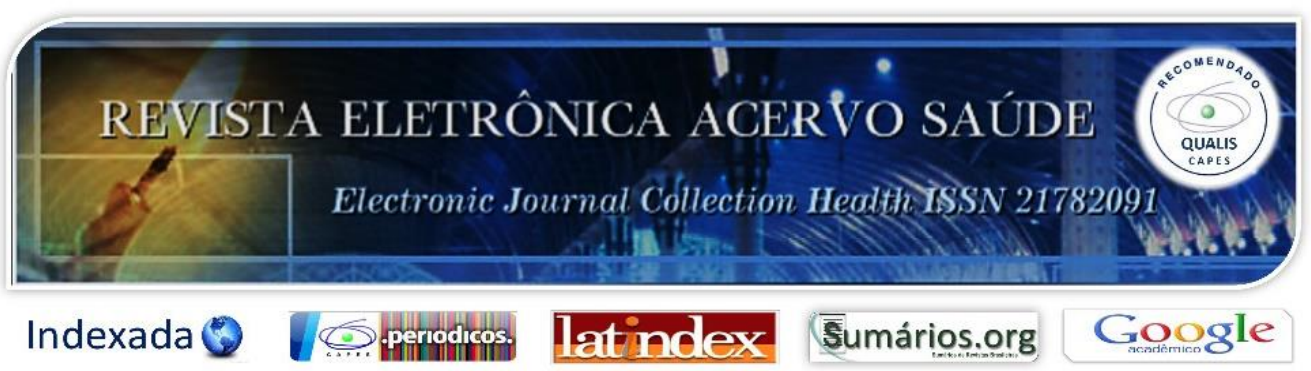




\section{SUMÁRIO}

SOBRE O EVENTO

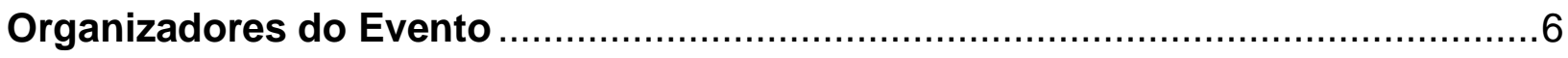

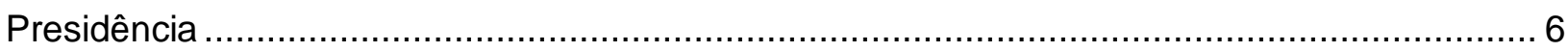

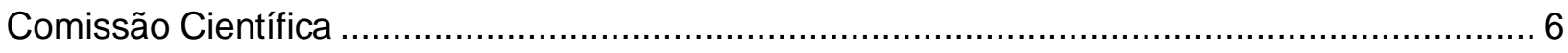

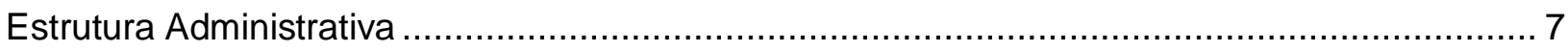

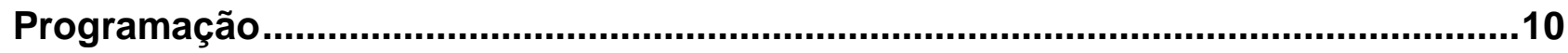

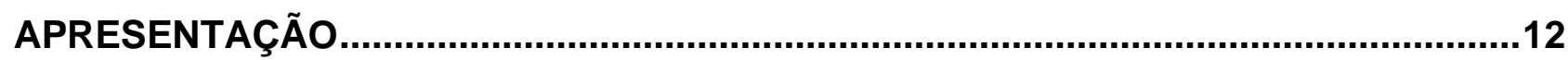

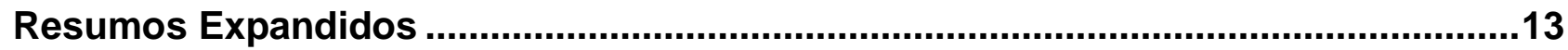

Título: Receptor CD147 como alvo terapêutico para COVID-19 ….........................13

Título: Morbimortalidade por Leishmaniose visceral em menores de 10 anos entre 2015-

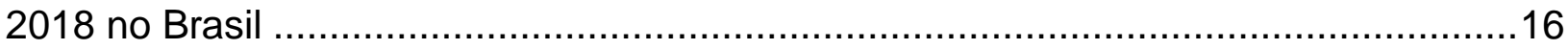

Título: Análise do potencial da protease NSP5 do SARS-CoV-2 como alvo para

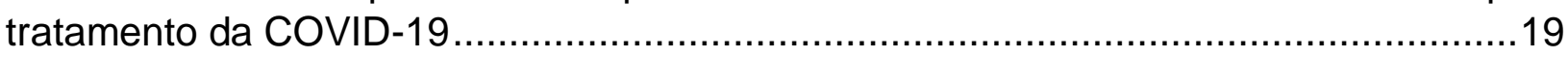

Título: Automedicação entre estudantes de ciências da saúde ...................................21

Título: Mortalidade por pneumonia em crianças menores de um ano na região Nordeste

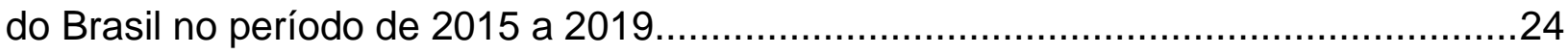

Título: Percentual de casos confirmados de tuberculose em presídios no estado de mato

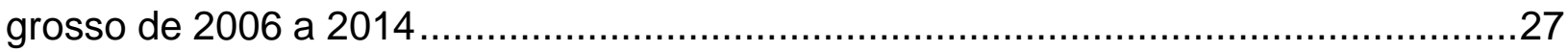

Título: O risco da cefaleia por uso excessivo de medicamentos entre os estudantes de

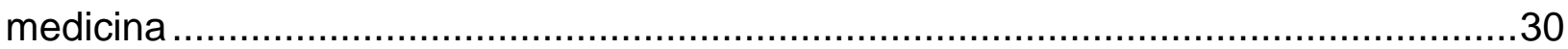

Título: Morbimortalidade hospitalar por Insuficiência Cardíaca no Brasil entre janeiro de

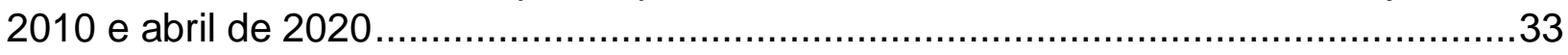

Título: Inserção da oftalmologia na formação médica do Rio Grande do Norte: análise

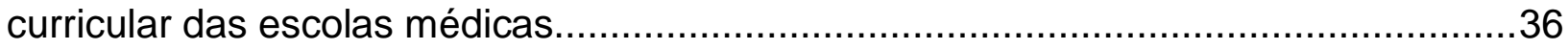

Título: Cobertura vacinal de crianças assistidas pela Estratégia de Saúde da Família em exame de rotina.

Título: Análise Temporal das fraturas de fêmur em idosos na região Sudeste do Brasil:

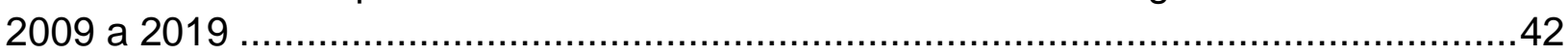

Título: Mortalidade por Melanoma maligno de pele na Bahia e em Santa Catarina ......44 Título: Manifestações cutâneas em pacientes com HIV: uma revisão integrativa da literatura

Título: Aconselhamento Genético na Atenção Primária: A importância da sua ampliação 
Título: Baloxavir Marboxil como uma nova opção de tratamento para Influenza: revisão narrativa . .52

Título: O papel da genética na tumorigênese: RNAcircular e sua relação com câncer de mama

Título: Capacitação de agentes comunitários de saúde em puericultura: relato de uma experiência..... .56

Título: Aspectos Epidemiológicos e Fisiopatológicos sobre Lesão Renal Aguda e COVID19

Título: Sistematização das Visitas Domiciliares em uma Estratégia de Saúde da Família do Norte de Minas Gerais.

Título: Análise da coinfecção HIV/Tuberculose .62

Título: Uso da imunoterapia em neoplasia de próstata .65

Título: O uso do Dimesilato de Lisdexanfetamina no tratamento do TDAH: uma revisão sobre o tema

Título: A extensão universitária e seus impactos na formação profissional: um relato de experiência no curso de medicina de uma universidade pública do estado da Paraíba69

Título: Quem pensa brinca com segurança: mensurando o aprendizado de crianças do ensino municipal acerca da prevenção do neurotrauma

Título: Comparação dos efeitos da Síndrome de Burnout entre professores escolares e universitários no Brasil: uma revisão sistemática ........................................................73

Título: Avaliação Imagiológica em Pacientes com Suspeita de COVID-19 ..................76

Título: Saúde bucal da gestante e suas consequências embrionárias e fetais: uma prevenção e um tratamento interprofissional...............................................................

Título: A vulnerabilidade dos imigrantes venezuelanos em meio à pandemia da COVID19 em Boa Vista-RR.

Título: Acidente vascular cerebral como complicação em pacientes com covid-19: uma revisão da literatura.

Título: Prevenção de Trauma Cranioencefálico e Raquimedular entre crianças de 8 a 14 anos em escolas públicas municipais.

Título: Como Conduzir o Primeiro Atendimento aos Pacientes Vítimas de Queimaduras .89

Título: Panorama da violência contra as mulheres: Uma revisão da literatura.

Título: Determinantes em saúde na faixa pediátrica: um relato de experiência em escolas públicas

Simples .95

Título: Análise da mortalidade por sepse em pacientes com doença falciforme .95

Título: Análise do gene APC no contexto da oncogenética: uma revisão sistemática ..97 
Título: Diagnósticos diferenciais da leucocoria e o papel da atenção básica no seu rastreio .99

Título: Diagnóstico diferencial entre Mutismo Seletivo e Autismo: uma revisão bibliográfica 101

Título: O uso de inibidores de SGLT2 em DM1 e o risco de cetoacidose diabética ....103 Título: Uso de células-tronco mesenquimais no tratamento de pneumonia por COVID-19 105

Título: Planejamento Familiar e sexualidade na escola: relato de experiência de uma ação educativa com foco na escuta 107

Título: Terapia nutricional na queimadura em crianças: uma revisão literária. 109

Título: A telessaúde em tempos de pandemia: o contato entre acadêmicos de medicina do segundo ano e idosos em distanciamento social.

Título: A influência dos fatores neuronais e do ambiente obesogênico no desenvolvimento da obesidade

Título: Impactos da intervenção em saúde na escola na graduação médica: um relato de experiência. 115

Título: Abordagem da lombalgia crônica inespecífica em adultos: aspectos clínicos e terapêuticos.

Título: A relação entre o foco restrito/interesse intenso na síndrome de Asperger e o desenvolvimento de alta habilidade. 119

Título: COVID-19: coagulação intravascular disseminada e o uso de anticoagulante como tromboprofilaxia.... 121

Título: Isoflavona de soja como terapia não-hormonal do climatério. 123

Título: Utilização de drogas vasoativas no choque distributivo: uma revisão sistemática 125

Título: Manifestação hemorrágica de cavernoma mesencefálico associado a outras malformações vasculares ocultas em paciente jovem.

Título: Staphylococcus aureus resistente à meticilina: um estudo sobre a pravalência de infecções nosocomiais 129

Título: Principais consequências da prática de automedicação em idosos: uma revisão integrativa. 131 


\section{SOBRE O EVENTO}

O I Congresso Interdisciplinar da Área Médica, que aconteceu entre os dias 31 de julho e 02 de agosto de 2020, surgiu diante da necessidade de se repensar o cuidado médico de forma integral e multidisciplinar. Buscou integrar os saberes e valorizar as diferentes culturas, que estão ligadas ao processo saúde-doença. Representou, antes de tudo, uma reflexão sobre a prática atual das diversas profissões e os desafios na promoção de uma saúde que atenda aos princípios da equidade, integralidade e universalidade, dispostos na Constituição Federal de 1988 e na Lei 8.080/1990.

O evento objetivou oferecer, aos acadêmicos da área da saúde, um espaço para discussão de um ser holístico e sujeito autônomo e, portanto, corresponsável pelo próprio cuidado. Também se colocou como fórum aberto para a interação e intercâmbio das diversas faces das ciências da saúde.

O I C.I.A.M. contou com palestrantes ilustres que, com propriedade, ensinaram uma medicina baseada em evidências e que tem a humanização como seu baluarte, como sua defesa.

O evento, organizado por acadêmicos do Centro Universitário Atenas (Paracatu) e da Faculdade Atenas (Passos e Sete Lagoas-MG), com apoio da sociedade civil, devido às restrições sanitárias, ocorreu em ambiente virtual. Contudo, o que antes parecia uma limitação transformou o congresso de um evento local para um evento de dimensão nacional, contando com mais de 1.000 inscritos, de todas as regiões do país. Mais uma vez evidenciando a necessidade de se discutir de forma plural, aberta e séria.

A grande adesão dos acadêmicos e profissionais foi um reflexo da grandiosidade do evento. Mesmo com a distância física, o I C.I.A.M. buscou maneiras para se manter próximo dos seus congressistas, seja através da interação promovida pelos moderadores, seja por meio da comunicação pelo chat de dúvidas no decorrer de toda a transmissão do evento, mostrando ser possível se transformar a discussão em saúde através do ambiente virtual.

SABRINA ALVES MAIA, Presidente da Comissão Organizadora do I C.I.A.M.;

JOSUÉ DA SILVA BRITO,

Diretor Científico do I C.I.A.M. 


\section{Organizadores do Evento}

\section{Presidência}

Sabrina Alves Maia - Presidente

Queren Hapuque Gonçalves Carneiro Santos - Vice-presidente

Comissão Científica

Orientadora do evento

Talitha Araújo Velôso Faria

Diretores científicos

Josué da Silva Brito

Jassiara Soares da Silva

Integrantes da comissão científica

Amabilly Dias Vieira Nazário Alves

Anna Emanueli Lacerda Garcez

Beatriz Lemos Baptistela

Cleudimar da Luz Araújo

Gabriela Teixeira Lima

Hellen Kristina Magalhães Brito

Isabela Ranieri Sillos

Isabela Simões Mendes

Isadora Andrade Porto Campos

Lara Mariana Rosa

Matheus Damas Campos

Pedro Paulo Batista de Abreu

Rhafael de Santana Fernandes

Talita de Oliveira Soares 


\section{Estrutura Administrativa}

Agda Lorena de Souza Oliveira

Alisson Cesar de Figueredo

Ana Karoline Mendes Lima

Ana Lídia Araújo Freitas

Ana Luiza Resende

Andressa Carvalho Freire

Anne Caroline Matos dos Santos

Bárbara Furtado de Noronha

Beatriz Carvalho Rodrigues

Beatriz de Oliveira

Bruna Albernaz Costa Couto

Camilla Dias da Cruz

Carolina Lelis Neiva

Douglas Ferreira Lima

Eduardo Henrique Antunes Mann

Esther Eloisa Magalhães de Paula

Fabrizzio German Fernandini Torres

Fernanda Pereira Alvarenga

Flávia Andrade Sousa

Francisco Vianna de Freitas Paiva

Gabriel Kewen da Costa

Giovanna Bizinoto Molinar Andrade

Guilherme Augusto Detome Vertelo

Guilherme Machado Moura

Hugo Ribeiro Vinhal de Sena

Izabella Martins Sales

João César Almeida Merçon

João Paulo Murta Alves

João Vítor Gonçalves Ferreira

José Calmito Fagundes Ledo Filho

Júlia Cristina de Sousa Ramos 


\author{
Júlia Rabelo Bitencourt \\ Junielly Priston Araujo \\ Kállita Marques da Silva \\ Karla Vanessa Rodrigues Morais \\ Kelton de Oliveira Conceição \\ Laís Maria Borges Marins \\ Larissa Fernandes Amaral \\ Larissa Ferreira Sá \\ Larissa Salles Reis Cardoso de Sá \\ Laura Marçal Silva \\ Letícia Fernandes Teixeira \\ Leticia Helena Araújo Silva \\ Letícia Helena Araujo Silva \\ Leticya Alves Guimarães \\ Luana Almeida Abreu \\ Luanna Marques de Paula \\ Lucas Lopes Malveira \\ Lucas Medeiros Ruas \\ Lucas Oliveira Castro \\ Luiz Gustavo Mesquita Ribeiro \\ Maria Clara Morais Melo \\ Maria Eugênia Costa Casagrande \\ Maria Luisa Miranda Macedo \\ Mariana Alves e Cruz \\ Mariana de Paula Ferreira \\ Mariana Paula Borges Silva \\ Marília Milena Andrade Rodrigues \\ Marina Rocha Arêdes \\ Matheus Garcia Ribeiro \\ Matheus Gontijo Lima de Oliveira Santos \\ Mirelly Dantas Caldeira Aeissami \\ Natália Bontempo Mendes \\ Nelissa Abud de Castro
}


Nicole Assis Valadares Tavares

Nilo Gonçalves dos Santos Neto

Núbia Nayra de Freitas Rabelo

Patrícia Guimarães Teixeira

Patrícia Knupp Miranda

Paulo Christian Pereira Araújo

Paulyanara Monique Alves de Souza

Rayane Pereira Vogado

Rayssa Mendes de Melo

Rosanna Rodrigues Mangabeira

Rubenrhaone Alberto Paulino

Silvano Araujo Ferreira Junior

Talita Carenzio Azevedo

Thallita do Vale Lima

Thayssa Assis Menezes

Yngrid Marques de Sousa 


\section{Programação}

\begin{tabular}{|c|c|c|}
\hline \multirow{2}{*}{ ATIVIDADE } & \multicolumn{2}{|c|}{ HORÁRIO } \\
\hline & INÍCIO & TÉRMINO \\
\hline \multicolumn{3}{|l|}{$31 / 07 / 2020$} \\
\hline Cerimônia de Abertura & $18: 00$ & 19:00 \\
\hline $\begin{array}{l}\text { Palestra 1: Magna: Entusiasmo e paixão pela } \\
\text { vida são aspectos normais da saúde perfeita } \\
\text { - Talitha Faria }\end{array}$ & & \\
\hline $\begin{array}{l}\text { Palestra 2: Magna: Saúde Mental do } \\
\text { Estudante de Medicina: realidade atual e } \\
\text { perspectivas - Dr. Arthur Danila }\end{array}$ & 19:00 & $20: 00$ \\
\hline $\begin{array}{l}\text { Palestra Magna: O amor e cura além das } \\
\text { fronteiras- Dr. Diego }\end{array}$ & 20:00 & $21: 00$ \\
\hline $\begin{array}{l}\text { Palestra Magna: De estudante de medicina a } \\
\text { ONU. Ultrapassando barreiras que a } \\
\text { faculdade não te ensino - Dr. Rafael Kenji }\end{array}$ & 21:00 & $22: 00$ \\
\hline \multicolumn{3}{|l|}{$01 / 08 / 2020$} \\
\hline $\begin{array}{l}\text { Palestra 1: Inovações em cirurgias } \\
\text { ortopédicas - Dr. Carlos César Vassalo } \\
\text { Palestra 2: Síndrome de Down e cardiopatias } \\
\text { - Dra Carolina Capuruço }\end{array}$ & 09:00 & $10: 00$ \\
\hline $\begin{array}{l}\text { Palestra 1: IOT e Vias aéreas - Dr. Weber } \\
\text { Tobias }\end{array}$ & & \\
\hline $\begin{array}{l}\text { Palestra 2: Lipoaspiração: Evolução, } \\
\text { Técnicas atuas e tecnologias - Dra Raquel e } \\
\text { Dr.Cristian }\end{array}$ & 10:00 & $11: 00$ \\
\hline $\begin{array}{l}\text { Palestra 1: Acne é só alteração hormonal? - } \\
\text { Dr. Guilherme Muzy }\end{array}$ & & \\
\hline $\begin{array}{l}\text { Palestra 2: Metódo clínico - Dr. Bruno } \\
\text { Farnetano }\end{array}$ & $11: 00$ & 12:00 \\
\hline INTERVALO & $12: 00$ & $14: 00$ \\
\hline $\begin{array}{l}\text { Palestra 1: Comunicação de más notícias - } \\
\text { Dra Ronny } \\
\text { Palestra 2: O que eu devo saber sobre o uso } \\
\text { de Esteroides - Dr Paulo Muzy }\end{array}$ & $14: 00$ & $15: 00$ \\
\hline $\begin{array}{l}\text { Palestra 1: Analgesia e sedação na criança } \\
\text { - Dr. Renato Lucas } \\
\text { Palestra 2: Lactentes Sibilantes - Dra Maria } \\
\text { Luiza Carneiro }\end{array}$ & $15: 00$ & $16: 00$ \\
\hline
\end{tabular}




\begin{tabular}{|c|c|c|}
\hline $\begin{array}{l}\text { Palestra 1: Porque me interessar pela } \\
\text { medicina esportiva - Dr. Jorge Henrique } \\
\text { Teles } \\
\text { Palestra 2: Desvendando a medicina } \\
\text { baseada em evidências - Dr. José Neto }\end{array}$ & $16: 00$ & $17: 00$ \\
\hline $\begin{array}{l}\text { Palestra 1: Indicação de Hemocompetentes } \\
\text { em tempos de pandemia- Dra Daniela } \\
\text { Werneck }\end{array}$ & $17: 00$ & $18: 00$ \\
\hline $\begin{array}{l}\text { Palestra 2: Empreendedorismo médico - Dr. } \\
\text { Rafael Bispo }\end{array}$ & & \\
\hline INTERVALO & $18: 00$ & $18: 30$ \\
\hline $\begin{array}{l}\text { Palestra 1: Contrariando as estatísticas - } \\
\text { Dra Kemi Salami }\end{array}$ & 19:30 & $20: 30$ \\
\hline \multicolumn{3}{|l|}{$02 / 08 / 2020$} \\
\hline $\begin{array}{l}\text { Palestra 1: Câncer de mama: Atualizações e } \\
\text { autocuidado - Dra Gabriela Moreira }\end{array}$ & $14: 00$ & $15: 00$ \\
\hline $\begin{array}{l}\text { Palestra 1: Ciência x Audiência! Como } \\
\text { equilibrar este cabo de guerra? - Dra. } \\
\text { Tassiana Alvarenga }\end{array}$ & $15: 00$ & $16: 00$ \\
\hline $\begin{array}{l}\text { Palestra 1: Como avaliar pacientes com } \\
\text { queixa de queda de cabelo em tempos de } \\
\text { Covid - Dra. Marina Barletta } \\
\text { Palestra 2: Uma abordagem sobre ECG- Dr. } \\
\text { Guilherme Neif }\end{array}$ & 16:00 & $17: 00$ \\
\hline $\begin{array}{l}\text { Palestra 1: O que todo estudante DEVE } \\
\text { saber sobre urgência e emergência - Dr. } \\
\text { Pedro Ernesto Miranda }\end{array}$ & $17: 00$ & $18: 00$ \\
\hline $\begin{array}{l}\text { Palestra 1: PCR em pacientes com Covid } 19 \\
\text { - Dr. Gustavo Deboni }\end{array}$ & & \\
\hline $\begin{array}{l}\text { Palestra 2: Caminhos da produção científica } \\
\text { durante a graduação- Josué Brito }\end{array}$ & $18: 00$ & $19: 00$ \\
\hline $\begin{array}{l}\text { Palestra 1: Como manter uma boa relação } \\
\text { com a equipe e ter espírito de liderança? - } \\
\text { Bené Júnior }\end{array}$ & $19: 00$ & $20: 00$ \\
\hline ENCERRAMENTO & $20: 00$ & $20: 30$ \\
\hline
\end{tabular}




\section{APRESENTAÇÃO}

"O conhecimento é uma aventura em aberto. O que significa que aquilo que saberemos amanhã é algo que desconhecemos hoje; e esse algo pode mudar as verdades de ontem".

Karl Popper

O I C.I.A.M. moldou-se tendo como princípio a promoção da discussão em saúde, por isso, buscou incentivar todas as formas de produção científica, recebendo desde as pequenas experiências individuais até os grandes trabalhos de campo. Recepcionou resumos de todas as áreas da saúde e correlatas, incluindo medicina, nutrição, psicologia, educação física, odontologia e direito sanitário. Essa proposta ampla resultou na recepção de 671 resumos, oriundos de todas as regiões do Brasil, de instituições públicas e particulares, dos tradicionais centros de pesquisa até as instituições ainda jovens e modestas no campo da pesquisa. Foram 371 resumos simples e 300 resumos expandidos, sendo 32 da enfermagem, 579 da medicina, 48 multidisciplinares, 4 da psicologia e outros $8 \mathrm{sem}$ área delimitada. Um número vultuoso, surpreendente e plural.

Dentro do universo de trabalhos, a Comissão Científica buscou os resumos que melhor contribuíssem para uma discussão plural e inovadora da saúde, aprovando os 52 resumos que constam nestes anais.

Os trabalhos selecionados apresentam o potencial de estimular novas discussões, apontam lacunas e dão norte a nós, jovens pesquisadores. Realizam, portanto, a função primordial da ciência: o estabelecimento de caminhos para a melhoria da qualidade da vida humana e a harmonia dela com o meio em que se insere.

JOSUÉ DA SILVA BRITO,

Diretor Científico do I C.I.A.M. 


\section{Resumos Expandidos}

\section{RESUMOS EXPANDIDOS: Estudo Original}

Título: Receptor CD147 como alvo terapêutico para COVID-19

Autor/coautores: Bruna Fernandes; Ériky Fernandes Guimarães Silva; Luan Gabriel Pinto; Anderson Dillmann Groto; Kádima Nayara Teixeira.

Instituição: Universidade Federal do Paraná (UFPR), Toledo - Paraná.

Palavras-chave: CD147, Molecular docking, SARS-CoV-2.

\section{INTRODUÇÃO}

O vírus SARS-CoV-2, causador da COVID-19, considerada pandêmica pela Organização mundial da saúde em março de 2020, despertou interesse mundial na busca de tratamentos eficazes, pois até final de junho já somava meio milhão de mortes ao redor do mundo. Apesar de variados estudos em relação à sua fisiopatologia, muitas dúvidas persistem. Uma das hipóteses para a entrada do vírus na célula hospedeira engloba o receptor CD147 (Basigin), que já é reconhecido na literatura por ter papel importante na infecção por vários outros vírus, como o Vírus da Imunodeficiência Humana, vírus da Hepatite B, entre outros (CUSABIO, 2020).

A ampla distribuição do receptor CD147 no organismo humano elucida que as manifestações atípicas da COVID-19, como alterações retinianas e no sistema nervoso central, podem estar associadas a essa possível porta de entrada (FIGUEIREDO CS e RAONY I, 2020; CUSABIO, 2020). A suposição da participação do receptor CD147 no mecanismo patológico da COVID-19 suscitou-o como um possível alvo para drogas, sendo uma delas o macrolídeo Azitromicina. Discute-se que esse fármaco impede a invasão do Plasmodium falciparum em células hospedeiras in vitro, e esse parasita também utiliza o mesmo receptor para a invasão celular (WILSON DW, et al., 2015).

\section{OBJETIVO}

Analisar, utilizando ferramentas de bioinformática por meio da metodologia de ancoragem molecular (molecular docking), as possíveis interações químicas e a energia de ligação entre a proteína humana CD147 com o fármaco Azitromicina no contexto de tratamento da doença COVID-19.

\section{MÉTODO}

Realizou-se molecular docking utilizando estrutura tridimensional 3BRH (receptor CD147), depositada no banco de dados Protein Data Bank (https://www.rcsb.org), resolvida por difração de raios-x com resolução de 2,80 . O ligante Azitromicina foi obtido na plataforma Zinc (https://zinc15.docking.org) com identificador "ZINC85537026". Após o preparo do receptor e do ligante no software AutoDock Tools, calculou-se a grid box utilizando o spacing de 1,0 A. A ancoragem molecular foi realizada utilizando o software AutoDock Vina onde se obteve as configurações possíveis da ancoragem e as energias de ligação dos confórmeros; o exhaustiveness utilizado foi de 15. Por meio do relatório gerado, escolheu-se o melhor confórmero e a análise das ligações formadas foi realizada pelo software Pymol.

\section{RESULTADOS}

$\mathrm{Na}$ ancoragem molecular entre o CD147 e a Azitromicina, utilizou-se grid box com dimensões $(x, y, z)$ de $126 \mathrm{x}$ $104 \times 104 \AA$ e valores de centralização $(x, y, z)$ de 11.256 x $-36.44 \times-14.755 \AA$. A docagem molecular pelo software AutoDock Vina forneceu nove confórmeros, sendo escolhido o mais energeticamente estável, com 
energia de afinidade de $-7,8 \mathrm{Kcal} / \mathrm{mol}$. Foram observadas cinco ligações polares entre o receptor e o ligante (Figura 1); os sítios de ligação do ligante Azitromicina no receptor abrangeu os resíduos Arginina 106 (ARG-106) que apresentou três ligações com distâncias de 2,3 $\AA, 2,6 \AA$ e 2,8 $\AA$ e duas ligações com a Aspartato 45 (ASP45) com distâncias de $3,4 \AA$ e $3,5 \AA$. Nesse confórmero não foram observadas ligações polares entre a Azitromicina e outros resíduos de aminoácidos do receptor. O seed aleatório obtido foi de 1108133904.

De acordo com o número de ligações polares formadas e a energia obtida na interação, pode-se pressupor que existe uma afinidade satisfatória entre o receptor CD147 e o ligante Azitromicina, principalmente com a ARG-106 e secundariamente com o ASP-45.

Figura 1 - Sítio de interação do receptor CD147 (azul) com a Azitromicina. As ligações são mostradas em tracejado amarelo e seu comprimento está em angstron $(\AA)$.

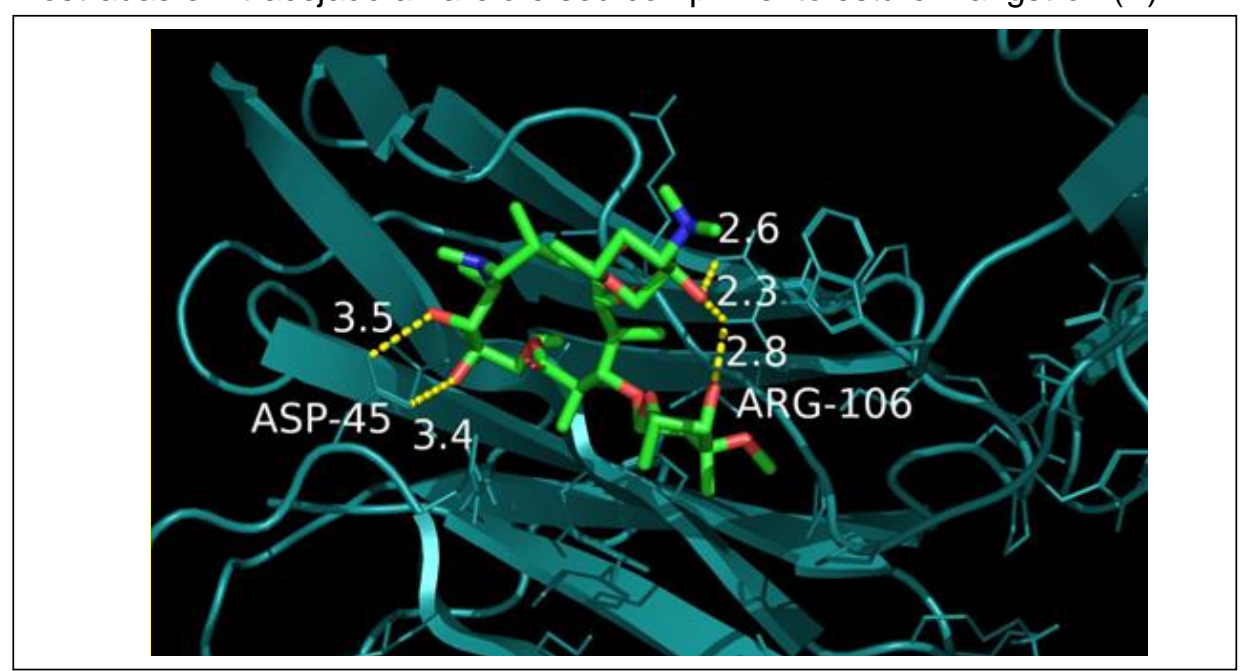

Fonte: FERNANDES B, et al., 2020.

\section{DISCUSSÃO}

A Azitromicina vem sendo estudada como potencial tratamento contra a COVID-19, devido à sua capacidade de inibir o CD147 por bloquear a interação entre esse receptor e o Homólogo de Proteínas de Ligação a Reticulócitos 5, um antígeno do protozoário Plasmodium falciparum, e consequentemente, a entrada do parasita nas células sanguíneas. A afinidade final do docking é o resultado da interação entre um receptor e um ligante definidos, e a significância para esse valor é variável na literatura; entretanto, valores de afinidade menores que $-6,0 \mathrm{kcal} / \mathrm{mol}$ são considerados expressivos. Assim, de acordo com os resultados obtidos neste estudo, a afinidade de $-7,8 \mathrm{kcal} / \mathrm{mol}$ é relevante, e possivelmente a Azitromicina poderia competir com o SARS-CoV-2 pela ligação ao CD147. Isso demonstra um provável efeito de inibição do CD147 e consequentemente impedimento da entrada do vírus na célula hospedeira, tornando esse receptor um possível alvo terapêutico para a COVID19.

\section{CONSIDERAÇÕES FINAIS}

Devido a relevante afinidade obtida nesse estudo entre a proteína CD147 e a Azitrocimina, essa interação mostrou-se importante na discussão em busca de um tratamento efetivo para doença COVID-19, necessitando, entretanto, de demais estudos para elucidar a eficácia da competição entre o fármaco e o vírus SARS- CoV-2 na ligação com a proteína CD147, considerada uma possível porta de entrada para a infecção viral.

\section{REFERÊNCIAS}

1. CUSABIO. CD147, a New Target of SARS-CoV-2 Invasion. 2020. 
2. RAONY I, FIGUEIREDO CS. Retinal outcomes of COVID-19: Possible role of CD147 and cytokine storm in infected patients with diabetes mellitus. Diabetes Research and Clinical Practice, 2020; in press.

3. WILSON DW, et al. Macrolides rapidly inhibit red blood cell invasion by the human malaria parasite, Plasmodium falciparum. BMC biology, 2015; 13: 52. 
RESUMOS EXPANDIDOS: Estudo Original

Título: Morbimortalidade por Leishmaniose visceral em menores de 10 anos entre 2015-2018 no Brasil

Autor/coautores: Artur de Paula Martins Tavares; Gabriel Gomide Marquez; Maria Fernanda de Castro Vilela; Mariana de Paula Martins Tavares; Pedro Silveira Carneiro.

Instituição: Centro Universitário Barão de Mauá (CBM) - Ribeirão Preto - São Paulo; Universidade de Ribeirão Preto (UNAERP) - Ribeirão Preto - São Paulo; Universidade de Rio Verde (UNIRV) - Rio Verde - Goiás.

Palavras-chave: Leishmaniose visceral, Morbimortalidade, Crianças.

\section{INTRODUÇÃO}

A Leishmaniose visceral (LV) é uma doença causada por protozoário da espécie Leishmania chagasi, sendo uma zoonose de evolução crônica e potencialmente fatal, podendo acarretar óbito em até $90 \%$ dos casos se não tratada adequadamente (BRASIL, 2020).

Atualmente, é analisada como uma doença de grande relevância em várias partes do mundo, devido a sua incidência e alta letalidade, especialmente em crianças e indivíduos não tratados, além de importante relação de coinfecção em portadores da infecção pelo vírus da imunodeficiência adquirida (HIV) (BRASIL, 2020).

Sendo uma doença endêmica em inúmeros países de diferentes continentes, a LV também atinge o continente americano, tendo o Brasil como principal local acometido, que, juntamente com Índia, Bangladesh, Sudão e Nepal, representam aproximadamente $90 \%$ dos novos casos (AGUIAR PF e RODRIGUES RK, 2017). A doença, antes restrita às áreas rurais, vem se urbanizando, atingindo todas as regiões do país, inclusive a periferia de grandes centros urbanos (CUNHA CR, et al., 2020).

A partir dos dados apresentados pelo DATASUS, através do Sistema de Informação de Agravos de Notificação (SINAN), entre os anos de 2015 e 2018, houve 14.858 casos de LV no Brasil, sendo 6030 em menores que 10 anos, representando aproximadamente $40 \%$ dos casos.

\section{OBJETIVO}

Analisar a relação entre o número de casos confirmados de Leishmaniose visceral em crianças menores de 10 anos de idade no Brasil, entre 2015 e 2018, e o número de óbitos ocorridos nesse mesmo período, faixa etária e país, com base nos dados apresentados pelo DATASUS, através do SINAN.

\section{MÉTODO}

O trabalho consta de uma pesquisa epidemiológica, quantitativa e descritiva, baseada nos dados de notificação de Leishmaniose visceral no Brasil fornecidos pelo DATASUS, através do SINAN. O período de 2015 a 2018 foi escolhido para atualizar as informações a respeito da morbimortalidade da doença, uma vez que a fonte escolhida oferece dados até o último ano analisado, sendo utilizado menores de 10 anos para "faixa etária" e 2015-2018 para "Ano $1^{\circ}$ sintoma(s)" como variável, e, posteriormente, empregou-se "Óbitos por LV" no quesito "Evolução", para uma análise minuciosa da epidemiologia da doença. A construção de uma tabela com as informações coletadas foi crucial para a organização e elaboração dos resultados e discussão do tema abordado.

\section{RESULTADOS}

Certificou-se que houve 6.030 casos confirmados de Leishmaniose visceral notificados no SINAN, em menores de 10 anos entre $2015-2018$, e o número de óbitos foi 258 , representando $4.2 \%$ dos casos. Dentro dessa faixa etária, observou-se que em crianças menores de 1 ano houve 1.278 casos e 125 óbitos, representando 9.7\%. Já entre 1 e 9 anos de idade, foram 4.752 casos e 133 óbitos, representando $2.7 \%$. 
Em uma segunda análise, verificaram-se os seguintes dados relacionados a menores de 10 anos: em 2015 foram 1.394 casos e 69 óbitos (4.9\% - a maior porcentagem dos 4 anos), em 2016 foram 1.378 e 60 óbitos (4.3\%), 2017 tiveram 1808 e 62 óbitos (3.4\% - a menor porcentagem dentre os 4 anos) e em 2018 ocorreram 1450 e 67 óbitos (4.6\%). Assim, comparando o primeiro ano (4.9\%) e o último analisado (4.6\%), houve uma pequena alteração da mortalidade pela doença, permanecendo quase inalterada a quantidade de óbitos. Além disso, nos 4 anos estudados, comprova-se a existência de uma faixa de óbitos que varia de 60 a 69 .

Tabela 1 - Relação entre o número de casos e óbitos por Leishmaniose visceral de 2015 a 2018, em menores de 10 anos. $\mathrm{N}=$ número de casos

\begin{tabular}{llll}
\hline Idade & $\mathbf{N}$ & Óbitos & $\%$ \\
\hline$<\mathbf{1}$ ano & 1278 & 125 & $9.7 \%$ \\
$\mathbf{1 - 4}$ anos & 3554 & 116 & $3.2 \%$ \\
$\mathbf{5 - 9}$ anos & 1198 & 17 & $1.4 \%$ \\
& & & $\%$ \\
Ano & $\mathbf{N}$ & Obitos \\
$\mathbf{2 0 1 5}$ & 1394 & 69 & $4.9 \%$ \\
$\mathbf{2 0 1 6}$ & 1378 & 60 & $4.3 \%$ \\
$\mathbf{2 0 1 7}$ & 1808 & 62 & $3.4 \%$ \\
$\mathbf{2 0 1 8}$ & 1450 & 67 & $4.6 \%$ \\
Total & 6030 & 258 & $4.2 \%$ \\
\hline
\end{tabular}

Fonte: VILELA MF, et al., 2020. Dados extraídos do SINAN (DATASUS), 2020.

\section{DISCUSSÃO}

É observado uma maior incidência dos casos de LV em menores de 10 anos em relação a outras faixas etárias, e a maior morbimortalidade se encontra em indivíduos menores de 1 ano, representando cerca de $48 \%$ dos óbitos dentro dessa variável e de $11 \%$ em relação a todos os casos.

Esse contexto faz necessário a presença de melhores estudos que consigam avaliar as particularidades de um número mais elevado de óbitos dentro de uma faixa etária em relação às outras idades, abrangendo de uma forma mais significativa questões que podem explicar esses dados, como os aspectos imunológicos de crianças menores de 1 ano e o tratamento para Leishmaniose visceral.

\section{CONSIDERAÇÕES FINAIS}

É explicitada uma maior morbimortalidade dos casos de Leishmaniose visceral em menores de 1 ano, e, a presença de uma boa resposta ao tratamento da doença, dado que o número de óbitos é relativamente pequeno em relação ao número de casos. Contudo, a incidência de LV não apresentou alternâncias consideráveis nos anos relatados, possibilitando inferir a necessidade de ampliar ações de prevenção na atenção primária à saúde. Assim, especialmente nas áreas endêmicas, o combate ao inseto transmissor, medidas de proteção individual, diagnóstico precoce e o tratamento adequado seriam medidas imprescindíveis para a diminuição dos casos no Brasil.

\section{REFERÊNCIAS}

1. AGUIAR PF, RODRIGUES RK. Leishmaniose visceral no Brasil: artigo de revisão. Unimontes Científica, 2017; 19(1): 191-204.

2. BRASIL. MINISTÉRIO DA SAÚDE. Leishmaniose Visceral: o que é, causas, sintomas, tratamento, diagnóstico e prevenção. 2019.

3. BRASIL. MINISTÉRIO DA SAÚDE. Manual de Vigilância e Controle da Leishmaniose Visceral. 2016. 
4. CUNHA CR, et al. Tipificação Epidemiológica dos casos de Leishmaniose Visceral Humana no Brasil, no período de 2013 a 2017. Revista Eletrônica Acervo Saúde, 2020; 41: e2578.

5. MINISTÉRIO DA SAÚDE. DATASUS. Leishmaniose visceral - casos confirmados notificados no sistema de informação de agravos de notificação - Brasil. 2020. 
RESUMOS EXPANDIDOS: Estudo Original

Título: Análise do potencial da protease NSP5 do SARS-CoV-2 como alvo para tratamento da COVID-19

Autor/coautores: Angélica de Fátima Marcussi; Ériky Fernandes Guimarães Silva; Bruna Fernandes; Luan Gabriel Pinto; Kádima Nayara Teixeira.

Instituição: Universidade Federal do Paraná (UFPR), Toledo - Paraná.

Palavras-chave: Molecular docking, NSP5, SARS-CoV-2.

\section{INTRODUÇÃO}

No fim de 2019, a doença hoje conhecida por COVID-19, começou a preocupar a China pelo excessivo número de casos e elevada morbimortalidade. Proporcionalmente à preocupação internacional com a doença causada pelo novo coronavírus SARS-CoV-2, surgiram vários estudos buscando um tratamento adequado para minimizar os danos (GAUTRET P, et al., 2020).

Apesar dos efeitos adversos, entre os medicamentos estudados, a hidroxicloroquina ganhou destaque principalmente pela hipótese de bloquear a entrada viral intervindo em receptores Enzima Conversora de Angiotensina 2 (ACE2) em humanos. No entanto, não apenas alvos no organismo hospedeiro surgiram como opção para controle da infecção, mas também as próprias proteínas virais (PROCACCI P, et al., 2020).

As proteínas que constituem o SARS-CoV-2 são divididas em proteínas estruturais e não-estruturais. Entre as não estruturais, a proteína NSP5 (também conhecida como 3CLpro) é uma protease do SARS-CoV-2, que ganha destaque na discussão como possível sítio de ação para medicamentos por apresentar relação direta com a replicação viral (RUT W, et al., 2020).

\section{OBJETIVO}

Analisar a possível interação, e suas características químicas, entre a protease NSP5 do SARS-CoV-2 com a hidroxicloroquina, medicamento amplamente discutido para o tratamento da COVID-19, por meio de ferramentas de bioinformática utilizando a metodologia de ancoragem molecular (molecular docking).

\section{MÉTODO}

O molecular docking foi realizado com a proteína NSP5 (PDB: 6YB7) depositada no banco de dados Protein Data Bank (https://www.rcsb.org) resolvida pelo método de difração de raios-x com resolução de 1,25 ̊̊. O ligante Hidroxicloroquina (ZINC1530652) foi obtido na plataforma Zinc (https://zinc.docking.org/). A proteína NSP5 teve as moléculas de água removidas e hidrogênios adicionados, e as torções do ligante foram detectadas utilizandose o software AutoDock Tools. Realizou-se, posteriormente a determinação da grid box com spacing de 1,0 A. A ancoragem molecular foi realizada utilizando o software AutoDock Vina que gerou as configurações possíveis de ancoragem para o ligante e as energias de ligação. Os resultados foram analisados no software Pymol observando as interações formadas.

\section{RESULTADOS}

$\mathrm{Na}$ ancoragem molecular realizada entre a proteína NSP5 e a hidroxicloroquina utilizou-se uma grid box com dimensões $(x, y, z)$ de 60x78x76 A e valores de centralização $(x, y, z)$ de 11,74x0,774x4,562 $\AA$ e exhaustiveness de 15. O resultado da ancoragem indicou que a hidroxicloroquina é capaz de interagir com a NSP5. Entre os confórmeros gerados foi selecionado aquele com medida de afinidade energeticamente mais negativa $(-6.8$ $\mathrm{Kcal} / \mathrm{mol}$ ); o seed foi de 319743316 . Foi observado que hidroxicloroquina se ligou à NSP-5 por meio do resíduo Treonina 198, que apresentou uma ligação polar com distância de 3,5 $\AA$, e por meio do Aspartato 298 que apresentou uma ligação polar com distância de 3,4 Å (Figura 1). 
Figura 1 - Sítio de ligação da hidroxicloroquina (verde e azul) com a proteína

NSP5. As ligações são mostradas em amarelo; o comprimento das ligações está em angstron (Å). ASP-298: Aspartato 298; THE-198: Treonina 198.

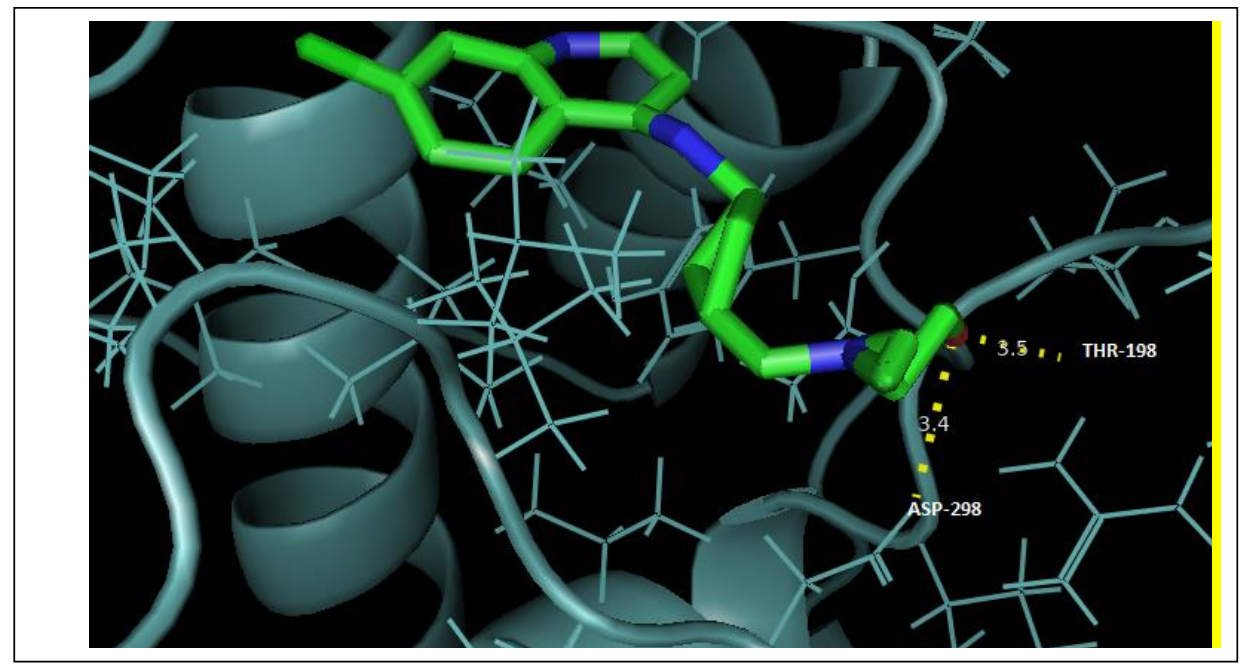

Fonte: MARCUSSI AF, et al., 2020.

\section{DISCUSSÃO}

Pelo fato de a NSP-5 ser a principal protease do SARS-CoV-2 e ter um papel central no processamento de proteínas que são traduzidas a partir do RNA viral, clivando a poliproteína orf1Ab em 11 locais (RUT W, et al., 2020), essa proteína não estrutural torna-se um alvo de estudo para a ação de fármacos. A ancoragem molecular apontou ligações polares formadas entre a hidroxicloroquina e a protease NSP5. Provavelmente essas ligações são ligações de hidrogênio, dada a natureza polar das cadeias laterais dos resíduos envolvidos. Apesar de serem apontadas apenas duas interações químicas, o valor da energia de afinidade pressupõe afinidade satisfatória entre o receptor e seu ligante, e a interação pode ser considerada estável. Tais resultados sugerem que ao se analisar unicamente as interações químicas in silico, a hidroxicloroquina é capaz de interagir com a protease NSP5, possivelmente interferindo em sua função normal.

\section{CONSIDERAÇÕES FINAIS}

Por se ligar de forma considerada estável à NSP5, a hidroxicloroquina pode ser capaz de promover a inibição da replicação viral no organismo hospedeiro. Apesar desse possível potencial terapêutico, em diversos estudos a ação da hidroxicloroquina sem a associação com outros fármacos, apresentou divergências em relação ao seu risco/benefício, logo são necessários estudos clínicos para validação de sua hipótese terapêutica. Em relação à utilização da NSP5 como alvo terapêutico para COVID-19, a possibilidade de interação com fármacos candidatos sugere um potencial de utilização que pode ser explorado.

\section{REFERÊNCIAS}

1. GAUTRET P, et al. Hydroxychloroquine and azithromycin as a treatment of COVID-19: results of an openlabel non-randomized clinical trial. International journal of antimicrobial agents. International Journal of Antimicrobial Agents, 2020; in press.

2. PROCACCI P, et al. Interaction of Hydroxychloroquine with SARS-CoV2 Functional Proteins Using All-atoms Non-equilibrium Alchemical Simulations. ChemRxiv, 2020; in press.

3. RUT W, et al. Substrate specificity profiling of SARS-CoV-2 Mpro protease provides basis for anti-COVID-19 drug design. Biorxiv, 2020; in press. 
RESUMOS EXPANDIDOS: Estudo Original

Título: Automedicação entre estudantes de ciências da saúde

Autor/coautores: João Gabriel da Freiria Maia; Fabíola Eugênio Arrabaça Moraes; Aldo Matos, Luiz Fernando Manzan.

Instituição: Universidade de Uberaba (UNIUBE), Uberaba-Minas Gerais.

Financiamento: Financiamento próprio.

Palavras-chave: Automedicação, Estudantes de ciências da saúde, Farmacoepidemiologia.

\section{INTRODUÇÃO}

O uso de medicamentos para tratar diversas moléstias, transmissíveis ou não, mudou a forma como o homem relaciona-se com sua própria saúde. Com o advento de várias classes farmacológicas, a automedicação tornouse motivo de preocupação para os gestores de saúde.

Há vários fatores relacionados com a automedicação, como qualidade e tempo de atendimento nos serviços de saúde, a presença massiva de publicidade de medicamentos isentos de prescrição veiculados na mídia, a existência de pequenas farmácias em casa e o hábito de crer que tudo pode ser resolvido com medicamentos (ARRAIS PSD, et al., 2016).

Esta prática não se restringe apenas àqueles sem conhecimentos sobre farmacologia. Profissionais e estudantes da área da saúde estão mais expostos a esse problema, tanto pelo contato constante, quanto pela facilidade em obter os medicamentos. Mesmo sabendo dos riscos, costumam ignorá-los, pois sentem-se seguros para se automedicarem, uma vez que frequentam o ambiente hospitalar e porque este comportamento costuma fazer parte do cotidiano em seu grupo de convívio social (SOUZA DRP e ESMÉRIA NETA M, 2016).

\section{OBJETIVO}

Descrever a automedicação entre os alunos de Enfermagem, Farmácia e Fisioterapia quanto à frequência, associação com o sexo, com o curso ou a etapa cursada, classes de fármacos utilizados e fontes de informação para obtenção dos medicamentos.

\section{MÉTODO}

Estudo transversal, descritivo e exploratório, de aspecto quantitativo, aprovado pelo Comitê de Ética em Pesquisa (CEP), Certificado de Apresentação para Apreciação Ética (CAAE): 66691417.0.0000.5145. A amostra foi composta por 206 universitários em diferentes etapas dos cursos de Enfermagem $(n=86)$, Farmácia $(n=44)$ e Fisioterapia $(\mathrm{n}=76)$ de uma universidade privada localizada no Triângulo Mineiro. Incluíram-se indivíduos com idade igual ou superior a dezoito anos, que assinaram o Termo de Consentimento Livre e Esclarecido (TCLE) após informados dos objetivos e condições da pesquisa. As informações foram coletadas através de questionário construído pelos autores e testado em amostra independente. Para as análises estatísticas, utilizou-se o software IBM SPSS Statistic 25. As associações foram avaliadas por meio do teste qui-quadrado, considerando significância quando $p<0.05$.

\section{RESULTADOS}

O sexo feminino foi predominante em todos os cursos, havendo 71 (82.6\%) mulheres na Enfermagem, 30 (68.2\%) na Farmácia e $62(81.6 \%)$ na Fisioterapia. Do total de alunos, 75 (36.4\%) declararam fazer automedicação; destes, 61 (81.3\%) eram mulheres. A Tabela 1 apresenta a distribuição da frequência de 
automedicação por curso e sexo, não tendo sido encontrada associação com o curso ( $p=0.230)$ e nem com sexo $(p=0.815)$.

No total de estudantes entrevistados, 61 (29.6\%) mulheres e $14(6.8 \%)$ homens se automedicam. A automedicação foi mais frequente nas etapas 2, 4 e 5 do curso de Enfermagem (19.4\%), etapa 2 do curso de Farmácia (28.6\%) e etapas 2 e 6 do curso de Fisioterapia (20\%), mas sem apresentar associação ( $\mathrm{p}=8.635)$.

As principais classes de fármacos utilizadas incluíram: analgésicos/antitérmicos (70.7\%) e anti-inflamatórios não esteroidais (AINES) (34.7\%). Os estudantes obtêm informações sobre os medicamentos sem prescrição principalmente com o farmacêutico (63.1\%) e familiares (57.2\%).

Tabela 1 - Frequência de automedicação declarada por curso e sexo entre estudantes das ciências da saúde, N=206

\begin{tabular}{ccccc}
\hline Variáveis & $\mathbf{N}$ & $(\%)$ & $\mathbf{N}$ & $(\%)$ \\
\hline Enfermagem & 31 & 36.0 & & \\
Masculino & & & 4 & 26.6 \\
Feminino & & & 27 & 38.0 \\
Farmácia & 14 & 31.8 & & \\
Masculino & & & 4 & 28.6 \\
Feminino & & & 10 & 33.3 \\
Fisioterapia & 30 & 39.5 & & \\
Masculino & & & 6 & 42.9 \\
Feminino & & & 24 & 38.7 \\
\hline Total & $\mathbf{7 5}$ & & \\
\hline
\end{tabular}

Fonte: MAIA JGF, et al., 2020.

\section{DISCUSSÃO}

A prevalência de automedicação entre a população brasileira é de $16.1 \%$, sendo maior entre as mulheres (ARRAIS PSD, et al., 2016). Esta prevalência é menor que a encontrada para estudantes de ciências da saúde e, diferentemente do estudo em questão, em nossa amostra não houve associação com o sexo.

Em uma revisão da literatura acerca da automedicação por profissionais e acadêmicos da área da saúde, encontrou-se que as principais classes dos fármacos automedicados incluíam analgésicos (80\%), antiinflamatórios (70\%) e antitérmicos (30\%) (SOUZA DRP e ESMÉRIA NETA M, 2016), resultado em consonância com este trabalho.

As principais fontes de informação para a escolha do medicamento sem prescrição em estudo realizado entre estudantes universitários no Norte do Paraná convergiram com aquelas mais citadas nesta pesquisa, sendo que $37.9 \%$ escolheram o medicamento por indicação do Farmacêutico e 33.7\% por indicação de amigos/parentes. (TOMASINI AB, et al., 2015).

\section{CONSIDERAÇÕES FINAIS}

A prevalência da automedicação entre estudantes da área de saúde foi maior que na população em geral. Uma parcela expressiva dos indivíduos busca informações sobre medicamentos sem prescrição com o farmacêutico, ressaltando o papel desses profissionais no aconselhamento da população sobre farmacoterapia. Além disso, o 
alto uso de medicamentos isentos de prescrição levanta o questionamento sobre a contribuição das propagandas veiculadas na mídia para a ocorrência desse fenômeno. Os resultados sugerem maior confiança dos estudantes de ciências da saúde para escolher o medicamento por conta própria, sendo necessárias ações educativas voltadas a esse público.

\section{REFERÊNCIAS}

1. ARRAIS PSD, et al. Prevalência da automedicação no Brasil e fatores associados. Revista de Saúde Pública, 2016; 50(2): 1-11.

2. SOUZA DRP, ESMÉRIA NETA M. Automedicação por profissionais e acadêmicos da área da saúde: uma revisão de literatura. Revista da Universidade Vale do Rio Verde, 2016; 14(2): 965-974.

3. TOMASINI AB, et al. Prevalência e fatores da automedicação entre estudantes universitários no Norte do Paraná. Biosaúde, 2015; 17(1): 1-12. 
RESUMOS EXPANDIDOS: Estudo Original

Título: Mortalidade por pneumonia em crianças menores de um ano na região Nordeste do Brasil no período de 2015 a 2019

Autor/coautores: Adricia Cristine de Souza Alves; Beatriz Nayara Muniz de Oliveira; Maria Eduarda Mendes Alves; Isabela Silva de Medeiros; Alex Sandro Rolland Souza.

Instituição: Universidade Católica de Pernambuco (UNICAP), Recife-Pernambuco; Centro Universitário Maurício de Nassau (UNINASSAU), Recife-Pernambuco; Universidade Federal de Pernambuco (UFPE), Recife-Pernambuco; Instituto de Medicina Integral Prof. Fernando Figueira (IMIP), Recife-Pernambuco.

Palavras-chave: Pneumonia, Mortalidade, Lactentes.

\section{INTRODUÇÃO}

Pneumonia é uma doença inflamatória aguda ou crônica causada por um agente etiológico (bactérias, vírus, fungos ou reações alérgicas) que se instala nos pulmões, acometendo o parênquima pulmonar, alvéolos pulmonares e/ou os interstícios, onde é realizada as trocas gasosas (BRASIL, 2015).

Na faixa etária pediátrica, geralmente a pneumonia ocorre como complicação de uma infecção viral das vias aéreas, alterando os mecanismos de defesa do trato respiratório por modificar as secreções, inibir a fagocitose, alterar a flora bacteriana e diminuir o movimento ciliar. Em menores de 1 ano, vários fatores de risco podem contribuir para o aumento da incidência e da gravidade da pneumonia, tais como prematuridade, baixo peso ao nascer, desmame precoce, desnutrição, baixo nível socioeconômico, exposição intradomiciliar, tabagismo passivo, vacinação incompleta e doenças de base que afetam os sistemas cardiopulmonar, imunológico ou neurológico (SCHAFER S, et al., 2019).

Nos dias atuais o impacto que a pneumonia exerce sobre a mortalidade infantil é preocupante, dessa maneira, melhorias no acesso a cuidados de saúde, programas de vacinação, condições de vida e nutrição são essenciais para reduzir a mortalidade da PAC e a falha em fazê-lo provavelmente afetará desproporcionalmente as crianças nos países em desenvolvimento e influenciará diretamente na incidência da pneumonia (RODRIGUES CMC e GROVES H, 2018).

\section{OBJETIVO}

Determinar o perfil epidemiológico, número de óbitos e a taxa de mortalidade referentes à pneumonia em menores de 1 ano no Nordeste (NE) do Brasil entre os anos de 2015 e 2019.

\section{MÉTODO}

Foi realizado um estudo descritivo de base populacional baseado nos dados obtidos do Ministério da Saúde do Brasil pelo sistema de dados do Sistema Único de Saúde (DATASUS). Foram incluídos menores de 1 ano, habitantes do Nordeste, descritos com pneumonia como causa da internação e consequente causa de óbito nos sistemas público e privado. As variáveis estudadas foram ano de atendimento, estado de residência, autorização de internamento hospitalar $(\mathrm{AlH})$ aprovadas, número de óbitos e taxa de mortalidade. A taxa de mortalidade foi calculada pela razão entre a quantidade de óbitos por pneumonia e o número de $\mathrm{AlH}$ aprovadas, computadas como internações, no período, multiplicada por 100.

\section{RESULTADOS}

No Nordeste foi notificado 361.483 internações de pacientes pediátricos com pneumonia, desses, 97.744 eram menores de 1 ano. O número de óbitos por doenças do aparelho respiratório no NE foi de 2.306 em menores de 
1 ano, desses, a pneumonia foi a principal causa de óbito, com 1.034 óbitos e taxa de mortalidade de 1,06 por 100 internações.

Em 2015 e 2017, o estado da Bahia apresentou o maior número de óbitos, 47 (0,92\%) e 40 (1,07\%), respectivamente, em 2016, Pernambuco se sobressai com $38(1,28)$ e em 2018 e 2019 o Maranhão com 42 $(1,5 \%)$ e $40(1,21 \%)$, respectivamente. O Rio Grande do Norte apresentou o menor número total de óbitos nos últimos 5 anos $(n=30)$, ficando atrás somente em 2015 no estado de Sergipe. Em contrapartida, o maior número total de óbitos em 5 anos foi no Maranhão $(n=198)$, sendo a maior TM em 5 anos em Sergipe $(1,92 \%)$ e a menor em Alagoas e RN (0,92\%).

Tabela 1 - número de óbitos e taxa de mortalidade por pneumonia em menores de um ano nos estados da região Nordeste nos anos de 2015 a 2019

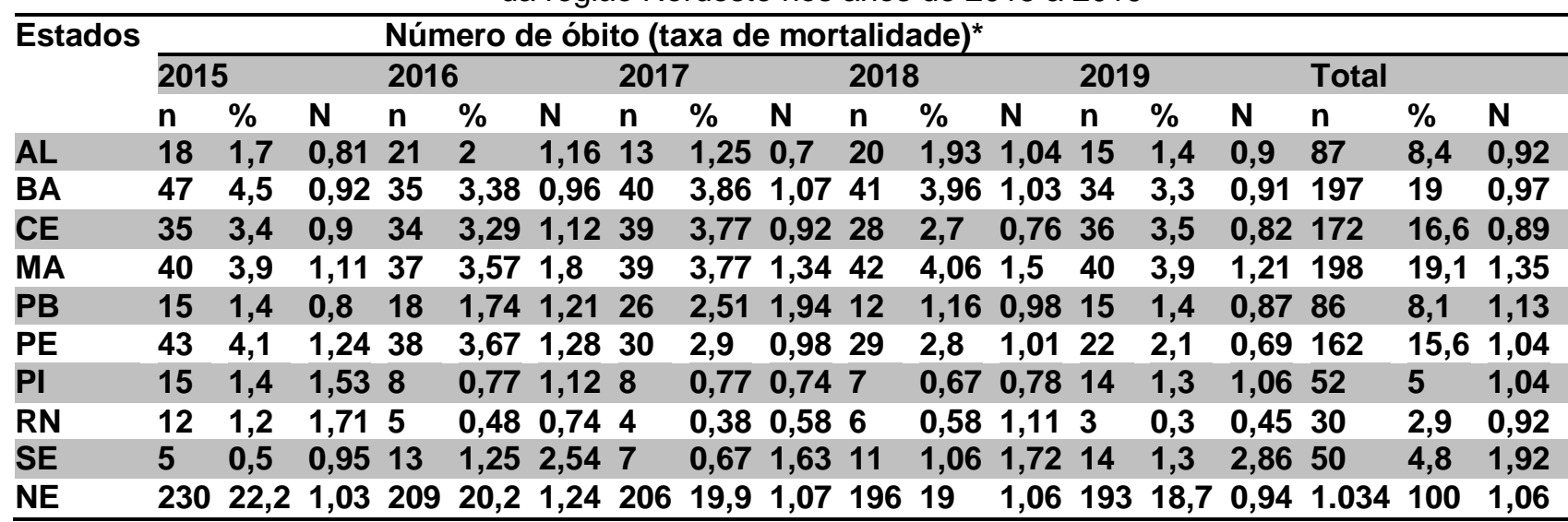

Legenda: ${ }^{\star} T a x a$ de Mortalidade: calculada pela razão entre a quantidade de óbitos e o número de AlH aprovadas, computadas como internações, no período, multiplicada por 100. Alagoas (AL), Bahia (BA), Ceará (CE), Maranhão (MA), Paraíba (PB), Pernambuco (PE), Piauí (PI), Rio Grande do Norte (RN), Sergipe (SE), Nordeste (NE).

Fonte: ALVES, et al., 2020. Dados extraídos do Ministério da Saúde - DATASUS - Departamento de Informática do SUS, 2020.

\section{DISCUSSÃO}

Apesar dos infantes menores de um ano estarem em segundo lugar no número de internações (97.744), ainda representam o maior número de óbitos (42,7\%), com taxa de mortalidade de $1,06 \%$, podendo ser explicado devido ao desenvolvimento incompleto do aparelho pulmonar e do sistema imunológico (FERRAZ RO, et al., 2017).

Nos últimos anos houve um expressivo progresso em relação ao desenvolvimento de métodos terapêuticos levando a redução do número de óbitos no NE. Além disso, um estudo conduzido em menores de 1 ano verificou uma redução de 19\% em PAC após a implantação da vacina conjugada pneumocócica 10-valente no calendário vacinal nacional. Diante disso, é importante a realização de novos estudos que contribuam com a redução do número de óbitos (FERRAZ RO, et al., 2017).

Destaca-se a escassez de pesquisas voltadas para menores de um ano e estudos que investigam diferenças na mortalidade por pneumonia entre os estados do Nordeste em relação às tendências temporais.

\section{CONSIDERAÇÕES FINAIS}

A pneumonia foi a principal causa de óbito entre as doenças do aparelho respiratório no Brasil em menores de 1 ano, representando um grave problema de saúde pública. Dentre as regiões, o NE se mostrou mais evidente devido ao grande número de óbitos nos últimos 5 anos. Assim, sugerimos melhoria dos projetos de planejamento de ações com o intuito de diminuir o índice de mortalidade por pneumonia em menores de 1 ano. 


\section{REFERÊNCIAS}

1. FERRAZ RO, et al. Tendência de mortalidade por pneumonia nas regiões brasileiras no período entre 1996 e 2012. J Bras Pneumol. 2017; 43(4): 274-279.

2. RODRIGUES CMC, GROVES $\mathrm{H}$. Community-acquired pneumonia in children; the challenges of microbiological diagnosis. J Clin Microbiol. 2018; 56 (3): e01318-17.

3. SCHAFER S, et al. Pneumonias comunitárias não complicadas em crianças imunocompetentes. Resid Pediatr. 2019; 9 (3): 265-269. 
RESUMOS EXPANDIDO: Estudo Original

Título: Percentual de casos confirmados de tuberculose em presídios no estado de mato grosso de 2006 a 2014

Autor/coautores: Kauanne Naysa Alves Pegaiani; Thayla Gabrielle Sampaio Pereira; Dayanne Caitano Oliveira e Shaiana Vilella Hartwig.

Instituição: Universidade Federal de Mato Grosso do Sul-UFMS; Universidade do Estado de Mato GrossoUNEMAT.

Palavras-chave: Epidemiologia, Tuberculose, Doenças Negligenciadas.

\section{INTRODUÇÃO}

Considerada um desafiador problema de saúde, por sua elevada morbimortalidade, a tuberculose (TB) é uma doença impactante nos indivíduos, pela capacidade de transmissão, principalmente, nas populações vulneráveis, o contato próximo é fator de risco. No encarceramento o risco de desenvolvê-la é superior, pois o ambiente apresenta potencialidades de dispersão da doença (MACEDO LR, et al., 2017).

Os padrões de salubridade correlacionados com as superlotações e as condições de atendimentos em saúde, principalmente em presídios, são causadores do aumento dos casos. O diagnóstico precoce e o começo do tratamento são primordiais para reprimir o progresso da doença tanto na pessoa contaminada, como no ciclo de transmissão (BRITTO MOF, et al., 2018). Mato Grosso possui 52 unidades penais, compostas por: Cadeia Pública, Centro de Detenção Provisória, Colônia Penal e Penitenciária (SESP, 2020).

Segundo a Organização Mundial de Saúde (OMS), um quarto da população mundial tem infecção por tuberculose (OPAS, 2020). Em Mato Grosso, a taxa de incidência da TB, entre 2006 a 2014, foi em média 46,42 casos por 100.000 habitantes. Diante disso, é importante ressaltar que a tuberculose faz parte das doenças negligenciadas, reproduzindo situações de pobreza, serviços e condições precárias de vida (INÁCIO M e INVERNIZZI N, 2019).

\section{OBJETIVO}

Descrever a taxa de incidência geral de tuberculose e a representatividade percentual dos casos novos de tuberculose em presídios do Estado de Mato Grosso ambos no período de 2006 a 2014.

\section{MÉTODO}

Trata-se de um estudo descritivo, transversal da taxa de incidência geral e do percentual dos casos novos de tuberculose em presídios de Mato Grosso, ambos no período de 2006 a 2014. Para a coleta de dados foi utilizada as bases de dados do DATASUS. Para taxa de incidência foi calculado através da fórmula: número de casos novos dividido pela população estimada multiplicado por 100.000 . Para verificação dos percentuais foi realizado cálculo do percentual do total no de casos das duas categorias, como banco de dados, ferramenta de cálculo e para criação de figuras e tabelas utilizou-se o software Microsoft Office Excel 2016.

\section{RESULTADOS}

Entre os anos de 2006 a 2014 no estado de Mato Grosso foram registrados 12.779 casos novos de tuberculose, tendo uma média anual de 1.419 casos. Também nesse período, o estado, atingiu uma média anual da taxa de incidência de 46,42 casos por 100.000 habitantes. Já relacionado ao percentual de casos confirmados de tuberculose em presídios do estado de Mato Grosso, durante esse período apresentou-se uma média anual de $8,8 \%$ de casos ano ano. 
Tabela 1 - Taxa de incidência de TB por ano em Mato Grosso, comparados ao percentual representativo dos casos de TB por ano nos presídios de Mato

Grosso no período de 2006 a 2014.

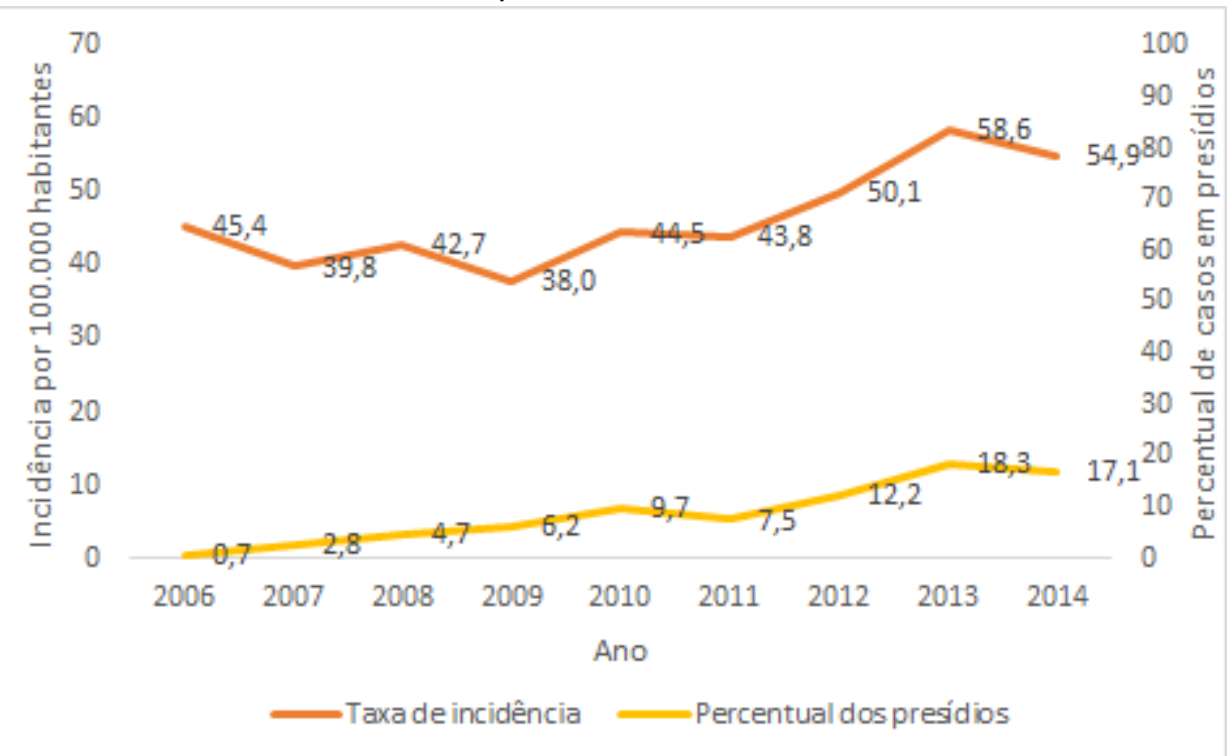

Fonte: PEGAIANI KNA, et al., 2020. Dados extraídos do DATASUS, 2020.

Conforme visto na Figura 1, durante o período estudado, a taxa de incidência e o percentual de casos nos presídios aumentaram ao final dos 8 anos, mesmo havendo alterações para mais e para menos em cada ano, principalmente na taxa de incidência. Desse modo a taxa de incidência em 2009 apresentou a menor taxa com 37,99 e em 2013 a maior taxa com 58,64 casos por 100.000 habitantes. Por fim com relação ao percentual de casos confirmados em presídios no Mato Grosso em 2006 o menor percentual de casos foi obtido, sendo $0,7 \%$, em 2013 foi o maior percentual com 18,3\% de casos novos.

\section{DISCUSSÃO}

O estado de Mato Grosso vem apresentando aumento no número de casos novos de tuberculose, tanto na população geral quanto no percentual de casos da população privada de liberdade. Provavelmente esse crescimento, deve estar associado às precárias condições de vida enfrentadas nas penitenciárias, uma vez que as mesmas facilitam essa propagação. Ainda mais, os exames fora das penitenciárias acarretam o diagnóstico tardio da tuberculose, contribuindo assim, no ciclo de contágio da doença (MACEDO LR, et al., 2017). Outrossim, as novas infecções adquiridas no local em específico, podem ser consequências de falhas estruturais. Parece ser indispensável que ocorra diagnóstico precoce, tratamento adequado, capacitação dos profissionais e educação popular referente a doença (LIMA LE, et al., 2018).

\section{CONSIDERAÇÕES FINAIS}

É de extrema importância a divulgação de levantamentos sobre a situação da tuberculose em presídios, para que órgãos responsáveis definam medidas de intervenções que gerem melhoramento da qualidade de vida da população carcerária. Devendo existir medidas não só da parte da gestão, mas também, dos profissionais e da sociedade para que se consiga mudar esse cenário que permanece aumentando por anos e, assim alcance a meta global de extinguir a tuberculose até 2030. 


\section{REFERÊNCIAS}

1. BRITTO MOF, et al. Tuberculose pulmonar: levantamento epidemiológico no conjunto penitenciário de Jequié-BA. Textura, 2018; 12(20):143-151.

2. INÁCIO M, INVERNIZZI N. Nanotecnologias para doenças negligenciadas no Brasil: trajetória de pesquisa, incentivos e perspectivas. Acta Scientiarum. Human and Social Sciences, 2019; 41: e45769.

3. LIMA LE, et al. Incidência de tuberculose nas penitenciárias da Paraíba de 2007 a 2014. Inter Scientia, 2018; 6(2).

4. MACEDO LR, et al. Tuberculose na população privada de liberdade do Brasil, 2007-2013*. Epidemiol. Serv. Saúde, 2017; 26(4): 783-794.

5. OPAS. Organização Pan-Americana de Saúde, 2020.

6. SESP. Secretaria Estadual de Segurança Pública. Nossas Unidades, 2020. 
RESUMOS EXPANDIDOS: Estudo Original

Título: O risco da cefaleia por uso excessivo de medicamentos entre os estudantes de medicina

Autor/coautores: Eva Gabryelle Vanderlei Carneiro; Maria Gabriela Rocha Melo; Laércio Pol Fachin; Mariana Cota Bastos.

Instituição: Centro Universitário Cesmac (CESMAC), Maceió-Alagoas.

Palavras-chave: Cefaleia, Medicamentos, Estudantes de medicina.

\section{INTRODUÇÃO}

A cefaleia acomete cerca de três bilhões de indivíduos no mundo e é uma das patologias mais prevalentes com alto impacto na qualidade de vida da população, sendo, por isso, considerada um relevante problema de saúde pública (STOVNER L, et al., 2016). Entretanto, esta permanece como uma patologia subdiagnosticada e subtratada em alguns grupos populações, especialmente nos estudantes universitários (BIRRU E, et al., 2016).

Ao longo dos anos, várias pesquisas epidemiológicas procuraram avaliar a frequência e impacto da cefaleia entre os estudantes universitários, principalmente no curso de medicina, já que estão mais susceptíveis a vários fatores físicos e de estresse psicológico (SANYA E, et al., 2017). Uma complicação cada vez mais frequente e pouco conhecida na população é o agravamento da cefaleia e o desenvolvimento da cefaleia induzida pelo uso excessivo de medicamentos (SANTOS R, et al., 2019), com uma prevalência mundial de $1 \%$ a $2 \%$ (WESTERGAARD $M$, et al., 2016).

\section{OBJETIVO}

Analisar o perfil do uso de medicamentos para cefaleia entre os estudantes de medicina de um Centro Universitário, bem como a prevalência do risco de cefaleia por uso excessivo e investigar as classes medicamentosas mais utilizadas pelos estudantes.

\section{MÉTODO}

Trata-se de um estudo exploratório de natureza quantitativa realizado em um Centro Universitário. A amostragem prevista para o estudo foi de 240 acadêmicos de medicina, sendo regularmente matriculados do $1^{\circ}$ ao $8^{\circ}$ período e que assinaram o Termo de Consentimento Livre e Esclarecido (TCLE). Aqueles do período do internato ( $9^{\circ}$ ao $\left.12^{\circ}\right)$ foram excluídos do estudo. Os pesquisadores elaboraram um questionário com 20 assertivas construídas com a escala do tipo Likert. Foi utilizado testes estatísticos (qui-quadrado de Pearson, correlação de Pearson e de Spearman) para avaliar o nível de significância dos resultados. $O$ estudo foi aprovado pelo parecer $n^{\circ} 3.227 .703$ do Comitê de Ética em Pesquisa (CEP) atendendo às exigências das Resoluções CNS n 466/2012 e n 510/2016.

\section{RESULTADOS}

O estudo alcançou a amostragem prevista de 240 participantes, sendo 30 discentes de cada período do $1^{\circ}$ ao $8^{\circ}$ período do curso de medicina. O perfil da amostra foi de 135 (56,25\%) do sexo feminino e 71 (29,58\%) do sexo masculino, $34(14,16 \%)$ não desejaram responder o gênero. A idade variou entre 18 e 42 anos, média de 25 anos.

Do total de $43(23,50 \%)$ discentes com critérios para cefaleia crônica, $26(60,47 \%)$ concordaram com as assertivas que preenchem os critérios para cefaleia por uso excessivo de medicamentos. Foi observado que a prevalência de cefaleia crônica foi uma variável dependente do consumo de alguns tipos de medicamentos, 
ou seja, existe uma correlação significativa, segundo o teste de Qui-quadrado de Pearson, de ocorrência delas na amostra estudada conforme apresentado na Tabela 1. Não foi encontrada associação significativa entre cefaleia crônica e anti-inflamatórios $(p=0,1282)$ ou opióides $(p=0,5576)$.

Ainda, a maioria $(76,25 \% ; n=183)$ discorda, totalmente ou parcialmente, da assertiva "todas as medicações que utilizo para controle da dor são prescritas por médico", sugerindo um elevado percentual de uso de medicamentos sem prescrição médica.

Tabela 1 - Associação de cefaleia crônica e uso excessivo de medicamentos, por classe farmacológica, entre os discentes de medicina, $n=43$.

\begin{tabular}{rcccc}
\hline Variável & $\begin{array}{c}\text { (N) } \\
\text { preenchem } \\
\text { critérios para } \\
\text { cefaleia } \\
\text { crônica e } \\
\text { utilizam a } \\
\text { classe } \\
\text { farmacológica }\end{array}$ & $\%$ & Valor de P & Significante? \\
\hline $\begin{array}{r}\text { Analgésicos } \\
\text { simples }\end{array}$ & 20 & 46,51 & $<0,0001$ & Sim \\
\hline $\begin{array}{r}\text { Analgésicos } \\
\text { combinados }\end{array}$ & 15 & 34,88 & $<0,0001$ & Sim \\
\hline $\begin{array}{r}\text { Derivados } \\
\text { do ergot }\end{array}$ & 9 & 20,93 & $<0,0001$ & Sim \\
\hline Triptanos & 2 & 4,65 & 0,0450 & Sim \\
\hline
\end{tabular}

Fonte: CARNEIRO EGV, et al., 2020.

\section{DISCUSSÃO}

Os resultados do estudo sugerem que existe uma alta prevalência $(23,50 \%)$ de cefaleia crônica entre os discentes do curso de medicina do Centro Universitário analisado. Em concordância com um estudo realizado na Nigéria que encontrou 3,5\% dos estudantes universitários apresentam cefaleia crônica, com dor quase diariamente (SANYA E, et al., 2017).

O presente estudo revelou um elevado percentual de automedicação $(76,25 \%)$, achado semelhante ao encontrado no estudo de Santos R, et al. (2019), onde a automedicação estava presente em $76,50 \%$ dos discentes de medicina de uma Universidade Pública de Alagoas.

Na população em estudo, a maioria $(60,47 \%)$ dos discentes com cefaleia crônica apresentam critérios para a cefaleia por uso excessivo de medicamentos com correlação significativa com as classes dos analgésicos simples e combinados, triptanos e derivados do ergot. Sendo a classe de analgésicos simples a mais prevalente no presente estudo, como encontrado na literatura (KUMAR A, et al., 2016; SANTOS R, et al., 2019).

\section{CONSIDERAÇÕES FINAIS}

A prevalência da automedicação entre estudantes da área de saúde foi maior que na população em geral. Uma parcela expressiva dos indivíduos. As análises realizadas mostram uma elevada taxa de uso excessivo de medicamento para cefaleia na população estudada, o que colabora para um número elevado de discentes com critérios para cefaleia por uso excessivo de medicamentos. As principais classes farmacológicas associadas ao desenvolvimento dessa cefaleia crônica secundária foram os analgésicos simples e 
combinados, triptanos e ergotamínicos. A facilidade de obtenção dessas medicações, sem prescrição médica, deve ser reavaliada pelas autoridades reguladoras a fim de minimizar os possíveis prejuízos advindos da utilização indiscriminada. Além da conscientização dos discentes sobre os riscos da automedicação bem como no uso crônico dessas medicações.

\section{REFERÊNCIAS}

1. BIRRU E, et al. Management of headache and associated factors among undergraduate medicine and health science students of University of Gondar, North West Ethiopia. Journal of Headache and Pain, 2016; 17(1).

2. KUMAR A, et al. Analgesics Self-Medication and its Association with Sleep Quality among Medical Undergraduates. Journal of Clinical and Diagnostic Research, 2016; 10(12).

3. SANTOS R, et al. Prevalência de cefaleia e seus impactos em estudantes de medicina em uma universidade pública. Rev. bras. neurol, 2019; 55(3): 5-8.

4. SANYA E, et al. Prevalence and clinical characteristics of headaches among undergraduate students in three tertiary institutions in llorin, Nigeria. Nigerian Journal of Clinical Practice, 2017; 20(11): 1411-1416.

5. STOVNER L, et al. Global, regional, and national burden of migraine and tension-type headache, 19902016: a systematic analysis for the Global Burden of Disease Study 2016. Lancet Neurol, 2018; 17: 95476.

6. WESTERGAARD M, et al. Medication-overuse headache: a perspective review. Therapeutic Advances in Drug Safety, 2016; 7(4): 147-158. 
RESUMOS EXPANDIDOS: Estudo Original

Título: Morbimortalidade hospitalar por Insuficiência Cardíaca no Brasil entre janeiro de 2010 e abril de 2020

Autor/coautores: Carlos Eduardo Real Fernandes; João Henrique Cardoso Xavier; José Valcir Fernandes Neto; Letícia Teixeira Guimarães; Jaqueline Teixeira Teles Gonçalves.

Instituição: Universidade Estadual de Montes Claros (UNIMONTES).

Palavras-chave: Hospitalização, Indicadores de Morbimortalidade, Insuficiência Cardíaca.

\section{INTRODUÇÃO}

Com a progressão do processo de transição epidemiológica em diversos países, tem-se observado um aumento da morbimortalidade por doenças crônicas, sendo que, atualmente, os distúrbios cardiovasculares são considerados as principais causas de morte no Brasil e no mundo (FERNANDES DF, et al., 2020). Nesse contexto, a insuficiência cardíaca (IC) apresenta uma alta prevalência, estando associada a diversas causas que levam à rigidez e/ou fraqueza do músculo cardíaco com redução de sua capacidade de contração e/ou relaxamento. Consequentemente, o coração não consegue efetuar sua função de maneira adequada sem ter que aumentar suas pressões de enchimento (COMITÊ COORDENADOR DA DIRETRIZ DE INSUFICIÊNCIA CARDÍACA, 2018).

O acúmulo de sangue no lado esquerdo do coração provoca congestão pulmonar e dificuldade respiratória, enquanto, no lado direito, esse mecanismo gera aumento da quantidade de líquidos em outras partes do corpo, como nas pernas e no fígado. Com o tempo, pode-se observar um funcionamento inadequado de outros órgãos, assim como a liberação de substâncias cardiotóxicas que, em um ciclo vicioso, aumentam o dano cardiovascular (JUNIOR VH e VILLACORTA AS). Os fatores de risco mais comuns são idade superior a 60 anos, histórico de obesidade, diabetes, tabagismo e hipertensão arterial (FERNANDES ADF, et al., 2020).

\section{OBJETIVO}

Analisar, do ponto de vista epidemiológico, a morbimortalidade hospitalar e custos associados à insuficiência cardíaca no período que vai de janeiro de 2010 até abril de 2020 no território brasileiro.

\section{MÉTODO}

Estudo epidemiológico descritivo com corte transversal, de caráter quantitativo. A base de dados do DATASUS (programa TABNET, http://www.datasus.gov.br) foi utilizada para coleta das informações. $O$ DATASUS é de domínio público e não é necessária uma autorização do Comitê de Ética em Pesquisa (CEP) para a utilização dos dados dessa plataforma na elaboração de estudos. Além disso, a própria dinâmica dessa base contribui para que não seja necessário usar instrumentos de tabulação ou softwares para análise dos dados. A população analisada corresponde a indivíduos hospitalizados com insuficiência cardíaca no Brasil entre janeiro de 2010 e abril de 2020. Variáveis pesquisadas: faixa etária, internações, óbitos, custos, regiões.

\section{RESULTADOS}

Ao se considerar as causas de morbimortalidade no sistema DATASUS, a insuficiência cardíaca esteve entre as 12 principais doenças associadas a internações ( $2 \%$ do total) e óbitos ( $4,9 \%$ do total) e foi a com maior número de pacientes afetados por esses desfechos dentre os distúrbios cardiovasculares.

Foram registradas 2.332.766 internações por insuficiência cardíaca, a maior parte delas no estado de São Paulo, N=445.710 (19,1\%), seguido por Minas Gerais, N=345.913 (14\%), e pelo Paraná, N=230.898 (9,9\%), 
nessa ordem. O número total de óbitos é de 237.102, a maioria em São Paulo, N=58.747 (24,7\%), Minas Gerais, $\mathrm{N}=30.776$ (13\%), e Rio de Janeiro, $\mathrm{N}=19.817$ (8,35\%), respectivamente. A região sudeste apresenta o maior número de internações, $\mathrm{N}=1.494 .508(41,7 \%)$, e óbitos, $\mathrm{N}=112.678(47,5 \%)$ por insuficiência cardíaca.

A maior parte das internações ocorreu entre indivíduos na faixa etária de 70-79 anos, $\mathrm{N}=615.515$ (26,4\%), seguida pelos pacientes entre 60-69 anos, $\mathrm{N}=550.527$ (23,6\%). A maioria dos óbitos foi registrada entre indivíduos com 80 anos ou mais, $\mathrm{N}=77.962$ (32,9\%), e entre pacientes com 70-79 anos, $\mathrm{N}=65.625$ (27,5\%), nessa ordem. Os custos associados ultrapassam 3 bilhões de reais.

Tabela 1 - Internações e óbitos por idade e regiões do Brasil de indivíduos hospitalizados com insuficiência cardíaca entre janeiro de 2010 e abril de 2020.

\begin{tabular}{|c|c|c|}
\hline Variável & $\begin{array}{l}\text { Número de } \\
\text { casos }(\mathrm{N})\end{array}$ & $\begin{array}{c}\text { Porcentagem } \\
(\%)\end{array}$ \\
\hline \multicolumn{3}{|l|}{ Idade - internações } \\
\hline 70-79 anos & 615.515 & $26,4 \%$ \\
\hline $60-69$ anos & 550.527 & $23,6 \%$ \\
\hline Total & 2.332 .766 & $100 \%$ \\
\hline \multicolumn{3}{|l|}{ Idade - óbitos } \\
\hline 80 anos ou mais & 77.692 & $32,9 \%$ \\
\hline $70-79$ anos & 65.625 & $27,5 \%$ \\
\hline Total & 237.102 & $100 \%$ \\
\hline \multicolumn{3}{|l|}{ Região - internações } \\
\hline Norte e nordeste & 672.186 & $28,8 \%$ \\
\hline Sudeste & 1.494 .508 & $41,7 \%$ \\
\hline Centro-oeste e sul & 171.072 & $29,45 \%$ \\
\hline Total & 2.332.776 & $100 \%$ \\
\hline \multicolumn{3}{|l|}{ Região - óbitos } \\
\hline Norte e nordeste & 59.602 & $25,1 \%$ \\
\hline Sudeste & 112.678 & $47,5 \%$ \\
\hline Centro-oeste e sul & 64.822 & $27,3 \%$ \\
\hline Total & 237.102 & \\
\hline
\end{tabular}

Fonte: FERNANDES, et al., 2020. Dados extraídos do Sistema de Informações Hospitalares do SUS (SIH/SUS), 2020.

\section{DISCUSSÃO}

Os resultados apontam que os estados mais afetados pela IC em número de internações, óbitos e custos associados estão na região Sudeste, sendo, respectivamente, São Paulo e Minas Gerais. Da mesma forma, os dados sugerem que o perfil de morbimortalidade por insuficiência cardíaca no Brasil entre 2010 e 2020 
está de acordo com a literatura, mostrando maior predisposição de indivíduos com mais de 60 anos a desenvolver IC (FERNANDES ADF, et al., 2020).

Este estudo evidencia a necessidade de investigações mais amplas sobre a IC, tendo em vista o elevado número de internações, óbitos e custos registrados. O estudo analisou apenas uma base de dados, o que pode ter prejudicado a obtenção de informações mais fidedignas à realidade. Além disso, algumas regiões brasileiras, como por exemplo o norte e o nordeste, podem apresentar uma subnotificação das internações e óbitos por insuficiência cardíaca (FERNANDES ADF, et al., 2020).

\section{CONSIDERAÇÕES FINAIS}

O índice de internações e óbitos por insuficiência cardíaca durante o período analisado, assim como os elevados custos associados, apresentaram um predomínio em indivíduos com mais de 60 anos (sobretudo naqueles entre 70-79 anos ou mais) e na região Sudeste. A elevada prevalência desse distúrbio cardiovascular está provavelmente associada a fatores como baixo investimento na saúde, inadequado acesso ao atendimento, acompanhamento insuficiente nos diversos níveis de atenção e falta de estímulo à adoção de hábitos de vida adequados. Por conseguinte, a melhoria dessas condições é essencial para possibilitar a prevenção e o manejo adequados da insuficiência cardíaca.

\section{REFERÊNCIAS}

1. COMITÉ COORDENADOR DA DIRETRIZ DE INSUFICIÊNCIA CARDÍACA. Diretriz Brasileira de Insuficiência Cardíaca Crônica e Aguda. Arq Bras Cardiol. 2018; 111(3):436-539.

2. FERNANDES DF, et al. Insuficiência Cardíaca no Brasil Subdesenvolvido: Análise de Tendência de Dez Anos. Arq Bras Cardiol. 2020; 114(2):222-231.

3. JUNIOR VH, VILLACORTA AS. Hipotensão Arterial e Disfunção Renal: Meus Fantasmas na Insuficiência Cardíaca. Arq Bras Cardiol. 2017; 109(2):165-168. 


\section{RESUMO EXPANDIDO: Estudo Original}

Título: Inserção da oftalmologia na formação médica do Rio Grande do Norte: análise curricular das escolas médicas

Autor/coautores: Tereza Brenda Clementino de Freitas; Lucas Christyan da Rocha Oliveira; José Alex Costa de França; Pedro Barreto Dantas; Maria Eduarda Baia Correia de Oliveira.

Instituição: Universidade Federal Rural do Semi-Árido (UFERSA), Mossoró-Rio grande do Norte; Hospital de Olhos de Mossoró, Mossoró-Rio Grande do Norte.

Financiamento: Autofinanciado.

Palavras-chave: Currículo, Educação Médica, Oftalmologia.

\section{INTRODUÇÃO}

O período da graduação forma o alicerce para a prática profissional de qualquer área, e no curso de medicina ele é orientado pelas Diretrizes Curriculares Nacionais (DCN) delimitadas pela Resolução $n^{\circ}$ 3, de 20 de junho de 2014. Nesse documento preconiza-se o preparo do graduando quanto ao entendimento das funções dos diversos órgãos e sistemas, além do desenvolvimento de habilidades referentes à abordagem clínica e terapêutica adequadas, com ênfase nas moléstias mais comuns, letais ou preveníveis (MEIRELES MAC, et al., 2019).

Desse modo, com a finalidade de preparar o estudante dentro das determinações para lidar com as variadas demandas, podem ser incluídas na grade curricular disciplinas relacionadas a sistemas (e.g. nefrologia, cardiologia), grupos (e.g. obstetrícia, geriatria) ou órgãos específicos (e.g. dermatologia, oftalmologia). Os últimos, com destaque para a oftalmologia, por serem consideradas por vezes como tangentes ao escopo do médico generalista, podem ser negligenciados na distribuição de horários e conteúdos ao longo dos semestres (ABREU AMA, et al., 2019).

Esse cenário, portanto, levanta preocupações uma vez que temas acerca de causas comuns de baixa visual e cegueira, que impactam na qualidade de vida do paciente e concernem à atenção primária à saúde, deixam de ser contemplados.

\section{OBJETIVO}

Avaliar a inserção da oftalmologia nas grades curriculares das escolas médicas no Rio Grande do Norte (RN), com enfoque em definir a carga horária despendida para esses tópicos e o momento no qual são abordados.

\section{MÉTODO}

Trata-se de um estudo observacional analítico transversal que tomou como referência os planos políticos pedagógicos, matrizes curriculares e ementas de disciplinas mais atuais das seis escolas médicas do RN, particulares e públicas. Os seguintes dados foram sumarizados em uma planilha: carga horária $(\mathrm{CH})$ total do curso, $\mathrm{CH}$ específica para oftalmologia, período no qual era cursada matéria e a existência de liga acadêmica de oftalmologia ou equivalente. Os dados foram então confrontados e analisados, determinando tendências gerais, semelhanças e diferenças entre eles, sintetizando um panorama geral acerca da abordagem da oftalmologia na graduação médica no RN e a tendência dos alunos em tentar suprir alguma demanda com as ligas acadêmicas. 


\section{RESULTADOS}

Analisando a inserção da oftalmologia no currículo da graduação de medicina nos cursos do RN foi percebido que as instituições (INST) 2, 4 e 6 especificam em seus currículos a abordagem dessa especialidade médica, propondo que sejam inseridos no sétimo período nas duas primeiras e no oitavo período na última. A carga horária média destinada a essa especialidade nas três universidades foi de 40 horas, sendo a moda 30 horas. Nessas instituições, a carga horária destinada à oftalmologia ocupa respectivamente $0,30 \%, 0,79 \%$ e $0,36 \%$, sendo a Instituição 4 detentoras da maior carga horária total e percentual destinada às habilidades e competências relacionadas aos cuidados oftalmológicos. Ademais, nas INST's 1, 3 e 5 não foram encontrados em seus projetos pedagógicos ou matrizes curriculares quaisquer menções delimitando o momento da integração da oftalmologia à grade.

Foi analisada a presença de ligas acadêmicas de oftalmologia ou similares como forma de suplantar o ensino e atender às demandas dos alunos e foi constatada a sua presença em todas as instituições. Contudo, nem todas se encontram filiadas à Associação Brasileira de Ligas Acadêmicas (ABLAM).

Tabela 1 - Inserção da oftalmologia no currículo médico nos cursos de medicina do RN.

\begin{tabular}{|c|c|c|c|c|c|c|c|}
\hline INSTITUIÇÃO & $\begin{array}{c}\mathrm{DCN}^{\prime} \\
\mathbf{S}\end{array}$ & INST 1 & $\begin{array}{c}\text { INST } \\
2\end{array}$ & $\begin{array}{c}\text { INST } \\
3\end{array}$ & $\begin{array}{l}\text { INST } \\
4\end{array}$ & INST 5 & $\begin{array}{c}\text { INST } \\
6\end{array}$ \\
\hline $\begin{array}{c}\text { Carga Horária } \\
\text { Total }\end{array}$ & $\begin{array}{c}>7200 \\
\mathrm{~h}\end{array}$ & $8536 \mathrm{~h}$ & $9680 \mathrm{~h}$ & $\begin{array}{c}7.560 \\
h\end{array}$ & $\begin{array}{l}7.54 \\
0 h\end{array}$ & $8560 \mathrm{~h}$ & $\begin{array}{c}8332 \\
h\end{array}$ \\
\hline $\begin{array}{l}\text { Período de } \\
\text { inserção }\end{array}$ & - & - & $7^{\circ}$ & - & $7^{\circ}$ & - & $8^{\circ}$ \\
\hline $\begin{array}{l}\text { Carga horária } \\
\text { específica(\%) }\end{array}$ & - & - & $\begin{array}{c}30 \mathrm{~h} \\
(0,3 \% \\
)\end{array}$ & - & $\begin{array}{c}60 \mathrm{~h} \\
(0,79 \\
\%)\end{array}$ & - & $\begin{array}{c}30 \mathrm{~h} \\
(0,36 \\
\%)\end{array}$ \\
\hline $\begin{array}{c}\text { Possui liga } \\
\text { acadêmica de } \\
\text { oftalmologia } \\
\text { ou } \\
\text { equivalente? }\end{array}$ & - & Sim & Sim & Sim & Sim & Sim & Sim \\
\hline
\end{tabular}

Fonte: FREITAS, et al., 2020.

\section{DISCUSSÃO}

No Rio Grande do Norte, as escolas mais antigas, implantadas anteriormente à consolidação das DCNs de 2014, possuem em seus currículos componentes exclusivos à oftalmologia, abordando as principais temáticas da área dentro dessas disciplinas, o que não ocorre nas demais, que possuem currículo integrado, não destinando carga horária específica para a especialidade. Outra característica das escolas médicas potiguares é a presença de ligas acadêmicas relacionadas à oftalmologia, o que pode indicar necessidade de ampliação do acesso a informações sobre o tema, uma vez que elas surgem, em muitos casos, objetivando o aprendizado de temas negligenciados ou pouco abordados na graduação formal (ARAÚJO RFA, et al., 2019).

\section{CONSIDERAÇÕES FINAIS}

Tendo em vista esse cenário, é notável a heterogeneidade da inserção da oftalmologia dentro das grades curriculares no RN, entretanto, não é possível realizar uma avaliação global, uma vez que as novas faculdades 
possuem módulos integrados e sem clareza quanto a abordagem da especialidade. Pensando em observar o nível de aprendizagem do tema nessas faculdades, é de suma importância a elaboração de avaliações interinstitucionais que visem identificar o desenvolvimento das competências e habilidades relacionadas à oftalmologia, principalmente voltado para aquelas essenciais na formação de um médico generalista.

\section{REFERÊNCIAS}

1. ABREU AMA, et al. Conhecimento dos Alunos de Medicina sobre Oftalmologia. Revista Brasileira de Educação Médica, 2019; 43(3): 100-109.

2. MEIRELES MAC, et al. Novas Diretrizes Curriculares Nacionais e a Formação Médica: Expectativas dos Discentes do Primeiro Ano do Curso de Medicina de uma Instituição de Ensino Superior. Revista Brasileira de Educação Médica, 2019; 43(3): 67-78. 
RESUMOS EXPANDIDOS: Estudo Original

Título: Cobertura vacinal de crianças assistidas pela Estratégia de Saúde da Família em exame de rotina

Autor/coautores: Ana Flávia Lopes Fortuna; Letícia Teixeira Guimarães; Maycon Willy Coelho; Jair Almeida Carneiro.

Instituição: Universidade Estadual de Montes Claros (UNIMONTES), Montes Claros - Minas Gerais.

Palavras-chave: Cobertura Vacinal, Serviços de Informação, Pesquisa sobre Serviços de Saúde.

\section{INTRODUÇÃO}

A vacina consiste em um método de prevenção e proteção contra inúmeros microrganismos, mediante a sensibilização do sistema imune do indivíduo com determinado antígeno e, consequentemente, produção de anticorpos. Esta torna-se essencial, uma vez que tem reconhecido impacto na redução da morbimortalidade de doenças imunopreveníveis (MORAIS JÚNIOR SLA, et al., 2018). Com efeito, a vacinação em massa é de extrema importância por ser fundamental na imunidade de rebanho, pois, aqueles vacinados e imunes, protegem indiretamente os não vacinados. Assim, é possível eliminar a circulação do agente infeccioso e, consequentemente, gerar a proteção da coletividade e de indivíduos vulneráveis (BARBIERI CLA, et al., 2017).

Nessa perspectiva da importância das vacinas, o Ministério da Saúde, em 1973, lançou o Programa Nacional de Imunizações (PNI), buscando controlar e erradicar possíveis doenças através da ampliação da cobertura vacinal em todo o país. Sua importância é explicitada na Lei no 8.069/90 regulamentada pelo Estatuto da Criança e do Adolescente (ECA), que estabelece obrigatoriedade da vacinação em crianças nos casos recomendados pelas autoridades sanitárias. Evidencia-se, portanto, o quão imprescindível e essencial é a vacinação em massa, especialmente na puericultura, para que esse grupo seja devidamente imunizado, reduzindo a circulação de agentes infecciosos e a morbimortalidade infantil.

\section{OBJETIVO}

Identificar a adequação do cartão vacinal em indivíduos assistidos pela Estratégia de Saúde da Família (ESF) conforme macrorregião do Brasil, considerando os atendimentos registrados com o CID Z00.1, no período de 2017 a 2019.

\section{MÉTODO}

Trata-se de estudo descritivo, transversal e quantitativo, a partir de consulta documental na base de dados do Sistema de Informação em Saúde para a Atenção Básica (SISAB), disponível no website http://sisab.saude.gov.br/. A consulta ao SISAB ocorreu em junho e julho de 2020. Filtraram-se os atendimentos registrados na ESF com a Classificação Internacional de Doenças (CID) Z00.1 - Exame de rotina da saúde da criança, entre janeiro de 2017 e dezembro de 2019. Avaliaram-se as variáveis: região do atendimento, ano do registro e adequação do cartão vacinal. Por se tratar de dados de domínio público, o estudo não foi submetido à apreciação do Comitê de Ética em Pesquisa (CEP).

\section{RESULTADOS}

Constatou-se que, no cenário nacional, a porcentagem de pacientes atendidos com o CID Z00.1 que apresentava esquema vacinal em conformidade com as preconizações do PNI manteve-se relativamente estável, variando entre 65 e $68 \%$ no período analisado. 
Em 2017, foram realizados 593.961 atendimentos, sendo que 65\% (387.117) dos pacientes estavam com o cartão vacinal completo. A cobertura vacinal completa registrada foi de 57\% (19.603) na região Centro-Oeste; 38\% (42.307) na região Sul; 94\% (25.960) na região Norte; 70\% (274.605) na região Sudeste e 80\% (33.165) na região Nordeste.

Em 2018, registraram-se 888.565 atendimentos, com conformidade vacinal de $68 \%$. Os resultados regionais apontam para 83\% (46.591) de cobertura no Centro-Oeste; 55\% (63.073) no Sul; $93 \%$ (42.640) no Norte; $66 \%$ (396.066) no Sudeste e 84\% (57.992) no Nordeste.

Em 2019, ocorreram 962.035 atendimentos e cobertura vacinal nacional de 67\% (646.541). Registrou-se $80 \%$ de cobertura (68.101) no Centro-Oeste; $50 \%$ (97.773) no Sul; $93 \%(60.268)$ no Norte; $67 \%$ (352.131) no Sudeste e $75 \%$ (68.268) no Nordeste.

\section{DISCUSSÃO}

Observam-se avanços nas taxas de cobertura vacinal nas regiões centro-oeste e sul. A região norte manteve o percentual de vacinação, a região sudeste mostra oscilação com melhora dos dados em 2019 e a região nordeste com queda no percentual de vacinação.

A redução da cobertura vacinal pode estar relacionada com as desigualdades socioeconômicas, pois baixa renda familiar e baixa escolaridade dos responsáveis relacionam-se com menor engajamento aos programas de imunização (ARROYO LH, et al., 2020). Porém, tal análise contrasta com o fato do Sul, região com melhores índices socioeconômicos, apresentar a menor proporção de imunizados, levantando a discussão do impacto cultural na participação da população nas campanhas de vacinação.

É preponderante ainda a influência do acesso da população aos serviços de saúde e das áreas de abrangência da ESF sobre a confiabilidade dos dados apresentados, bem como a informatização incompleta dos registros, cabendo a análise dessas variáveis em estudos posteriores.

Tabela 1 - Esquema vacina completo em atendimentos registrados com o CID Z00.1

\begin{tabular}{c|c|c|c|c|c|c|c|c|c}
\hline & \multicolumn{3}{|c|}{2017} & \multicolumn{3}{c|}{$\mathbf{2 0 1 8}$} & \multicolumn{3}{c}{2019} \\
\hline & AR & EVC & C & AR & EVC & C & AR & EVC & C \\
V & & & & & & V \\
\hline Centro & 19.60 & 11.08 & 57 & 56.37 & 46.59 & 83 & 85.04 & 68.10 & 80 \\
- & 3 & 0 & $\%$ & 7 & 1 & $\%$ & 0 & 1 & $\%$ \\
Oeste & & & & & & & & & \\
\hline Sul & 110.9 & 42.30 & 38 & 114.8 & 63.07 & 55 & 194.1 & 97.77 & 50 \\
& 46 & 7 & $\%$ & 75 & 3 & $\%$ & 49 & 3 & $\%$ \\
\hline Norte & 27.55 & 25.96 & 94 & 45.67 & 42.64 & 93 & 64.48 & 60.26 & 93 \\
& 8 & 0 & $\%$ & 2 & 0 & $\%$ & 2 & 8 & $\%$ \\
\hline Sudes & 394.5 & 274.6 & 70 & 602.7 & 396.0 & 66 & 526.7 & 352.1 & 75 \\
te & 43 & 05 & $\%$ & 97 & 66 & $\%$ & 45 & 31 & $\%$ \\
\hline Norde & 41.31 & 33.16 & 80 & 68.84 & 57.99 & 84 & 91.34 & 68.26 & 67 \\
ste & 1 & 5 & $\%$ & 4 & 2 & $\%$ & 9 & 8 & $\%$ \\
\hline Total & 593.9 & 378.1 & 65 & 888.5 & 606.3 & 68 & 962.0 & 646.5 & 67 \\
& 61 & 17 & $\%$ & 65 & 62 & $\%$ & 35 & 41 & $\%$ \\
\hline
\end{tabular}

Legenda: AR: atendimentos registrados; EVC: esquema vacinal completo e CV: cobertura vacinal.

Fonte: FORTUNA, et al., 2020. Dados extraídos de Sistema de Informação em Saúde para a Atenção Básica, 2020. 


\section{CONSIDERAÇÕES FINAIS}

Este estudo permitiu o conhecimento da cobertura vacinal de crianças assistidas pela Estratégia de Saúde da Família por macrorregião do Brasil durante o período entre 2017 e 2019. Percebe-se que houve avanços nas taxas de cobertura vacinal de crianças nas regiões centro-oeste e sul. A região norte manteve o percentual de vacinação, a região sudeste mostra oscilação com melhora dos dados em 2019, enquanto a região nordeste evidencia queda no percentual de vacinação.

\section{REFERÊNCIAS}

1. ARROYO LH, et al. Áreas com queda da cobertura vacinal para BCG, poliomielite e tríplice viral no Brasil (2006-2016): mapas da heterogeneidade regional. Cadernos de Saúde Pública, 2020; 36: e0001561.

2. BARBIERI CLA, et al. A (não) vacinação infantil entre a cultura e a lei: os significados atribuídos por casais de camadas médias de São Paulo, Brasil. Cadernos de Saúde Pública, 2017; 33: e00173315.

3. DE MORAIS JÚNIOR SLA, et al. A evolução histórica do calendário vacinal brasileiro infantil. Revista Enfermagem Atual In Derme, 2018; 85(23). 
RESUMOS EXPANDIDOS: Estudo Original

Título: Análise Temporal das fraturas de fêmur em idosos na região Sudeste do Brasil: 2009 a 2019

Autor/coautores: Isabelle Gualberto Souza; João Vitor Moreira Silva; Katyane Benquerer Oliveira de Assis.

Instituição: Centro Universitário Faculdades Integradas Pitágoras (UNIFIPMoc), Montes Claros - Minas Gerais.

Palavras-chave: Epidemiologia, Fraturas do fêmur, Saúde da Pessoa Idosa.

\section{INTRODUÇÃO}

Com o processo de envelhecimento, várias alterações de ordem fisiológica, morfológica e funcional ocorrem no indivíduo, tornando-o mais vulnerável a ocorrência de traumas intrínsecos e extrínsecos. Dentre os traumas mais prevalentes na atualidade, destaca-se a fratura de fêmur que é hoje um dos maiores problemas de saúde pública no país. É uma das patologias com maior repercussão na população idosa por sua alta morbidade e mortalidade. No Brasil, possuiu alta incidência e apresenta-se em crescimento ao longo dos anos, gerando altos custos econômicos e sociais (NETO AADS, et al., 2017).

A fratura de fêmur impacta diretamente na qualidade de vida dos idosos. Por ser um agravo com muitas complicações, requer um período de recuperação maior, muitas vezes em unidades de terapia intensiva, podendo evoluir com sequelas em alguns casos. Nesse sentido, esse tipo de trauma pode levar à perda da autonomia, capacidade funcional e independência do indivíduo, sendo uma das principais causas de incapacidade na população de 60 anos ou mais (MACEDO GG, et al., 2019).

\section{OBJETIVO}

Analisar a evolução temporal das internações por fratura de fêmur na população idosa com idade igual ou maior que 60 anos na região Sudeste do Brasil, em um período de 11 anos.

\section{MÉTODO}

Trata-se de um estudo ecológico com componente de série temporal com dados extraídos do Sistema de Internações Hospitalares do Sistema Único de Saúde (SIH-SUS). A amostra foi composta por indivíduos acometidos por fratura de fêmur, com idade maior ou igual a 60 anos, internados em regime público ou privado na região Sudeste do Brasil, no período de 2009 a 2019. Os dados foram coletados nos meses de maio a junho de 2020, utilizando como critério de busca o termo fratura de fêmur em idosos e as variáveis epidemiológicas que possibilitaram o delineamento do estudo. Os dados foram tabulados e analisados por meio de estatística descritiva no programa Microsoft Excel 2010 e posteriormente apresentados na forma de gráficos e tabelas para exposição e interpretação dos resultados.

\section{RESULTADOS}

Os resultados obtidos neste trabalho revelaram que no período estudado ocorreram 269.224 internações por fratura de fêmur em pessoas com idade maior ou igual a 60 anos na região Sudeste do Brasil. Foi possível verificar um aumento percental de aproximadamente $62 \%$ no total de internações quando comparados os valores dos anos de 2009 e 2019. Quanto à incidência, observou-se que o ano de 2018 foi o que apresentou o maior número de hospitalizações (30.099), seguido de 2019 e 2017, com 29.827 e 29.091 casos cada, respectivamente. Em todos os anos as fraturas de fêmur aconteceram mais no sexo feminino, representando $67,97 \%$ do total no período analisado. $\mathrm{Na}$ análise quanto a faixa etária, foi possível verificar que a maior prevalência de casos concentrou-se em indivíduos com idade maior ou superior à 80 anos (48,3\%). Dentre o total de casos de fratura nesses 11 anos, observou-se que o maior número de internações foi registrado no 
estado de São Paulo (142.646), seguido de Minas Gerais com 73.913 hospitalizações e Rio de Janeiro, com 43.010.

Tabela 1 - Internações por fratura de fêmur, segundo sexo e faixa etária, na região Sudeste do Brasil, de 2009 a $2019, \mathrm{n}=269.224$.

\begin{tabular}{|c|c|c|}
\hline Variável & $\mathbf{N}$ & $\%$ \\
\hline \multicolumn{3}{|l|}{ Sexo } \\
\hline Feminino & 182.999 & 67,97 \\
\hline Masculino & 86.225 & 32,03 \\
\hline \multicolumn{3}{|l|}{ Faixa Etária } \\
\hline $60-69$ anos & 53.346 & 19,81 \\
\hline 70-79 anos & 85.845 & 31,89 \\
\hline 80 anos ou mais & 130.033 & 48,3 \\
\hline TOTAL & 269.224 & 100 \\
\hline
\end{tabular}

Fonte: SOUZA IG, et al., 2020. Dados extraído do Sistema de Informações Hospitalares (SIH-DATASUS), 2020.

\section{DISCUSSÃO}

Este estudo analisou a incidência de fratura de fêmur em idosos na região Sudeste do Brasil a partir de dados secundários obtidos pelo SIH-SUS. Na análise das internações quanto ao gênero, foi observada uma prevalência significativa das hospitalizações em mulheres. Quanto à idade, verificou-se que os pacientes com idade maior ou igual a 80 anos foram os mais acometidos pelo problema. O mesmo perfil foi identificado em um estudo retrospectivo realizado no Brasil, em que foi observado que houve prevalência de aproximadamente $68 \%$ do total de casos de fratura em pacientes do sexo feminino e que os indivíduos com idade igual ou superior à 80 anos são os mais vulneráveis tanto à morbidade quanto à mortalidade da patologia (MACEDO GG, et al., 2019).

\section{CONSIDERAÇÕES FINAIS}

Os resultados encontrados nessa pesquisa corroboram com a literatura acerca do tema: predomínio de fraturas de fêmur em pacientes do sexo feminino e em idosos com idade maior ou igual a 80 anos. Ainda, verficou-se um aumento crescente do número de fraturas na região. Nesse sentido, é fundamental a implementação de políticas públicas de saúde com vistas ao controle de fatores que predispõem a ocorrência do evento, através da ampliação e melhoramento de programas que estimulem a capacidade funcional dos idosos, de forma a minimizar o risco de quedas e consequente ocorrência de fraturas.

\section{REFERÊNCIAS}

1. MACEDO GG, et al. Fraturas do fêmur em idosos: um problema de saúde pública no Brasil. Revista Eletrônica Acervo Científico, 2019; 6:1-7.

2. NETO AADS, et al. Fratura de fêmur em idosos hospitalizados: revisão integrativa. Ciências Biológicas e da Saúde Unit, 2017; 4(2):203-214. 
RESUMOS EXPANDIDOS: Estudo original

Título: Mortalidade por Melanoma maligno de pele na Bahia e em Santa Catarina

Autor/coautores: Juliana Cavalcanti de Andrade Silva; Caroline Sampaio Portugal Andrade.

Instituição: Centro Universitário Faculdade de Tecnologia e Ciências (UniFTC), Salvador - Bahia.

Palavras-chave: Câncer de pele, Melanoma maligno de pele, Epidemiologia.

\section{INTRODUÇÃO}

O câncer de pele é a neoplasia de maior incidência no Brasil, e o melanoma é o mais maligno dos tumores cutâneos, por gerar metástase com maior facilidade e rapidez (MÂNICA A, 2017). Ao longo dos anos, a incidência e a mortalidade por essa neoplasia vêm aumentando consideravelmente (GUIDETTE MV, 2016).

O fator de maior importância para o desenvolvimento do melanoma é a exposição solar, e associado a isso, a cor de pele. A população de pele clara desenvolve com maior frequência esse câncer, já que possuem menor quantidade de melanina em comparação com pessoas de pele escura, tendo menor proteção contra a radiação ultravioleta. Isso predispõe ao desenvolvimento da mutação celular e consequente câncer de pele (DUARTE IF, 2017).

O estudo compara a mortalidade por melanoma em dois estados opostos em relação a cor da pele da população. A Bahia, por apresentar mais de $75 \%$ da população autodeclarada preta ou parda, e Santa Catarina, por possuir em quase sua totalidade, mais de $80 \%$, indivíduos de pele branca. De modo a acrescentar dados à literatura científica, debatendo acerca da importância da prevenção, diagnótico e tratamento precoce, para reduzir as taxas de mortalidade.

\section{OBJETIVO}

Realizar um estudo epidemiológico sobre a mortalidade por melanoma maligno de pele, comparando os estados Bahia e Santa Catarina, no período de 2009 a 2018. Além disso, descrever os principais fatores de risco para essa neoplasia, dando importante valorização a raça/cor da pele, faixa etária e sexo.

\section{MÉTODO}

Trata-se de um estudo realizado com base em dados agregados e secundários, obtidos através da plataforma do Instituto Brasileiro de Geografia e Estatística (IBGE), para obter os dados demográficos, e o Departamento de Informática do Sistema Único de Saúde (DATASUS), entre os anos de 2009 a 2018. A população alvo incluiu adultos, variando de 20 a mais de 80 anos de idade, do sexo feminino e masculino, que morreram por melanoma maligno de pele nos estados Bahia e Santa Catarina. Através de tabulação e análise estatística, foi realizada a análise dos dados, apresentados por meio de frequência simples, absoluta e porcentagem, num banco de dados criado no Microsoft Excel.

\section{RESULTADOS}

Observou-se que 2017 foi o ano com maior mortalidade, apresentando grande importância para o estudo. Nesse ano, Santa Catarina apresentou um total de 163 óbitos, um pouco mais que 3 vezes o valor observado na Bahia, que teve 48 mortes. A cor da pele com maior mortalidade em 2017 na Bahia foi a parda, com 50\% da amostra, seguida da raça branca, com $35 \%$. Por outro lado, em Santa Catarina a população de pele branca apresentou quase a totalidade da amostra, com $97 \%$ dos óbitos, sendo apenas $2 \%$ na raça preta. 
No mesmo ano, a faixa etária predominante nos dois estados foi de 60 a 69 anos, correspondendo a $29 \%$ da amostra na Bahia, e a $22 \%$ em Santa Catarina; em contrapartida, as faixas etárias que apresentaram baixos valores de mortalidade na Bahia foram aquelas abaixo de 50 anos, enquanto que em Santa Catarina foram aquelas abaixo de 40 anos. O sexo masculino apresentou o maior número de óbitos nos dois estados, ambos representados por $56 \%$ da amostra. Já no sexo feminino, o valor observado foi de $44 \%$.

Tabela 1 - Mortalidade por melanoma maligno de pele em 2017, $n=211$.

\begin{tabular}{|c|c|c|c|c|}
\hline \multirow[b]{2}{*}{ Variável } & \multicolumn{2}{|c|}{ Bahia } & \multicolumn{2}{|c|}{ Santa Catarina } \\
\hline & $\mathbf{N}$ & $\%$ & $\mathbf{N}$ & $\%$ \\
\hline \multicolumn{5}{|l|}{ Raça } \\
\hline Branca & 17 & 35 & 158 & 97 \\
\hline Preta & 3 & 6 & 3 & 2 \\
\hline Parda & 24 & 50 & 2 & 1 \\
\hline Ignorado & 4 & 8 & 0 & 0 \\
\hline \multicolumn{5}{|l|}{ Idade } \\
\hline 20 a 29 anos & 1 & 2 & 7 & 4 \\
\hline 30 a 39 anos & 3 & 6 & 14 & 9 \\
\hline 40 a 49 anos & 3 & 6 & 20 & 12 \\
\hline 50 a 59 anos & 9 & 19 & 29 & 18 \\
\hline 60 a 69 anos & 14 & 29 & 36 & 22 \\
\hline 70 a 79 anos & 6 & 13 & 31 & 19 \\
\hline 80 anos e mais & 12 & 25 & 26 & 16 \\
\hline \multicolumn{5}{|l|}{ Sexo } \\
\hline Masculino & 27 & 56 & 92 & 56 \\
\hline Feminino & 21 & 44 & 71 & 44 \\
\hline Total & 48 & 100 & 163 & 100 \\
\hline
\end{tabular}

Fonte: SILVA JCA e ANDRADE CSP, 2020. Dados extraídos do Departamento de Informática do Sistema Único de Saúde (DATASUS), 2020.

\section{DISCUSSÃO}

O estudo evidenciou que a população de pele branca morre mais por essa neoplasia e que esse é um fator de grande importância no desenvolvimento da doença (DUARTE IF, 2017). Observou-se que moradores do Sul do Brasil estão mais vulneráveis a essa patologia por ser maioria caucasianos (MÂNICA A, 2017); semelhante a isso, em 2017, Santa Catarina teve $97 \%$ dos óbitos por pessoas brancas, enquanto que na Bahia, $50 \%$ das mortes foram de pardos e $35 \%$ de pessoas brancas.

Faz-se necessário realizar novas pesquisas que abranjam esses estados tão antagônicos, para identificar a influência da raça preponderante deles sob a mortalidade por esse câncer. Deve-se associar aos estudos 
outros fatores e características que possam predispor ao desenvolvimento dessa neoplasia, já que são poucos os dados fornecidos, gerando limitações para analisar epidemiologicamente e consolidar a prevenção, diagnóstico e tratamento precoce, de modo que seja capaz de reduzir suas taxas de mortalidade.

\section{CONSIDERAÇÕES FINAIS}

O melanoma maligno de pele ainda é muito prevalente no Brasil, e apresenta alta mortalidade. Evidenciouse diferença importante entre Bahia e Santa Catarina, esta com 3 vezes mais mortes, maioria registradas na raça branca. Em ambos os estados houve mais óbitos de homens, e da faixa etária entre 60-69 anos. A exposição solar e a cor da pele têm importante influência no mecanismo de desenvolvimento da doença. Assim, são necessárias mais pesquisas nessa área, principalmente com esses estados antagônicos, para identificar as causas das diferenças nos valores de mortalidade, e evidenciar a necessidade da prevenção, diagnóstico e tratamento precoce.

\section{REFERÊNCIAS}

1. DUARTE IF. Fatores de risco de melanoma maligno: intrínsecos ou extrínsecos? Tese de Doutorado Universidade de Coimbra, 2017.

2. GUIDETTI MV, et al. Incidência e importância do diagnóstico precoce de melanoma no Brasil. Revista Brasileira Multidisciplinar, 2016; 19(1).

3. MÂNICA A. Relação entre o desenvolvimento do melanoma cutâneo e o estresse oxidativo. RBAC, 2017; 49(1). 
RESUMOS EXPANDIDOS: Revisão Bibliográfica

Título: Manifestações cutâneas em pacientes com HIV: uma revisão integrativa da literatura

Autor/coautores: Camila França Arruda; Jordana Daniella Inez da Silva; Débora Borges de Oliveira Silva; Sérgio José de Melo Filho; Aline de Araújo Freitas.

Instituição: Centro Universitário de Anápolis (UniEVANGÉLICA), Anápolis-Goiânia; Hospital Municipal de Goiatuba (HMG), Goiatuba-Goiás.

Palavras-chave: Dermatopatias, HIV, Síndrome da Imunodeficiência Adquirida.

\section{INTRODUÇÃO}

A Síndrome da Imunodeficiência Adquirida (AIDS) é causada pelo Vírus da Imunodeficiência Humana (HIV), que acopla o seu DNA viral no genoma do hospedeiro de modo definitivo. A infecção causa depleção de linfócitos T CD4+ acarretando uma queda da imunidade e a predisposição para doenças oportunistas graves (BRASIL, 2018).

No contexto de imunossupressão pelo HIV, a pele é um dos órgãos mais acometidos e as manifestações cutâneas podem ser provenientes tanto de quadros infecciosos, quanto não infecciosos, como as neoplasias, além da ocorrência de farmacodermias. Essas dermatopatias podem sofrer influência do estágio da doença, do estado imunológico do paciente e até de medicamentos tomados (SANTIAGO IMDM, et al., 2019).

Assim, pode-se afirmar que muitas dessas afecções dermatológicas podem contribuir no processo diagnóstico do paciente HIV positivo e atuar como um marcador prognóstico da doença, pois, com a progressão da síndrome, as lesões passam a apresentar-se com maior frequência, gravidade e refratariedade ao tratamento habitual (CHANDRAKALA C, et al., 2017).

\section{OBJETIVO}

Descrever as principais manifestações cutâneas relacionadas à infecção pelo HIV e identificar a importância do reconhecimento dessas no contexto da doença no que se refere ao diagnóstico, prognóstico e terapêutica.

\section{MÉTODO}

Trata-se de uma revisão integrativa da literatura, realizada a partir de uma busca nas bases de dados National Library of Medicine and National Institutes of Health (PubMed), Scientific Electronic Library Online (SciELO) e Google Acadêmico. Os critérios utilizados na seleção dos artigos foram: trabalhos publicados entre os anos de 2017 a 2020, nos idiomas português e inglês, disponíveis eletronicamente e que abordem, detalhadamente, a questão norteadora desta pesquisa. Foram utilizados os seguintes descritores em ciências da saúde: manifestações cutâneas, dermatopatias, HIV e Síndrome da Imunodeficiência Adquirida. Dentre os 206 artigos encontrados, foram selecionados 25 para análise, dos quais 13 se enquadraram nos critérios.

\section{REVISÃO BIBLIOGRÁFICA}

O desenvolvimento das principais afecções dermatológicas encontradas em pacientes HIV positivos, está principalmente associado, ao tempo de evolução da infecção, idade de contágio e contagem de linfócitos TCD4+ (PÉREZ RO, et al., 2020). Quanto as afecções mais observadas, tem-se as dermatofitoses, candidiase oral, dermatite seborreica, sarcoma de Kaposi, xerose cutânea, reações cutâneas induzidas por drogas, verrugas genitais, herpes zoster, sífilis, escabiose e eczema fotossensível, sendo que estudos apontam a candidíase oral como sendo a dermatose mais frequente (BOUSHAB BM, et al., 2017; SANTIAGO IMDM, et 
al., 2019; TITOU H, et al., 2018). Ademais, nota-se que a prevalência das dermatopatias infecciosas e não infecciosas é maior quando comparada com as farmacodermias (CHANDRAKALA C, et al., 2017).

Acerca da contagem de línfócitos TCD4+, nota-se que a maior parte dessas manifestações cutâneas ocorrem em pacientes com valores abaixo de 250 células $/ \mathrm{mm} 3$, sendo mais significativas em contagens inferiores a 200 células/mm3 (CAMPOS PM, 2016; PÉREZ RO, et al., 2020; TITOU H, et al., 2018). Outrossim, um quadro com múltiplas dermatoses pode estar relacionado com uma contagem de línfócitos TCD4+ abaixo de 200 células $/ \mathrm{mm} 3$, ao passo que manifestações únicas são mais observadas em contagens acima de 200 células $/ \mathrm{mm} 3$. Clinicamente, observa-se que quanto mais frequente é o surgimento de dermatoses de cunho infeccioso menos frequentes são as não infecciosas, indicando deteriorização da imunidade do hospedeiro (CHANDRAKALA C, et al., 2017).

O reconhecimento dessas dermatopatias podem auxiliar no diagnóstico da infecção pelo HIV, pois são frequentemente observadas em pacientes recém-diagnosticados (CHANDRAKALA C, et al., 2017; SANTIAGO IMDM, et al., 2019). Ademais, a noção dessas afecções pode apontar para um prognóstico da doença, pois quanto mais imunossuprimido o indivíduo se encontra ou quanto maior é a carga viral, maior é a incidência das doenças dermatológicas (SANTIAGO IMDM, et al., 2019).

\section{DISCUSSÃO}

Devido o decréscimo, numérico e funcional, das células apresentadoras de antígenos e células TCD4+ nesses pacientes, a pele torna-se mais vulnerável aos agentes infecciosos oportunistas e neoplásicos. Logo, quanto maior a imunossupressão, maior é o acometimento cutâneo, o que indica uma relação entre o surgimento dessas afecções com a evolução da infecção pelo HIV, a redução da contagem de linfócitos TCD4+ e o estágio da doença (DAVARPANAH MA, et al., 2018; SANTIAGO IMDM, et al., 2019).

Assim, o reconhecimento dessas manifestações cutâneas é de suma importância para a instituição de medidas terapêuticas adequadas, podendo influenciar na progressão da imunodeficiência (SANTIAGO IMDM, et al., 2019). Ademais, é notório que a adesão aos cuidados gerais com a pele e de medidas de fotoproteção influencia no tempo de resolução das dermatoses e geram qualidade de vida a esses pacientes (CHAULA $\mathrm{BM}, 2018)$.

\section{CONSIDERAÇÕES FINAIS}

Dessa forma, nota-se que a avaliação dermatológica nesses pacientes é fundamental, pois pode auxiliar no rastreamento e diagnóstico precoce da AIDS e, portanto, possibilitar a instituição da terapêutica adequada afim de retardar a progressão dessa enfermidade. O reconhecimento dessas afecções no acompanhamento clínico do paciente com HIV pode indicar o estado imunológico desse e o estágio da doença, traçando um prognóstico. Portanto, é evidente a relevância do conhecimento das dermatopatias nesse contexto, de modo que essa temática necessita ser mais abordada no meio científico, além de debatida com a população, como numa estratégia de educação em saúde.

\section{REFERÊNCIAS}

1. BRASIL. MINISTÉRIO DA SAÚDE. Manual Técnico para o Diagnóstico da Infecção pelo HIV em Adultos e Crianças. Brasília: Ministério da Saúde. 2018.

2. BOUSHAB BM, et al. Mucocutaneous manifestations in human immunodeficiency virus (HIV)-infected patients in Nouakchott, Mauritania. International Journal of Dermatology, 2017; 56(12):1421-1424.

3. CAMPOS PM. Marcados na pele - lesões dermatológicas em pacientes HIV/AIDS: uma revisão integrativa. Lume - Repositório Digital da UFRGS, 2016. 
4. CHANDRAKALA C, et al. Correlating CD4 count with mucocutaneous manifestations in HIV-positive patients: A prospective study. Indian J Sex Transm Dis AIDS, 2017; 38(2):128-135.

5. CHAULA BM. HIV-Infection and Associated Dermatoses. Pigmented Ethnic Skin and Imported Dermatoses, 2018; 415-427.

6. DAVARPANAH MA, et al. Dermatological Manifestations of HIV/AIDS Individuals in Shiraz, South of Iran. Journal of global infectious diseases, 2018; 10(2):80-83.

7. SANTIAGO IMDM, et al. Dermatoses em pacientes com HIV acompanhados em um hospital de referência em João Pessoa-Paraíba no ano de 2017. Revista de Ciências da Saúde Nova Esperança, 2019; 17(3):18-24.

8. TITOU H, et al. Dermatologic manifestations among human immunodeficiency virus patients in Morocco and association with immune status. International Journal of Dermatology, 2018; 57(2):156-161.

9. PÉREZ RO, et al. Principales dermatosis primarias asociadas a pacientes con VIH. Enfermedades Infecciosas Microbiología, 2020; 39(3):103-108. 
RESUMOS EXPANDIDOS: Revisão Bibliográfica

Título: Aconselhamento Genético na Atenção Primária: A importância da sua ampliação

Autor/coautores: Ana Célia Costa Matos Silva; Mariana Cabral de Oliveira Cardoso; Juliane Marques Andrade; Isabel Silva Araujo Borges; Constanza Thaíse Xavier Silva.

Instituição: Centro Universitário de Anápolis - UniEVANGÉLICA, Anápolis-Goiás.

Palavras-chave: Pandemia, Acidente de Trabalho, Enfermagem.

\section{INTRODUÇÃO}

O aconselhamento genético é uma modalidade que surgiu nos Estados Unidos da América, nos anos 1940. Atualmente, apesar de bem disseminada no continente europeu, e na América do Norte, ainda se encontra em um crescente de desenvolvimento no Brasil. Ele consiste no acompanhamento do indivíduo acometido por alguma doença genética e seus familiares, com o objetivo de orientar os pacientes sobre todos os aspectos que permeiam a sua doença em questão (CARDOSO MCV e CORDEIRO JÚNIOR DA, 2016). Ademais, baseando-se em testes genéticos, também tem a finalidade de informar a população sobre a probabilidade e os riscos oriundas das doenças genéticas (SOUZA MPC, et al., 2019).

Esse processo é dividido em duas etapas. A primeira é prospectiva, em que a conduta nas consultas é voltada para o planejamento e a fertilização, enquanto a segunda se trata de uma abordagem retrospectiva, realizada durante o pré-natal (CARVALHO BM, et al., 2020). Além disso, é executado, normalmente, pelo médico geneticista, o que na prática torna-se uma dificuldade na implementação em nível nacional do acesso à genética clínica (CARDOSO MCV e CORDEIRO JÚNIOR DA, 2016).

\section{OBJETIVO}

Definir a importância da ampliação e implementação do serviço da genética na atenção primária, não só como medida para redução da mortalidade perinatal e infantil, como também para melhoria na qualidade de vida daqueles com acometimento genético.

\section{MÉTODO}

Trata-se de uma revisão integrativa, descritiva, na qual foram compilados dados de diversos estudos publicados. A coleta de dados foi feita através de fonte secundárias de seis artigos selecionados a partir da escolha da questão norteadora, que consiste em definir qual importância da ampliação do aconselhamento genético na atenção primária? Desse modo, realizou-se as buscas nas plataformas Public Medlines (Pubmed), Scientific Electronic Library Online (SciELO) e Literatura Latino Americana e do Caribe em Ciências da Saúde (LILACS), com os descritores "genetic couseling", "genetic diseases" AND "inborn perinatal, mortality", e selecionados artigos entre os anos de 2016 e 2020.

\section{REVISÃO BIBLIOGRÁFICA}

O acesso ao aconselhamento genético é escasso no Brasil. Esse fato associa-se a diversos motivos, entre eles o desconhecimento da sociedade sobre a importância, a falta de profissionais atuantes e a ausência da genética médica na atenção primária (CAMPOS DA, et al., 2017). Relacionado a isso, os serviços de genética, hoje, no Brasil, se concentram apenas nas grandes universidades das regiões Sul e Sudeste que possuem hospitais escola voltados para a pesquisa, o que comprova a insuficiência dessa área nas demais regiões do país (SOUZA MPC, et al., 2019). Apesar do desconhecimento da sociedade em relação à genética médica e suas doenças, a incidência desta é alta, correspondendo a $46 \%$ das concepções que resultam em abortos espontâneos. Além de outras patologias no decorrer da vida (CAMPOS DA, et al., 2017). 
Em relação à mortalidade perinatal e infantil, tem-se que a má-formação congênita é um dos principais fatores que contribuem para esse elevado índice, representando $20 \%$ da mortalidade neonatal e 30 a $50 \%$ da mortalidade perinatal (CARVALHO BM, et al., 2020). Além do mais, as anomalias de causa congênita e genética passaram do quinto para o segundo lugar, em mortalidade infantil, no Brasil, nas últimas três décadas (SANTOS NSA e BRAGA JRM, 2017).

Diante disso, a Triagem Neonatal, que visa detectar portadores de diversas doenças de fundo genético em recém-nascidos, é responsável por uma intervenção rápida e efetiva, o que causa uma redução dos índices de mortalidade (CARVALHO BM, et al., 2020). Já o aconselhamento genético, permite, também, que as famílias possam entender todo o processo envolvido nas doenças genéticas e optarem, previamente, por ter um ou mais membros afetados por alguma doença (CARDOSO MCV e CORDEIRO JÚNIOR DA, 2016).

\section{DISCUSSÃO}

O processo de comunicação associado à ocorrência ou ao risco de ocorrência de uma doença genética em uma família, que é a base do aconselhamento genético, envolve profissionais especializados (OSTERMANN AC, et al., 2017). Dessa forma, a má distribuição de tais profissionais deixa milhares de brasileiros sem atendimento, o que acarreta um aumento a incidência de determinadas doenças genéticas e, consequentemente, da mortalidade (SANTOS NSA e BRAGA JRM, 2017).

Além disso, a prevalência dessas más-formações congênitas é decorrente da falta de informação e do insuficiente uso de estratégias preventivas (CAMPOS DA, et al., 2017). Soma-se a isso, a ineficácia de políticas públicas em sua totalidade. Ademais, é preciso que haja um diagnóstico precoce e assertivo, para que seja elaborado estratégias que garantiram a esses pacientes um melhor prognóstico (CARVALHO BM, et al., 2020).

\section{CONSIDERAÇÕES FINAIS}

O acometimento genético no Brasil apresenta elevados índices e uma curva crescente de casos. $O$ conhecimento da doença pode trazer maior qualidade de vida ao portador, além de minimizar a mortalidade infantil, o que contribui positivamente para o cumprimento de um dos objetivos do milênio.

Dessa forma, é de grande importância que haja um investimento na formação profissional nessa área, para que se consiga ter uma distribuição por todo o território brasileiro. Associado a isso, a implementação do atendimento de genética médica no serviço de saúde, por meio da atenção primária, é uma ferramenta que contribuirá para um melhor reconhecimento.

\section{REFERÊNCIAS}

1. CAMPOS DA, et al. Fatores Genéticos: Prevalência de mortalidade neonatal e anomalias congênitas. Journal of Biology \& Pharmacy and Agricultural Management, 2017; 13(2): 1-10.

2. CARDOSO MCV, CORDEIRO JÚNIOR DA. Enfermagem em Genômica: O aconselhamento genético nas práticas assistenciais. Revista Mineira de Enfermagem, 2016; 20:e956.

3. CARVALHO BM, et al. Acesso precoce à triagem neonatal biológica: articulação entre ações de programas de atenção à criança. Revista Latino-Americana de Enfermagem. Ribeirão Preto, 2020; 28(0): e3266.

4. SANTOS NSA, BRAGA JRM. Morte neonatal por anomalia genética e congênita em Salvador-BA: Um estudo retrospectivo. Revista Eletrônica Atualiza Saúde, 2017; 5(5): 07-19.

5. SOUZA MPC, et al. Chromosomal analyses in genetic counseling of patients with developmental and congenital abnormalities from Belém, Pará State, Brazil: A retrospective study of 17 years. Revista Pan-Amazônica de Saúde, 2019; 10(0): e201901597.

6. OSTERMANN AC, et al. Perspectivas otimistas na comunicação de notícias difíceis sobre a formação fetal. Caderno de Saúde Pública, 2017; 33(8): e00037716. 
RESUMOS EXPANDIDOS: Revisão Bibliográfica

Título: Baloxavir Marboxil como uma nova opção de tratamento para Influenza: revisão narrativa

Autor/coautores: Filipe Pivato Brizon; Julia Harumi Takume Minoda; Igor Goes Teixeira; Bruna Silva Terra.

Instituição: Universidade José do Rosário Vellano (UNIFENAS), Belo Horizonte - Minas Gerais.

Palavras-chave: Influenza, Baloxavir marboxil, Ensaios clínicos.

\section{INTRODUÇÃO}

A Influenza é uma infecção viral aguda de fácil disseminação, sendo os seus subtipos A e B de grande importância na sintomatologia clínica. Cerca de 1 bilhão de pessoas são infectadas por ano e 500.000 vão à óbito pela doença, a qual possui rápida transmissão, sendo ainda favorecida por mutações constantes na proteína viral, que Ihe atribui característica epidêmica. Devido aos "shifts antigênicos" no tipo A, o vírus acomete de modo indiferenciado os grupos populacionais, sendo os mais acometidos as crianças e, mais gravemente, idosos e pessoas com condições médicas subjacentes, havendo alto risco de morte. Atualmente, o tratamento padrão ouro da infecção consiste-se no uso de fármacos inibidores de neuraminidase, como o oseltamivir e zanamivir, no entanto já foi identificada resistência viral, dificultando terapêutica adequada e controle dessa patologia. Frente a este cenário, novos medicamentos contra a Influenza tornam-se necessários, sendo o baloxavir marboxil um novo fármaco antiviral promissor (GHEBREHEWET S, et al., 2016).

Esse fármaco, ainda sob estudo, tem demonstrado eficácia contra uma variedade de cepas de vírus e bons resultados na prática clínica atuando na inibição da etapa cap-snatching, no início da transcrição do RNA viral (WATANABE A, et al., 2019).

\section{OBJETIVO}

Apresentar os resultados dos estudos clínicos do medicamento antiviral baloxavir marboxil, nos quais demonstram sua eficácia e segurança quando comparado ao placebo e outros tratamentos de Influenza, como os inibidores de neuraminidase.

\section{REVISÃO BIBLIOGRÁFICA}

A fase clínica 1 constou com um estudo randomizado, duplo-cego, controlado por placebo e com a participação de 55 voluntários. Constatou boa segurança e tolerância medicamentosa na ingestão de doses de $6 \mathrm{mg}$ a $80 \mathrm{mg}$, com efeitos adversos leves. Ainda, observou-se que o estado alimentado diminuiu a exposição do fármaco $(20 \mathrm{mg})$ comparado com o estado em jejum, após análise dos parâmetros farmacocinéticos $\left(\mathrm{C}_{\max }=25,7 \mathrm{ng} / \mathrm{mL}\right.$ e $A U C_{\infty}=2429 \mathrm{ng} \cdot \mathrm{h} / \mathrm{mL} ; \mathrm{C}_{\max }=49,1 \mathrm{ng} / \mathrm{mL}$ e $A U C_{\infty}=3867 \mathrm{ng} \cdot \mathrm{h} / \mathrm{mL}$, respectivamente) (KOSHIMICH H, et al., 2018).

No estudo de fase 2 randomizado, duplo-cego, controlado por placebo com a participação de 400 pacientes foi analisada a eficácia em $24 \mathrm{hrs}$ de doses orais únicas de $10 \mathrm{mg}, 20 \mathrm{mg}$ ou $40 \mathrm{mg}$. Comparado com o placebo, o baloxavir apresentou bom controle sintomático (redução de sintomas em 54.2hrs, em contraste com 77.7hrs com placebo) e significativa redução da carga viral em 1 dia do início do tratamento, obtendo $p<0,0001$ na redução da carga viral da Influenza tipo $A$ e $p<0,05$ na redução da carga viral da Influenza tipo $B$ (WATANABE A, et al., 2019).

$\mathrm{Na}$ fase 3, um estudo randomizado, duplo-cego, controlado por placebo e oseltamivir com a participação de 1366 que completaram o estudo, não foram notadas diferenças relevantes nos atributos demográficos e clínicos entre baloxavir, oseltamivir e placebo; sendo que o baloxavir $(40 \mathrm{mg})$ obteve alívio sintomático mais 
rápido e maiores declínios na carga viral infecciosa em relação ao placebo ou ao oseltamivir (queda da carga viral de 4.8, 2.8, e 1.3 log10 TCID50 por milímetro no grupo baloxavir, oseltamivir e placebo, respectivamente). O tempo médio para alívio sintomático foi menor no grupo baloxavir em contraste com placebo nos infectados (53,7hrs vs. $80,2 \mathrm{hrs}, \mathrm{p}<0,001)$. Houve ainda menores efeitos colaterais comparado aos medicamentos já em uso (HAYDEN F, et al., 2018).

\section{DISCUSSÃO}

O estudo clínico de fase 1 do baloxavir demonstrou que ele é um fármaco seguro, com uma boa absorção por via oral em diferentes dosagens e aumento proporcional à dose, entretanto sofre influência da alimentação, sendo necessárias orientações aos pacientes durante a prescrição (KOSHIMICH H, et al., 2018). As possíveis limitações apresentadas nos estudos são o financiamento dos estudos pela indústria farmacêutica fabricante do fármaco e a existência de autores do estudo empregados por essa mesma indústria, além da amostra utilizada ser, majoritariamente, japoneses. Os estudos clínicos de fase 2 e 3 demonstraram a sua eficácia em diminuição da carga viral, da intensidade e da duração dos sintomas comparada ao placebo e ao oseltamivir (HAYDEN F, et al., 2018). Além disso, estudos de farmacovigilância em grupos populacionais diferentes são imprescindíveis para comprovar a sua efetividade.

\section{CONSIDERAÇÕES FINAIS}

Observou-se o baloxavir marboxil como fármaco promissor para uma nova terapêutica contra a Influenza. O novo medicamento apresentou melhores resultados, benefícios e facilidades terapêuticas durante a clínica médica quando comparados com o padrão ouro, no qual já apresenta limitações. Entretanto, em razão de ser um fármaco recente no mercado, é impreterível a realização de estudos de acompanhamento para assegurar, detalhadamente a eficácia, segurança medicamentosa e resistência a longo prazo deste novo fármaco.

\section{REFERÊNCIAS}

1. GHEBREHEWET S, et al. Influenza. BMJ, 2016; 355: i6258.

2. HAYDEN F, et al. Baloxavir Marboxil for Uncomplicated Influenza in Adults and Adolescents. New England Journal of Medicine, 2018; 379(10): 913.

3. KOSHIMICH H, et al. Tolerability and Pharmacokinetics of the novel anti-influenza agent Baloxavir Marboxil in healty adults: Phase I Study Findings. Clinical Drug Investigation, 2018; 38(12): 1189.

4. WATANABE A, et al. Baloxavir marboxil in Japanese patients with seasonal influenza: Dose response and virus type/subtype outcomes from a randomized phase 2 study. Antiviral Research, 2019; 163: 75. 
RESUMOS EXPANDIDOS: Revisão Bibliográfica

Título: O papel da genética na tumorigênese: RNAcircular e sua relação com câncer de mama

Autor/coautores: Danielle Correia Furtado; Fernanda Clara da Silva; Millena Fontes Soares; Lívia Nornyan Medeiros Silva.

Instituição: Universidade do Estado do Rio Grande do Norte (UERN), Mossoró - Rio Grande do Norte.

Palavras-chave: Câncer de Mama, RNA Circular, Tratamento.

\section{INTRODUÇÃO}

De acordo com a Global Cancer Statistics 2018, mais de 2 milhões de mulheres foram diagnosticadas com Câncer de Mama (CM) e mais de 60 mil mortes foram causadas por CM. O CM é um dos cânceres mais comuns e, apesar das abordagens de tratamento terem avançado, é necessário descobrir novos biomarcadores para a detecção, tratamento e prognóstico precoces (LI Z, et al., 2019).

Para maximizar a eficácia da terapia, é importante entender as vias moleculares envolvidas na patogênese do CM que causam metástase e resistência à quimioterapia (LIANG H-F, et al., 2017). Os RNA circulares (circRNAs) são altamente abundantes em humanos e possuem funções reguladoras pré e pós-transcricionais significativas em células de mamíferos. Evidências crescentes sugerem que os circRNAs estão envolvidos na patogênese de uma variedade de doenças, como distrofia neurológica e câncer. Alterações na abundância de circRNAs podem afetar a expressão gênica, favorecendo o surgimento de tumores. Assim, estudos recentes mostram que os circRNAs atuam na promoção da tumorigênese e contribuem para a proliferação e invasão de uma variedade de cânceres, incluindo o CM (NAIR AA, et al., 2016).

\section{OBJETIVO}

Revisar o que a literatura mais recente aponta sobre a relação dos RNA circulares com o Câncer de Mama.

\section{MÉTODO}

Revisão de literatura, com busca sistemática, na qual foram analisados artigos nos idiomas português e inglês publicados nos últimos 5 anos. Os descritores utilizados foram "Circular RNA AND Breast Cancer" na base de dados PubMed. Foram incluídos estudos primários e excluiu-se revisões sistemáticas e duplicatas. Foram encontrados um total de cento e seis artigos relacionados aos descritores utilizados. A partir da leitura dos títulos e resumos, foram selecionados seis artigos, de acordo com os critérios de elegibilidade, sendo realizada a leitura na íntegra dos mesmos.

\section{REVISÃO BIBLIOGRÁFICA}

A relação do circRNA com o CM se elucida através da sua grande variedade, incluindo circ_ANKS1B, circ_AGFG1, circ_IRAK3, circ_GFRA1 e circ_EPSTI1 encontrado em material coletado na biópsia de diversas mamas que continham tumor maligno. Esses circRNAs mostram grande potencial para funcionar na carcinogênese, metástase ou quimiorresistência do CM pela regulação transcricional de RNAs como o miRNA e o mRNA (LI Z, et al., 2019). Ainda, há evidências da relação de circRNAs e mutações na proteína p53, que atua na prevenção da progressão tumoral. Os circRNAs presentes em tecidos mamários com tumores malignos induzem mutações na p53 (FANG L, et al., 2018).

Os circRNAs são agrupados como RNAs não codificantes, no entanto, alguns demonstraram codificar peptídeos de proteínas e isso mostra seu potencial papel regulador. Além de sua estrutura canônica e capacidade de ligar proteínas, os circRNAs podem formar estruturas e conformações tridimensionais 
complexas, isso permite que eles adquiram um impacto adicional na expressão gênica e na ligação às proteínas (FANG L, et al., 2018).

O papel do circRNA em nível molecular é atuar como uma "esponja" que absorve miRNA funcional, diminuindo assim a abundância deste no citoplasma. Os miRNA são capazes de regular a expressão gênica através da degradação ou repressão da tradução de moléculas-alvo de RNA mensageiras. Isso evidencia a relação com circRNA com o câncer, já que por diminuir a quantidade de miRNAs no citoplasma, diminui também a degradação de moléculas (NAIR AA, et al., 2016).

\section{DISCUSSÃO}

O circRNA é um tipo de RNA recentemente reconhecido, expresso em muitos tecidos cancerígenos cujas quantidades e tipos detectados são estudados. Essas moléculas servem como "esponja" para os miRNAs, regulando a invasão, o desenvolvimento e a metástase das células tumorais. No entanto, recentes estudos mostram que essa função é pouco recorrente, sendo imperativo novos estudos na área (WANG X, FANG L, 2018).

Ademais, constatou-se que os circRNAs podem estar associados à carcinogênese, às metástases e à quimiorresistência, por exemplo. No entanto, nosso conhecimento sobre os circRNAs ainda é limitado e não se sabe como eles desempenham sua expressão e funções oncogênicas no CM. Assim, há necessidade de mais evidências para elucidar o papel dos circRNAs e compreender por meio de investigações mais profundas, os mecanismos de ação para possíveis alvos de aplicações diagnósticas e terapêuticas (LI Z, et al., 2019).

\section{CONSIDERAÇÕES FINAIS}

É notória a importância dos circRNAs, uma vez que eles desempenham papéis importantes na tumorigênese, metástase e resistência à terapia. Assim, é possível inferir que descobrir circRNAs específicos de doenças pode ajudar a identificar alvos de diagnóstico em doenças heterogêneas, como o CM. Além disso, eles podem atuar como biomarcadores moleculares diagnósticos confiáveis para tumores, já que sua quantidade é aumentada em indivíduos com câncer.

\section{REFERÊNCIAS}

1. FANG L, et al. Enhanced breast cancer progression by mutant p53 is inhibited by the circular RNA circCcnb1. Cell Death e Differentiation, 2017; 25(12).

2. $\mathrm{LI} Z$, et al. Roles of circular RNA in breast cancer: present and future. American Journal of Translational Research, 2019; 11(7).

3. LIANG H-F, et al. Circular RNA circ-ABCB10 promotes breast cancer proliferation and progression through sponging miR-1271. American Journal of Cancer Research, 2017; 7(7).

4. NAIR AA, et al. Circular RNAs and their associations with breast cancer subtypes. Oncotaget, 2016; 7(49).

5. WANG X, FANG L. Advances in circular RNAs and their roles in breast Cancer. Journal of Experimental \& Clinical Cancer Research, 2018; 37(206). 
RESUMOS EXPANDIDOS: Relato de experiência

Título: Capacitação de agentes comunitários de saúde em puericultura: relato de uma experiência

Autor/coautores: Daniel Meira Nóbrega de Lima; Renata Maria Santos de Freitas; Kamilla Priscila Coelho da Costa.

Instituição: Universidade Federal da Paraíba (UFPB), João Pessoa - Paraíba.

Palavras-chave: Atenção primária à saúde; Saúde da criança; Agentes comunitários de saúde.

\section{INTRODUÇÃO}

Entre as assistências oferecidas na atenção primária de saúde está a puericultura. Fundamental não apenas para promoção à saúde e prevenção de doenças, mas também para o crescimento e desenvolvimento global das crianças, visando dessa forma, uma assistência integral e universal.

Dessa forma, para atuar de forma efetiva a nível de núcleo familiar, a equipe multiprofissional de saúde da família tem no agente comunitário de saúde (ACS) um interlocutor, que facilita o intercâmbio entre o conhecimento médico-científico e os saberes populares, bem como atua a nível domiciliar (BRIGIDO A, et al., 2019)

O conjunto dessas ações visam assegurar a integralidade e a sistematização do atendimento prestado pelos profissionais de saúde inseridos nos diversos serviços de saúde, deslocando o enfoque de uma assistência baseada em doenças para uma modalidade de atenção que contemple a criança no seu processo de crescimento e desenvolvimento, que constitui o eixo central do atendimento prestado, uma vez que permite evidenciar, de maneira precoce, os transtornos que afetam a saúde, a nutrição e o desenvolvimento da criança (SILVA L, et al., 2020).

\section{OBJETIVO}

Realizar oficinas com o intuito de instruir e esclarecer os ACS acerca dos conhecimentos médico-científicos voltados a puericultura, além de desenvolver habilidades frente ao uso das escalas de crescimento e desenvolvimento por meio da educação continuada.

\section{RELATO DE EXPERIÊNCIA}

A maior dificuldade dos ACS foi de compreender o conceito mais amplo e atualizado do que é a puericultura, conforme o Ministério da Saúde, e quantas consultas são essenciais as crianças de zero a 12 meses de vida. Muitos ACS acreditavam que o número correto de consultas era dez, e não sete. Porém, esses profissionais compreendiam o que a puericultura visa analisar, os parâmetros utilizados e a importância de investigá-los a cada consulta.

Outro ponto importante foi ensiná-los a utilizar a escala de índice de massa corpórea. Muitos acreditavam que deveria apenas buscar o peso da criança e observar até onde a escala era marcada. Também foi ensinado como deveriam ser postos em curva e o que cada traço da curva significava, sua relevância em observar os gráficos e enquadrá-los em classificações. E a partir desses dados, qual seria a abordagem das mães dessas crianças.

Alguns ACS informaram que a consulta seria mais organizada, caso fosse agendada por eles em concordância com o médico e a enfermeira, e que apenas o ACS responsável por determinada área agendaria para aquele dia, e que esse seria o responsável por engajar-se naquela consulta nesse respectivo dia (pesando, medindo, calculando o IMC e avaliando acerca da vacinação, anotando dados específicos aos seus 
prontuários, obtendo os dados das crianças de sua microárea). Referiram não compreender acerca de medidas de proteção contra acidentes e agravos as crianças.

Foi formulado um cardápio com as classes alimentares e nutrientes variados, baseado nos dez passos alimentares da caderneta da criança, sendo impresso e ofertado as genitoras das crianças para que todas as dúvidas acerca da alimentação de seus filhos fossem sanadas.

\section{DISCUSSÃO}

Uma vez que a puericultura, enquanto pediatria preventiva, necessita intrinsecamente do papel ativo da família para o cuidado da criança. Portanto, percebe-se que existe uma urgência de modificar a cultura da comunidade em buscar a unidade de saúde apenas em estado de enfermidade. Pois, esta impossibilita o processo de co-construção do cuidado de forma autônoma e singular no núcleo família, não possibilitando assim, atuar no sujeito integralmente, quebrando com a medicina biologizante-medicalizante que enxerga o usuário como uma máquina a ser consertada (VIEIRA DE BRITO G, et al., 2018). A importância da educação continuada do médico e do enfermeiro junto aos ACS, o que permiti não apenas a correção das práticas falhas realizadas no dia-a-dia, como também a reflexão em equipe do processo de cuidado multiprofissional oferecido ao usuário (GARCIA F, et al., 2018). Enfatiza-se a relevância da construção do vínculo com a família durante o pré-natal, bem como a instrução precoce acerca da vacinação, alimentação, higienização fundamental a criança.

\section{CONSIDERAÇÕES FINAIS}

Dessa forma, compreende-se que existe a necessidade de repactuação entre a equipe de saúde da família Nova República, uma vez que existem lacunas de atuação no âmbito dos três profissionais membros da equipe. Sendo determinante a postura ativa do médico, enquanto chefe da equipe, em reestruturar e reorganizar a assistência à saúde da criança.

Entende-se que o aumento da liberdade dos ACS sob tutela do médico, enquanto agentes ativos na comunidade, para uma primeira abordagem e verificação diretamente no núcleo familiar, podem ser utilizados como estratégia de vinculação, sobretudo, das crianças com parâmetros de desenvolvimento global mais comprometido.

\section{REFERÊNCIAS}

1. BRIGIDO A, et al. Qualificação do cuidado a puericultura: uma intervenção em serviço na estratégia de Saúde da Família. Revista de Pesquisa Cuidado é Fundamental Online, 2019; 11(2).

2. GARCIA F, et al. Contribuições do enfermeiro para boas práticas na puericultura: revisão integrativa da literatura, 2018; 71(suppl 6): 2974-2983.

3. SILVA L, et al. Capacitação para ACS: Contribuições ao processo de desenvolvimento de ações de saúde da família - um relato de experiência. Revista de Extensão da Univasf, 2020; 8(1).

4. VIEIRA DE BRITO G, et al. Consulta De Puericultura Na Estratégia Saúde Da Família: Percepção De Enfermeiros. Revista de APS, 2018; 21(1): 48-55. 
RESUMOS EXPANDIDOS: Revisão Bibliográfica

Título: Aspectos Epidemiológicos e Fisiopatológicos sobre Lesão Renal Aguda e COVID-19

Autor/coautores: Juliana Pelição Moraes; Luisa Schilmann Frisso; Maitê Perini Mameri Pereira; Mariana Stefenoni Ribeiro; Carlos Eduardo Dilen da Silva.

Instituição: Escola Superior de Ciências da Santa Casa de Misericórdia de Vitória (EMESCAM), VitóriaEspírito Santo.

Palavras-chave: COVID-19, Lesão Renal Aguda, Mortalidade.

\section{INTRODUÇÃO}

O Severe Acute Respiratory Syndrome Coronavirus 2 (SARS-CoV-2), o novo coronavírus, desde dezembro de 2019, espalhou-se pelo mundo e provocou uma das maiores pandemias da história, descrita como COVID19 (Coronavirus Disease 2019). O COVID-19 é uma doença que evolui rapidamente, causando aumento de morbimortalidade, e a propagação da infecção vem crescendo de forma alarmante (ADAPA S, et al., 2020).

A relação entre lesão renal aguda (LRA) e infecção por coronavírus foi previamente identificada nas epidemias provocadas pelo coronavírus da síndrome respiratória aguda grave (SARS-CoV) e o coronavírus da síndrome respiratória do Oriente Médio (MERS-CoV). Do mesmo modo, o envolvimento renal é frequente no COVID-19, com apresentação clínica variando de proteinúria leve a lesão renal aguda progressiva (RONCO C, REIS T, 2020; LIM JH, et al., 2020).

Há evidências que a LRA está associada a altas taxas de mortalidade nesse contexto, principalmente quando é necessária terapia de substituição renal. Assim, o reconhecimento precoce do envolvimento renal no COVID-19 e o uso de medidas preventivas e terapêuticas para limitar a LRA subsequente ou a progressão para estágios mais graves são cruciais para reduzir a morbimortalidade (GABARRE P, et al., 2020; RONCO C, REIS T, 2020).

\section{OBJETIVO}

Revisar os aspectos epidemiológicos e a fisiopatologia da lesão renal aguda empreendida pelo SARS-CoV2, visto que uma parcela importante dos pacientes com manifestação grave de COVID-19 evolui para essa patologia.

\section{MÉTODO}

A revisão foi realizada na base de dados MEDLINE e os artigos foram coletados entre as datas de junho a julho de 2020. Os descritores utilizados foram "Coronavirus Infections", "Acute Kidney Injury" e "Mortality" definidos pelo DeCS. Os critérios de inclusão foram a data de publicação entre 2015 e 2020, idioma (português e inglês) e assunto semelhante ao objetivo. Já os critérios de exclusão foram artigos incompletos, outros idiomas e que não se adequaram ao tema. A princípio, 40 artigos foram identificados e, após os critérios de inclusão e exclusão, 5 artigos foram selecionados.

\section{REVISÃO BIBLIOGRÁFICA}

A lesão renal aguda pode ocorrer nos pacientes contaminados com o COVID-19 e está relacionada a um fator de pior prognóstico e aumento da mortalidade. Estudos evidenciam que mais de $40 \%$ dos pacientes apresentam proteinúria anormal no momento da admissão e que os pacientes graves são mais propensos a desenvolverem lesão renal (RONCO C, REIS T, 2020). Um estudo de coorte realizado em Nova York com 5449 pacientes hospitalizados com COVID-19, observou que $36,6 \%$ dos pacientes desenvolveram LRA 
durante hospitalização. Vale ressaltar que este estudo evidenciou uma forte relação com a insuficiência respiratória, visto que $89,7 \%$ dos pacientes que precisaram de ventilação mecânica desenvolveram lesão renal, enquanto apenas $21,7 \%$ dos não ventilados desenvolveram a lesão (HIRSCH JS, et al., 2020). Além disso, em relação ao estadiamento KDIGO, a maioria se encontra no estágio 1 (leve), seguido pelos estágios 3 (grave) e 2 (moderado). Infelizmente, foi evidenciado que a mortalidade dos pacientes em estágio 3 eram bem próximas de 100\% (LIM JH, et al., 2020; HIRSCH JS, et al., 2020).

A partir de autópsias, foi possível identificar que tanto o endotélio pulmonar como o renal são afetados, o que pode explicar a presença de proteinúria em muitos pacientes contaminados. $O$ fator responsável pelo dano consiste na capacidade do vírus de infectar diretamente o epitélio tubular e os podócitos, através da ligação ao receptor da enzima conversora de angiotensina 2 (ACE2). Com isso, ocorre disfunção mitocondrial, necrose tubular aguda e aumento da permeabilidade a proteínas (RONCO C, REIS T, 2020). Além disso, observa-se que hipovolemia, agentes nefrotóxicos e sepse, podem contribuir para o desenvolvimento da lesão renal aguda (LIM JH, et al., 2020).

\section{DISCUSSÃO}

A partir dos estudos que embasaram a revisão, foi evidenciada a existência de correlação entre a lesão renal aguda e o aumento da mortalidade em paciente com COVID-19. Observa-se que os pacientes que evoluíram para insuficiência respiratória possuem mais chance de desenvolver LRA. Além disso, o uso de agentes nefrotóxicos e a presença de sepse e hipovolemia, são considerados desencadeantes importantes de lesão renal. Embora muitos pacientes contaminados com SARS-CoV-2 evoluam com LRA, a fisiopatologia desse processo ainda não é bem compreendida. Dessa forma, por ser um tema muito importante para o cenário atual, além de estar relacionado ao aumento da mortalidade, torna-se necessário mais estudos a respeito dessa temática.

\section{CONSIDERAÇÕES FINAIS}

A Lesão Renal Aguda secundária ao COVID-19 é uma entidade que indica aumento da mortalidade e pior prognóstico. Assim, estudos indicam que alta porcentagem de pacientes graves pode evoluir com envolvimento renal. Devido à ampla apresentação clínica, que pode se apresentar desde proteinúria até lesão renal aguda progressiva, são necessários mais estudos randomizados e controlados que identifiquem os riscos para tal evolução e orientar formas de manejo precoce desses pacientes. Dessa forma, prevenir a LRA nas hospitalizações pode contribuir para diminuição da mortalidade e melhora do quadro clínico do paciente.

\section{REFERÊNCIAS}

1. ADAPA S, et al. COVID-19 and Renal Failure: Challenges in the Delivery of Renal Replacement Therapy. Journal of Clinical Medicine, 2020; 2020;12(5):276-285.

2. GABARRE P, et al. Acute kidney injury in critically ill patients with COVID-19. Intensive Care Med. 2020;46(7):1339-1348.

3. HIRSCH JS, et al. Acute kidney injury in patients hospitalized with COVID-19. Kidney International, 2020; 98(1):209-218.

4. LIM JH, et al. Fatal Outcomes of COVID-19 in Patients with Severe Acute Kidney Injury. Journal of Clinical Medicine, 2020; 9(6):E1718.

5. RONCO C, REIS T. Management of acute kidney injury in patients with COVID-19. The Lancet Respiratory Medicine, 2020. 
RESUMOS EXPANDIDOS: Relato de experiência

Título: Sistematização das Visitas Domiciliares em uma Estratégia de Saúde da Família do Norte de Minas Gerais

Autor/coautores: Myrna Rocha de Sales; Luma Pinheiro Vieira; Ana Paula Figueiredo Guimarães de Almeida; Débora Layze de Freitas Sá; Ludmila Godinho Ribeiro.

Instituição: Faculdades Unidas do Norte de Minas (FUNORTE), Montes Claros-Minas Gerais; Universidade Estadual de Montes Claros (Unimontes), Montes Claros-Minas Gerais; Hospital Público Regional Professor Osvaldo Rezende Franco (HRPB), Betim-Minas Gerais.

Palavras-chave: Visita Domiciliar, Assistência Domiciliar, Medição de Risco.

\section{INTRODUÇÃO}

A Estratégia de Saúde da Família (ESF) é um programa que propõe uma atenção com foco na família e no território, baseando-se em ações de prevenção das doenças e promoção da saúde (ARANTES LJ, et al., 2016).

A ESF propõe a visita domiciliar como ferramenta fundamental no processo de trabalho das equipes multidisciplinares (CAMARGOS MH, 2016). Nota-se uma crescente necessidade dessa ação devido às alterações sofridas pela sociedade, como o envelhecimento populacional, o qual acarreta o aumento percentual de doenças crônico-degenerativas que, consequentemente, demandam cuidados mais frequentes (PINHEIRO JV, et al., 2019).

A proposta é que a visita domiciliar seja oferecida àqueles que precisam de cuidados contínuos e possuam dificuldade no acesso às redes de saúde. Além disso, possibilita o estabelecimento de vínculos com a população e a realização de um diagnóstico local para programação das ações (DIAS MB, et al., 2015).

Porém, vem sendo realizada de forma fragmentada devido à falta de planejamento dentro da equipe multiprofissional, o que compromete a gestão da vigilância à saúde na assistência domiciliar.

\section{OBJETIVO}

Relatar a experiência da implantação do processo organizativo das visitas domiciliares em uma equipe de saúde, visando sua sistematização e reorientação do trabalho para melhorar a produção do cuidado em saúde.

\section{RELATO DE EXPERIÊNCIA}

A Escala de Risco Familiar de Coelho-Savassi é um instrumento de estratificação utilizado para estabelecer prioridade na visita domiciliar a partir da soma dos escores de risco de cada família. É baseada em dados considerados sentinelas de risco que permitem determinar indicadores demográficos, socioeconômicos e nosológicos, refletindo, assim, o potencial de adoecimento de cada núcleo familiar. A partir da soma dos escores de risco de cada família, elas são classificadas em risco baixo, médio e alto. Ela foi aplicada a 65 famílias de pacientes indicados como usuários do serviço de assistência domiciliar pelos agentes comunitários de saúde (ACS). Dentre elas, 28 foram classificadas como risco alto (43\%), 15 risco médio (23\%) e 22 riscos baixo (34\%). A variável que mais contribuiu para a situação de risco das famílias foi a baixa condição de saneamento.

Após a aplicação das escalas, foi realizada uma reunião com a equipe para a programação do processo de trabalho. Os pacientes seriam visitados mensalmente pelos ACS. As famílias com risco alto, receberiam visita 
do médico bimestral e da enfermagem mensal; as de risco moderado, quadrimestral pelo médico e bimestral pela enfermagem e as de risco baixo, semestral pelo médico e trimestral pela enfermagem. Em caso de intercorrências, poderiam ocorrer a qualquer momento conforme solicitação e disponibilidade. As visitas realizadas deveriam ser atualizadas em uma planilha no Microsoft Excel, disponibilizada no Google Drive, contendo dados pessoais, dados clínicos e programação da atividade. Em reuniões mensais seriam construídos os planos de cuidados individualizados e agendadas as visitas do próximo mês, para que os profissionais possam executar a atividade com programação.

\section{DISCUSSÃO}

A realidade observada no presente estudo é de que o planejamento das visitas domiciliares é definido pela solicitação dos ACS e a presença de outros profissionais é pontual e geralmente realizada com enfoque distinto, em consonância com o descrito na literatura (NUNES CA, et al.,2018).

A Escala de Risco Familiar de Coelho-Savassi, embora não apresente validação científica, é um instrumento de estratificação de risco familiar, que tem sido amplamente utilizado para se estabelecer prioridade na visita domiciliar de equipes com grande número de usuários (CAMARGOS MH, 2016).

Foi verificada uma baixa frequência de reuniões de equipe, pouco focadas na discussão dos processos de trabalho e no planejamento das ações. O planejamento prévio dos atendimentos domiciliares permitiria estruturar o processo da equipe, surgindo como uma oportunidade para o desenvolvimento de um trabalho multiprofissional mais integrado e a realização efetiva da vigilância em saúde destes pacientes.

\section{CONSIDERAÇÕES FINAIS}

O presente estudo possibilitou perceber que muitos usuários que necessitam de visitas domiciliares não estavam sendo avaliados de forma contínua, mesmo esta atividade sendo realizada de maneira frequente pela equipe. Percebeu-se, ainda, que é preciso integralidade da atenção com ações assistenciais de caráter interdisciplinar para maior efetividade do trabalho. A utilização da escala de risco familiar permitiu identificar os fatores que contribuem para maior vulnerabilidade dos pacientes, mostrando-se ferramenta útil para o planejamento das ações de vigilância da atenção domiciliar e redirecionamento do cuidado em saúde, a fim de contemplar a equidade e prestar assistência de maneira resolutiva.

\section{REFERÊNCIAS}

1. ARANTES LJ, et al. Contribuições e desafios da Estratégia Saúde da Família na Atenção Primária à Saúde no Brasil: revisão da literatura. Ciência e Saúde Coletiva, 2016; 21(5), 1499-1510.

2. CAMARGOS MH. Como priorizar as visitas domiciliares com base na escala de risco familiar. Centro de Telessaúde Hospital da Clínicas-UFMG, Minas Gerais, 2016.

3. DIAS MB, et al. A Política Nacional de Atenção Domiciliar no Brasil: potencialidades, desafios e a valorização necessária da atenção primária à saúde. Journal of Management and Primary Health Care, 2015; 6(1), 1-7.

4. NUNES CA, et al. Visitas domiciliares no Brasil: características da atividade basilar dos Agentes Comunitários de Saúde. Saúde em Debate, 2018; 42, 127-144.

5. PINHEIRO JV, et al. Ferramenta para avaliação e gestão da visita domiciliar na atenção primária à saúde: um relato de experiência. Revista Brasileira de Medicina de Família Comunidade, 2019; 14(41), 18181818. 
RESUMOS EXPANDIDOS: Revisão Bibliográfica

Título: Análise da coinfecção HIV/Tuberculose

Autor/coautores: Daniele Buitrago de Souza; Felix Pereira Júnior; Luiza Helena Santos Giorni; Rodrigo Júnio Santana Brandão; Mariana Araújo Pena Bastos.

Instituição: Centro Faculdade Atenas, Sete Lagoas - Minas Gerais; Centro Universitário Atenas, Paracatu Minas Gerais; Faculdade Ciências Médicas de Minas Gerais, Belo Horizonte - Minas Gerais.

Palavras-chave: HIV, Tuberculose, coinfecção.

\section{INTRODUÇÃO}

A tuberculose (TB) caracteriza-se por ser uma doença infectocontagiosa de magnitude mundial causada pelo Mycobacterium tuberculosis, cujo em 2015, teve incidência mundial de 10.4 milhões de pessoas, das quais $11 \%$ eram soropositivas (JIAMSAKUL A, et al., 2018). Diante deste cenário, a TB se torna ainda mais preocupante quando acomete pacientes com o vírus da imunodeficiência (HIV), uma vez que a sua forma extrapulmonar é a condição definidora da Síndrome da Imunodeficiência Humana (AIDS) - contagem de linfócitos TCD4 abaixo de 200 - mais frequente no mundo. Essas manifestações se dão por acometimento de inúmeros tecidos com formação de granulomas tuberculoides como por exemplo em região linfonodal, urogenital e outros causando grandes danos teciduais. (GANA E, et al., 2018).

Os componentes da coinfecção HIV/TB são representados etiologicamente pela primeira e segunda maiores causas de morte infecciosas no mundo, respectivamente. Além disso, a TB é a patologia com maior risco de vida nos pacientes HIV positivos, tendo ocorrência 30 vezes maior nestes do que nos não infectados (OLIVEIRA L, et al., 2018).

\section{OBJETIVO}

Revisar as características epidemiológicas da coinfecção por HIV/TB. Além de discutir a clínica do acometimento extrapulmonar da TB nesses pacientes e expor fatores predisponentes a adesão ao tratamento nesse contexto.

\section{MÉTODOS}

Realizou-se uma revisão bibliográfica integrativa da literatura buscando estudos a respeito da relação entre portadores do HIV e a coinfecção da Tuberculose. Os estudos foram pesquisados nas bases de dados Google Acadêmico, SciELO e PUBMED. Foram usadas as palavras chave HIV, Tuberculose, coinfecção, nas línguas português, inglês e espanhol. As buscas bibliográficas se estenderam de 09/05/2020 até 01/07/2020. Os critérios de inclusão foram estudos que eixo principal da temática girava em torno da análise das manifestações clínicas desenvolvidas durante a coinfecção HIV-TB, características epidemiológicas, fatores de risco associados, eficácia do diagnóstico. Já o critério de exclusão foi artigos que tinham mais de cinco anos.

\section{REVISÃO BIBLIOGRÁFICA}

No ano de 2015 a Organização Mundial de Saúde (OMS) estimou que ocorreram 9,6 milhões de novos casos de TB em todo o mundo e, cerca de um terço destes pacientes podem nunca ter sido diagnosticado ou tratados; entre os novos casos, 1,2 milhão foram coinfecção pelo o vírus HIV e $0,4 \%$ das mortes ocorreram associadas ao acometimento concomitante HIV-TB, e esses números são preponderantes para países em desenvolvimento. (OLIVEIRA L, et al., 2018). 
Além da imunodeficiência a coinfecção está relacionada às condições socioeconômicas e à pressão da infecção exógena pela TB. A incidência do aparecimento da TB em pacientes HIV positivo se dá pela reativação da TB latente - na coinfecção as chances são maiores - ou pelo aumento da susceptibilidade de contágio, principalmente devido à imunossupressão. (JIAMSAKUL A, et al., 2018)

O Mycobacterium tuberculosis possui facilidade de disseminação por ter as vias respiratórias, linfáticas e hematogênicas como vias de transporte, acometendo assim, outros sítios além do pulmão - o pleural, o linfonodal, o urogenital, o osteoarticular e o sistema nervoso central -, sendo que a hematogênica é a principal responsável pelo desenvolvimento da forma extrapulmonar. (OLIVA $\mathrm{H}$, et al., 2019)

É importante salientar que o teste utilizado para diagnóstico de infecção por $M$. tuberculosis ainda não possui acurácia suficiente para designar um tratamento precoce. Ademais, apesar dos inúmeros antimicobacterianos e da terapia antirretroviral disponíveis para o tratamento, do esforço produzido pelas organizações de saúde desde 1970, juntamente com governos de diversos países para implementar estratégias de controle para TB, há fatores que impedem a efetivação do tratamento em tempo hábil a fim de erradicar danos permanentes aos portadores (ANDRADE F, et al., 2016).

Tabela 1 - Artigos analisados.

\begin{tabular}{|c|c|c|c|}
\hline Artigo & $\begin{array}{l}\text { A } \\
\mathbf{n} \\
\mathbf{0}\end{array}$ & Tipo de estudo & Conclusão a respeito da coinfecção \\
\hline $\begin{array}{l}\text { ANDRADE F } \\
\text { et al. }\end{array}$ & $\begin{array}{l}2 \\
0 \\
1 \\
6\end{array}$ & $\begin{array}{l}\text { Observacional, descritivo e } \\
\text { retrospectivo }\end{array}$ & $\begin{array}{l}\text { M. tuberculosis é a mais importante } \\
\text { coinfecção micobacteriana com HIV, } \\
\text { mesmo com a incidência entre a } \\
\text { conifecção tendo tendência mundial de } \\
\text { queda, cepas resistentes estão } \\
\text { aumentando. }\end{array}$ \\
\hline $\begin{array}{l}\text { BRUCHFELD } \\
\text { J, et al. }\end{array}$ & $\begin{array}{l}2 \\
0 \\
1 \\
5\end{array}$ & Revisão & $\begin{array}{l}\text { Para melhorar o desfecho deve se } \\
\text { investir em diagnóstico ativo de HIV e } \\
\text { TB, terapia preventiva com isomiazida, } \\
\text { controle da infecção da TB por meios } \\
\text { educativos, ambientais e sociais e } \\
\text { ampliação da vacinação }\end{array}$ \\
\hline $\begin{array}{l}\text { GANA E, et } \\
\text { al. }\end{array}$ & $\begin{array}{l}2 \\
0 \\
1 \\
8\end{array}$ & $\begin{array}{l}\text { Comparação de exames de } \\
\text { imagens de Tomografia } \\
\text { Computadorizada em TB }\end{array}$ & $\begin{array}{l}\text { Tomografia computadorizada é um } \\
\text { exame que além de ser útil no } \\
\text { diagnóstico é extremamente válida para } \\
\text { avaliar as complicações e } \\
\text { TB extrapulmonares muito comuns em } \\
\text { pacientes imunodeprimidos como os } \\
\text { portadores de HIV }\end{array}$ \\
\hline $\begin{array}{l}\text { JIAMSAKUL } \\
\text { A, et al. }\end{array}$ & $\begin{array}{l}2 \\
0 \\
1 \\
8\end{array}$ & $\begin{array}{l}\text { Estudo de caso controle } \\
\text { entre HIV-positivo/TB- } \\
\text { positivo com HIV- } \\
\text { positivo/TB-negativo }\end{array}$ & $\begin{array}{l}\text { Fatores socioeconômicos estão } \\
\text { intimamente relacionados com o } \\
\text { aumento do risco de coinfecção entre } \\
\text { TB-HIV sendo crucial ser levado em } \\
\text { conta para tratamento de surtos e } \\
\text { aumento da sobrevida }\end{array}$ \\
\hline $\begin{array}{l}\text { OLIVA H, et } \\
\text { al. }\end{array}$ & $\begin{array}{l}2 \\
0\end{array}$ & $\begin{array}{l}\text { Estudo epidemiológico } \\
\text { descritivo, de delineamento } \\
\text { retrospectivo e transversal }\end{array}$ & $\begin{array}{l}\text { Ainda há elevada incidência de casos de } \\
\text { TB extrapulmonar mesmo após a } \\
\text { implementação da BCG. Mais pesquisas }\end{array}$ \\
\hline
\end{tabular}




\begin{tabular}{llll}
\hline & 1 & $\begin{array}{l}\text { na coleta de dados e } \\
\text { abordagem quantitativa }\end{array}$ & $\begin{array}{l}\text { precisam ser feitas para entender a } \\
\text { efetividade dos métodos de tratamento e } \\
\text { prevenção }\end{array}$ \\
\hline $\begin{array}{l}\text { OLIVEIRA L, } \\
\text { et al. }\end{array}$ & 2 & Estudo descritivo & $\begin{array}{l}\text { Maioria dos infectados TB/HIV do sexo } \\
\text { masculino, 35-49 anos, forma pulmonar } \\
\text { mais prevalente. O diagnóstico precoce } \\
\text { epidemiológico retrógrado }\end{array}$ \\
1 & & $\begin{array}{l}\text { de HIV é essencial ampliação da } \\
\text { testagem de HIV e recomenda-se } \\
\text { testagem de HIV em pacientes com TB. }\end{array}$ \\
& 8 &
\end{tabular}

Fonte: BUITRAGO D, et al., 2020.

\section{DISCUSSÃO}

A tuberculose é a mais importante coinfecção micobacteriana relacionada ao HIV e sua ocorrência é íntima a inúmeros fatores, como socioeconômicos e culturais e, por isso precisam ser levados em consideração, afim de se reduzir a incidência e obter melhores desfechos (JIAMSAKUL A, et al.,2018). Visando evitar e identificar a coinfecção HIV-TB, uma ampla testagem para sorologia do HIV, rastreio e tratamento dos pacientes com TB, testagem do HIV em pacientes com TB são medidas essenciais. Ainda, medidas educativas básicas como recomendação do sexo seguro, distribuição de preservativos, testagem ampla para HIV e ampla vacinação contra tuberculose são medidas essenciais a serem feitas por políticas públicas com enorme potencial redutor da incidência dessa coinfecção (BRUCHFELD J, et al.,2015).

\section{CONSIDERAÇÕES FINAIS}

Ao analisar os estudos realizados, nota-se que há uma correlação entre a infecção pela TB, com os pacientes portadores do HIV, seja por primo-infecção, período de latência bacilar ou até mesmo coinfecção. A TB é uma doença infectocontagiosa que merece reconhecimento de variados níveis da saúde pública. Exige, portanto, a adequação de prevenção, diagnóstico e terapêutica a fim de minimizar os malefícios que pode acarretar ao ser negligenciada. Dessa forma, é pertinente que a hipótese de infecção por HIV seja levantada e confirmada a partir das testagens quando se está diante de um quadro de infecção tuberculosa.

\section{REFERÊNCIAS}

1. ANDRADE F, et al. Coinfección por virus de inmunodeficiencia humana y micobacterias en un hospital universitario de alta complejidad en Colombia. Infectio, 2016; 20(3):158-164.

2. BRUCHFELD J, et al. Tuberculosis and HIV coinfection. Cold Spring Harbor Perspectives in Medicine, 2015; 5(7):1-16.

3. GANA E, et al. Manifestaciones tomográficas extrapulmonares de TBC y algunas de sus complicaciones asociadas. Revista Argentina de Radiologia, 2018; 82(28):28-35.

4. JIAMSAKUL A, et al. Socio-economic status and risk of tuberculosis: A case-control study of HIV-infected patients in Asia. International Journal of Tuberculosis and Lung Disease, 2018; 22(2):179-186.

5. OLIVA H, et al. Incidência de tuberculose extrapulmonar. Sociedade Brasileira Clínica Médica, 2019; 17(2):63-65.

6. OLIVEIRA L, et al. Epidemiological analysis of tuberculosis/HIV coinfection. Cogitare Enfermagem, 2018; 23(1):10-16. 
RESUMOS EXPANDIDOS: Revisão Bibliográfica

Título: Uso da imunoterapia em neoplasia de próstata

Autor/coautores: Ana Julia Ribeiro Gomes; Carolina Silva Carvalho; Natalia Silva Bueno; Sarah Rhaquel Rodrigues Oliveira; Henrique Poletti Zani.

Instituição: Centro Universitário de Anápolis - UniEVANGÉLICA, Anápolis - Goiás.

Palavras-chave: Immunotherapy, Neoplasms, Prostate.

\section{INTRODUÇÃO}

O câncer de próstata é a quarta neoplasia maligna mais comum no mundo, superado apenas por câncer de pulmão, mama e colorretal. Essa patologia geralmente está relacionada a idade, uma vez que tanto a mortalidade como a incidência aumentam consideravelmente após os 50 anos. Os pacientes confirmados com câncer de próstata são estratificados conforme a classificação de risco D`Amico, em que possui as categorias risco baixo, intermediário e alto, essa divisão considera a possibilidade de o paciente apresentar recorrência bioquímica posteriormente ao tratamento (HOOD SP, et al., 2019). Relacionado a isso, a imunoterapia tem se tornado uma abordagem promissora de tratamento para muitos tipos de câncer, incluindo o de próstata, pois tem como estratégia combater o tumor induzindo externamente o sistema imunológico para modular respostas às células tumorais ou estimulando a apresentação de antígenos exógenos típicos do tumor, naturais ou artificiais, para serem reconhecidos pelo sistema imunológico do paciente (EREMINA NV, et al., 2020).

\section{OBJETIVO}

Revisar a eficácia da imunoterapia no tratamento do câncer de próstata, a fim de estabelecer o cenário atual das pesquisas acerca das estratégicas imuterapêuticas, e salientar a necessidade de investigação dentro da temática.

\section{MÉTODO}

O presente trabalho trata-se de uma revisão integrativa e para sua realização foram selecionados cinco artigos dos anos de 2019 e 2020. A busca pelos estudos foi realizada utilizando os bancos de dados: "PubMed", "Scielo", "Lilacs" e Google Acadêmico. Para a estratégia de busca, foram utilizados os seguintes descritores, encontrados por meio dos Descritores em Ciências da Saúde (DeCS): "Immunotherapy", "neoplasms" e "prostate" e excluindo revisões e artigos que não se relacionavam com o tema.

\section{REVISÃO BIBLIOGRÁFICA}

A maior vantagem do uso de anticorpos do tipo receptor de células T é sua capacidade de atingir antígenos tumorais intracelulares com manipulação mínima in vitro. Entretanto, existem vários obstáculos como ambiente imunossupressor, limitação em usar a terapêutica só com um determinado grupo de pacientes e regulação negativa ou ausência de complexos peptídeos/complexo principal de histocompatibilidade (HE Q, et al., 2019).

Os desfechos evidenciaram que o uso de sipuleucel-T para o câncer de próstata possui um perfil de tolerabilidade favorável, porém vários fatores não relacionados ao câncer do paciente são associados ao seu uso, incluindo renda do paciente, etnia e região do CEP, e a especialidade do prescritor (CARAM EVM, et al., 2019). 
O estudo também demonstrou que a injeção intraprostática de Mobilan (adenovírus recombinante autoativador de Toll-like 5) teve os efeitos farmacodinâmicos esperados em vários parâmetros, confirmando a funcionalidade do construto e representando seu mecanismo de ação conhecido como agente imunoregulador (EREMINA et al., 2020).

Os resultados demonstraram que o priming e ativação das células NK têm potencial como imunoterapia para o tratamento do câncer de próstata, também mostra que nem todos os pacientes se beneficiarão de uma abordagem terapêutica específica, por isso é importante a aplicação de um interrogatório sobre as consequências do priming e ativação na biologia celular NK oferece uma oportunidade para prever e otimizar o potencial terapêutico (HOOD SP, et al, 2019).

Ainda há dúvidas sobre os efeitos das imunoterapias no microambiente do tumor para melhorar os resultados clínicos. Além disso, a pluralidade da expressão de neoantígeno em contraposição a expressão de neoantígeno clonal no microambiente do tumor também pode influenciar substancialmente o resultado das imunoterapias. Portanto, será essencial aplicar várias estratégias de tratamento em combinação com imunoterapias para aumentar seu potencial (BAXEVANIS CN, FORTIS SP e PEREZ SA, 2019).

\section{DISCUSSÃO}

A maior vantagem do uso de anticorpos do tipo TCR é sua capacidade de atingir antígenos tumorais intracelulares com manipulação mínima in vitro. O uso de sipuleucel-T para o câncer de próstata possui um perfil de tolerabilidade favorável. Entretanto, existem vários obstáculos como ambiente imunossupressor e limitação em usar a terapêutica só com um determinado grupo de pacientes. Já outro estudo demonstrou que a injeção intraprostática de Mobilan, teve os efeitos esperados, confirmando a funcionalidade da terapêutica. Além disso, segundo outro artigo, os resultados demonstraram que o priming e ativação das células NK têm potencial como imunoterapia para o tratamento do câncer de próstata, porém nem todos os pacientes podem se beneficiar de uma abordagem terapêutica específica. Em todas as pesquisas foram observadas que nem todos os pacientes conseguem se beneficiar desse tratamento, pois existem variáveis. Também, são necessários mais estudos aprofundados comprovando a eficácia da terapêutica.

\section{CONSIDERAÇÕES FINAIS}

As estratégicas imunoterapêuticas têm demonstrado eficácia no tratamento do câncer de próstata, porém com ressalvas, existindo ainda muitos desafios a serem enfrentados na busca de um tratamento de alta eficácia e abrangência. Logo, é imprescindível a investigação de estratégias alternativas e inovadoras, atendo-se as considerações e as adversidades apontadas por esses estudos, com o objetivo de obter, futuramente, pleno potencial imunoterapêutico contra o câncer de próstata. É certo, portanto, que a imunoterapia se revela como a nova geração de recurso terapêutico contra o câncer.

\section{REFERÊNCIAS}

1. BAXEVANIS CN, et al. Prostate cancer: any room left for immunotherapies?. Immunotherapy, 2019; 11(2).

2. CARAM EVM, et al. Factors associated with use of sipuleucel-T to treat patients with advanced prostate cancer. JAMA network open, 2019; 2(4): e192589-e192589.

3. EREMINA NV, et al. First-in-human study of anticancer immunotherapy drug candidate mobilan: safety, pharmacokinetics and pharmacodynamics in prostate cancer patients. Oncotarget, 2020; 11(14).

4. HE Q, et al. TCR-like antibodies in cancer immunotherapy. Journal of Hematology \& Oncology, 2019; 12(99).

5. HOOD, SP et al. Phenotype and function of activated natural killer cells from patients with prostate cancer: Patient-dependent responses to priming and IL-2 activation. Frontiers in immunology, 2019; 9. 
RESUMOS EXPANDIDOS: Revisão Bibliográfica

Título: O uso do Dimesilato de Lisdexanfetamina no tratamento do TDAH: uma revisão sobre o tema

Autor/coautores: Ana Luiza Antony Gomes de Matos da Costa e Silva; Kamila Catta Preta Carneiro de Sousa; Gustavo Carvalho Oliveira.

Instituição: Centro Universitário de Brasília - UniCEUB/Distrito Federal.

Palavras-chave: Transtorno de Déficit de Atenção/Hiperatividade; Tratamento; Lisdexanfetamina.

\section{INTRODUÇÃO}

Segundo o Manual de Diagnóstico e Estatístico de Transtornos Mentais (DSM-V), o Transtorno de Déficit de Atenção/Hiperatividade (TDAH) é caracterizado pela persistência de desatenção e/ou hiperatividadeimpulsividade interferindo no funcionamento e desenvolvimento pessoal (BANASCHEWSKI T, et al., 2017). Comumente esse transtorno é identificado na infância, com as manifestações características que precisam estar presentes em mais de um ambiente e não apenas na escola, por exemplo. O tratamento do TDAH é baseado em uma abordagem conjunta, incluindo psicoterapia, intervenções farmacológicas, e participação dos familiares, educadores e dos profissionais de saúde para evitar o comprometimento educacional e do desenvolvimento (BANASCHEWSKI T, et al., 2017). As drogas usadas como tratamento de primeira linha do TDAH são os agentes estimuladores do sistema nervoso central (SNC), dentre eles, os principais são o Metilfenidato e o dimesilato de lisdexanfetamina (LDX) (STUHEC M, et al., 2015).

O dimesilato de lisdexanfetamina é uma pró-droga inativa da dexanfetamina, que atua no bloqueio da recaptação da dopamina e pela da liberação de dopamina e noradrenalina, favorecendo então o aumento da atenção e diminuição da impulsividade e hiperatividade pelo estímulo ao SNC. Possui efeitos semelhantes ao do metilfenidato; no entanto, com menor número de estudos clínicos para avaliar suas características (SANTOS JBR, et al., 2016).

\section{OBJETIVOS}

Identificar as características positivas e negativas da utilização da farmacologia de primeira linha para o TDAH, com foco principal nos efeitos do Dimesilato de Lisdexanfetamina, avaliando seus benefícios em comparação com os estimuladores do SNC e fármacos indicados para o tratamento do TDAH.

\section{MÉTODO}

Esse trabalho é uma revisão integrativa de literatura, em que foram analisados artigos dos últimos 5 anos, nas bases de dados SciELO e PubMed. Foram pesquisados os termos com o conector "E" (Scielo) ou "AND" (PubMed): Transtorno de déficit de atenção; dimesilato de lisdexanfetamina; metilfenidato; atomoxetina e seus equivalentes em inglês, sendo escolhidos estudos que abordassem eficácia de modo comparativo, tolerabilidade, segurança, riscos e benefícios dos medicamentos em questão.

\section{REVISÃO BIBLIOGRÁFICA}

Com o uso dos descritores acima, foram encontrados 30 estudos no Pubmed e 1 no SciELO. Foram utilizadas nessa revisão seis referências, incluindo-se estudos comparativos.

O TDAH é um transtorno que exige gerenciamento e tratamento de longo prazo, devido a isso, estudos sobre eficácia, segurança e tolerabilidade são indispensáveis (COGHILL, et al., 2017). Com relação à segurança foram avaliados aspectos como eventos adversos emergentes do tratamento (TEAEs), sinais vitais, eletrocardiograma e perfil de crescimento (altura e peso). A incidência de TEAEs incluiu diminuição do 
apetite, perda de peso, insônia e dor de cabeça, a ocorrência foi similar nos estudos com porcentagem semelhante nos medicamentos, ocorrendo poucos TEAs graves, sendo a maior parte moderados (COGHILL $\mathrm{DR}$, et al., 2017). Ademais, em alguns estudos, foi numericamente constatado que os TEAEs que levaram a descontinuação do tratamento foram ligeiramente mais altos no uso de LDX do que com metilfenidato, mas a frequência de TEAEs mais graves foi numericamente mais baixa no uso de lisdexanfetamina. Alterações cardiovasculares foram maiores no uso de metilfenidato, enquanto a perda de peso foi mais comum com o uso de LDX (NEWCORN JH, et al., 2017).

Estudos comparativos em relação à eficácia mostraram que o LDX teve grande eficácia na redução dos sintomas de TDAH (NEWCORN JH, et al., 2017) e ela também teve eficácia superior quando comparada aos sais de anfetamina e ao metilfenidato em suas doses clínicas habituais (STUHEC M, et al., 2018).

\section{DISCUSSÃO}

STUHEC M, et al., 2018, realizaram uma importante metanálise por meio de uma comparação entre as drogas psicoestimuladoras, para avaliar eficácia, aceitabilidade e tolerabilidade dos fármacos quando comparados ao placebo. Foi demonstrado que o LDX é um medicamento muito eficiente no tratamento do TDAH, sendo seu efeito superior quando contrastado com sais mistos de anfetamina e com o metilfenidato.

NEWCORN JH, et al., 2017, realizaram um estudo randomizado, duplo-cego, com o controle das doses dos medicamentos, mostrando resultados positivos para a redução da sintomatologia e redução da gravidade do TDAH, tanto do metilfenidato quanto ao dimesilato de dexanfetamina (LDX). No subgrupo de crianças e adolescentes, o LDX foi estatisticamente superior na redução dos sintomas do TDAH e no aumento do desenvolvimento global do paciente, quando comparado ao metilfenidato.

\section{CONCLUSÃO}

Esse trabalho mostrou que o uso da lisdexanfetamina é seguro e com baixa incidência de efeitos adversos graves, sendo uma droga bastante eficaz no tratamento do TDAH em populações de diversas faixas etárias. Há evidências significativas de que seu uso pode ter eficácia superior no controle do TDAH mesmo a outras drogas com indicação terapêutica consolidada, como o metilfenidato, sendo, assim, uma opção terapêutica que pode ser considerada e indicada.

\section{REFERÊNCIAS}

1. BANASCHEWSKI T, et al. Attention-deficit/hyperactivity disorder-a current overview. Dtsch Arztebl Int, 2017; 114: 149-59. DOI: 10.3238/arztebl.2017.0149.

2. COGHILL DR, et al. Long-term safety and efficacy of lisdexamfetamine dimesylate in children and adolescents with ADHD: A phase IV, 2-year, open-label study in Europe. CNS drugs, 31(7), 2017; 625-638.

3. NEWCORN JH, et al. Randomized, double-blind, placebo-controlled acute comparator trials of Lisdexamfetamine and extended-release methylphenidate in adolescents with attention-deficit/hyperactivity disorder. CNS drugs, 2017; 31(11), 999-1014.

4. SANTOS JBR, et al. Dimesilato de lisdexanfetamina para Transtorno de Déficit de Atenção com Hiperatividade. Centro de Colaborador do SUS (CATES), nota técnica 3/2016.

5. STUHEC M, et al. Efficacy, Acceptability, and Tolerability of Lisdexamfetamine, Mixed Amphetamine Salts, Methylphenidate, and Modafinil in the Treatment of Attention-Deficit Hyperactivity Disorder in Adults: A Systematic Review and Meta-analysis. Annals of Pharmacotherapy, 2018; 53(2), 121-133.

6. STUHEC M, et al. Comparative efficacy and acceptability of atomoxetine, lisdexamfetamine, bupropion and methylphenidate in treatment of attention deficit hyperactivity disorder in children and adolescents: a metaanalysis with focus on bupropion. Journal of affective disorders, 2015; 178, 149-159. 
RESUMOS EXPANDIDOS: Relato de experiência

Título: A extensão universitária e seus impactos na formação profissional: um relato de experiência no curso de medicina de uma universidade pública do estado da Paraíba

Autor/coautores: Daniel Meira Nóbrega de Lima; Renata Maria Santos de Freitas Kamilla Priscila Coelho da Costa; Natalia Paiva Lima; Maurus Marques de Almeida Holanda.

Instituição: Universidade Federal da Paraíba, João Pessoa - Paraíba.

Palavras-chave: Extensão comunitária, Prevenção de acidentes, Trauma.

\section{INTRODUÇÃO}

A formação médica no Brasil, hoje, engloba de forma mais abrangente todos os níveis de atenção à saúde - primário, secundário e terciário. Dispor-se de mais significativo protagonismo na atenção primária oferece aos estudantes o ganho e aprimoramento de habilidades fundamentais na prevenção das doenças e afecções que assolam a sociedade brasileira atualmente.

Dentre essas, o trauma figura como uma das principais causas de morbimortalidade da população, especialmente entre as primeira e segunda décadas de vida, sendo o traumatismo cranioencefálico (TCE) e o trauma raquimedular (TRM) importantes agentes causadores da morte pediátrica.

Com o objetivo de permitir a aquisição de competências necessárias à atuação na atenção básica, a extensão universitária permite vivências não somente em ambiente acadêmico, mas também no comunitário, ampliando desta forma os mecanismos de aprendizado entre os estudantes em formação (SOUSA PR, et al., 2019).

Ademais, a extensão universitária permite uma educação mais autonoma, coconstruída e fomenta uma responsabilização social dos futuros profissionais (SANTOS MS e PINHO MJ, 2019).

\section{OBJETIVO}

Determinar o impacto que as ações desenvolvidas na extensão universitária "Prevenção do TCE e TRM em crianças de 08 a 14 anos em escolas públicas do município de João Pessoa" exerceram na formação médica de alunos da universidade federal da Paraíba.

\section{RELATO DE EXPERIÊNCIA}

Os universitários participantes do projeto conseguiram assimilar os conceitos básicos referentes à extensão, para que, portanto, pudessem repassar tais ensinamentos ao público-alvo, nas escolas. Determinados fatores de risco puderam ser postos em evidência, favorecendo atuação mais efetiva em termos de prevenção dos TCE e TRM, à medida que porções do cotidiano das crianças foram sendo observadas e apreendidas pelos agentes da extensão.

Logo, aferiu-se e confirmou-se, por meio dos discursos obtidos em reuniões, que os futuros profissionais desenvolveram conhecimentos acerca do tema central do projeto, mas também acerca de práticas de observação e interação com a população em geral.

Observou-se também a conquista de ferramentas linguísticas e didáticas adequadas à comunicação efetiva com a faixa etária pediátrica. Os extensionistas relataram que houve uma transferência e contratransferência entre eles e os alunos da escola, fazendo com que houvesse uma maior assimilação para ambos de vivências, experiências e conhecimetnos. 
Verificou-se que esses alunos estavam mais propensos a seguir a carreira de docência após a extensão, mudando suas percepções de ensino. Os participantes também evidenciaram que suas apresentações e atividades na universidade melhoraram após a experiência, uma vez que passaram a refletir acerca do processo de aprendizagem durante suas práticas.

Salienta-se que os estudantes universitários discutiram a possibilidade de possíveis projetos de pesquisa para abordar e complementar o processo de ensino-extensão, assim, solidificando o tripé universitário. Por fim, os extensionistas compreenderam a responsabilidade social a qual estavam inseridos, e da necessidade de retornar às contribuições da universidade pública para as diversas instâncias da sociedade civil.

\section{DISCUSSÃO}

Através da interação com a comunidade, serviços e conhecimento popular, a extensão não apenas fomenta a docência, como também a pesquisa, e o retorno dela a sociedade. A extensão universitária está, intrinsecamente, associada a uma responsabilização social da universidade com a sociedade, e esta promove nos alunos uma corresponsabilização, contribuindo para a formação profissional de seus participantes (CANON CA e PELEGRINELLI G, 2019). A universidade deve buscar uma nova centralidade no ensino, atribuindo em seus processos formativos, uma coesão social e um aprofundamento dessas vivências. Ademais, esse processo educativo reflete na identidade profissional e pessoal dos alunos, e alicerça competências, não adquiríveis na educação tradicional (MARINHO CM, et al., 2019)

\section{CONSIDERAÇÕES FINAIS}

Dessa forma, permitindo uma interlocução mais próxima da realidade dessa população, não apenas comportando a resolução de problemas devido a um exame clínico mais claro e respostas ao paciente mais compreensíveis, como também a criação de um vínculo. Deve-se ressaltar a capacidade de articulação adquirida dos extensionistas com os profissionais e educadores da escola para uma maior reverberação dos conhecimentos trazidos sobre prevenção do TCE e TRM para além dos encontros realizados com os extensionistas. Ademais, as vivências nos campos de prática trouxeram aos estudantes novas perspectivas em torno da situação socioeconômica e cultural do estado da Paraíba.

\section{REFERÊNCIAS}

1. CANON CA, PELEGRINELLI, G. Extensão universitária: o impacto de um projeto de extensão na formação profissional dos discentes na educação superior. Revista UFG, 2019; 19: e59799.

2. MARINHO CM, et al. Por que ainda falar e buscar fazer extensão universitária? Revista de Extensão Univasf, 2019; 7(1): 121-140.

3. SANTOS MS, PINHO MJ. A extensão universitária e sua contribuição na formação do estudante de graduação. Revista UFG, 2019; 19: e61317.

4. SOUSA PR, et al. Indissociabilidade entre o ensino, pesquisa e extensão no ensino superior. Revista Eletrônica Acervo Saúde, 2019; supl.32, e938. 
RESUMOS EXPANDIDOS: Relato de Experiência

Título: Quem pensa brinca com segurança: mensurando o aprendizado de crianças do ensino municipal acerca da prevenção do neurotrauma

Autor/coautores: Daniel Meira Nóbrega de Lima; Renata Maria Santos de Freitas; Kamilla Priscila Coelho da Costa; Natalia Paiva Lima; Maurus Marques de Almeida Holanda.

Instituição: Universidade Federal da Paraíba, João Pessoa - Paraíba.

Palavras-chave: Extensão comunitária; Prevenção de acidentes; Trauma.

\section{INTRODUÇÃO}

Os traumas neurológicos consistem no traumatismo cranioencefálico (TCE) e traumatismo raquimedular (TRM), também denominados de neurotraumas. Sua incidência na infância e adolescência é elevada, cerca de $70 \%$, pois sua ocorrência é comum, e está diretamente vinculada ao ato de brincar (GONÇALVES DV, et al., 2019). Muitas atividades recreativas consistem na realização de esportes como patins, skate, bicicleta, saltos de cabeça no raso das piscinas, inclinação da cadeira balançando-se para frente e trás, ou mesmo girar a "cadeira de rodinhas" do escritório (BABIKIAN T, et al., 2015).

Além desses, ainda se atrela o fato de adolescentes utilizarem-se de caronas em motos e pilotar quadriciclos sem o uso do capacete. Sob essa ótica, o perigo cresce diante da inocência. A criança e/ou adolescente não se dá conta do quanto é arriscado. São simples atos praticados e percebidos em seu universo como brincadeiras inofensivas (GUILHERI J, et al., 2017). Recentemente, observou-se a brincadeira "quebracrânio", essa não apenas gerou danos neurológicos, em várias crianças, como também levou ao óbito.

\section{OBJETIVO}

Mensurar o aprendizado dessas crianças frente as rodas de conversas e oficinas ofertadas pela extensão acerca da prevenção do neurotrauma. Assim, como expandir o conhecimento preventivo sobre os neurotraumas a esse grupo.

\section{RELATO DE EXPERIÊNCIA}

O conteúdo das oficinas era de caráter preventivo, e contava com materiais de elaboração realizada pelos membros da extensão. Esse demonstrava de forma ilustrativa os riscos que essas crianças correm ao se expor a brincadeiras sem refletir nas suas consequências, e principalmente quando ainda não conhece os atos preventivos aos neurotraumas (TCE e TRM).

Assim, com resultado das respostas, foi realizada a análise de 250 questionários, e foi perceptível que $89 \%$ das respostas apresentaram coerência com o aprendizado esperado. As crianças eram capazes de distinguir a importância do uso do capacete, além de recomendarem o uso desse aos seus familiares e colegas durante a pratica de esportes e uso de motocicleta.

Além disso, cerca de $95 \%$ da amostra passou a reconhecer a existência e a utilidade da escadaria da piscina, bem como os perigos de empurrar ou jogar seus amigos de qualquer forma durante brincadeiras. $O$ ato que mais fez as crianças refletirem foi o de equilibrar a cadeira em duas pernas e balançá-la para frente e para trás, pois cerca de $100 \%$ da amostra referiu praticar o ato de forma autonômica, sem perceber que estava fazendo. 
Os alunos desconheciam as graves consequências que essas brincadeiras poderiam trazer a sua vida. $E$ ignoravam as repercussões negativas entendidas como sequelas, dentre elas: a paraplegia, tetraplegia, comprometimento neurológico, dependência para desenvolver suas atividades diárias e até mesmo o coma.

Os professores e funcionários da escola relataram uma diminuição das brincadeiras perigosas, bem como pais, avós e tios. Sendo assim, percebeu-se uma mudança da postura e atitude de alguma dessas crianças.

\section{DISCUSSÃO}

Uma vez que, as particularidades da comunidade alteram as percepções e identidades dos estudantes, tentar compreendê-la é um dos primeiros passos para sabermos como devemos atuar, bem como fatores de risco para o trauma cranioencefálico e o raquimedular, próprios dessa comunidade, bem como o grau de vulnerabilidade da população desse território para esses eventos (AMORIM ES, et al., 2017). Assim como esperado, foi uma troca muito rica, haja vista, os estudantes re-elaboraram as informações e redimensionaram em suas realidades, tornando um conhecimento co-construído e crítico (SILVA GG, et al., 2018). Foi inesgotável o número de exemplificações pessoais e de familiares que de alguma forma estavam inseridos nos temas em pauta. Dessa forma, não só perceberam como se faz importante a prevenção do trauma cranioencefálico e raquimedular, bem como a necessidade de difundir os conhecimentos construídos na discussão em suas casas, núcleos de apoio.

\section{CONSIDERAÇÕES FINAIS}

Concluiu-se que as atividades preventivas, são também educativas, quando implementadas na fase de maior aprendizado da vida, sendo a infância e adolescência o período de formação dos bons costumes que passam a vigorar para fase adulta da vida. A partir do momento que essa população começa a ser treinada, educada e bem conduzida, o número de acidentes passa a ser reduzido. Assim, há aplicabilidade do cuidado consigo mesmo e com o outro, além desses compreenderem a gravidade que uma simples brincadeira pode ofertar, além dos riscos e danos que pode trazer por toda uma vida.

\section{REFERÊNCIAS}

1. AMORIM ES, et al. Perfil epidemiológico de vítimas infantis de trauma cranioencefálico. Revista de Enfermagem da UFPE, 2017; 11(supl. 10): 4150-4156.

2. BABIKIAN T, et al. Chronic aspects of pediatric traumatic brain injury: review of the literature. Journal of neurotrauma, v. 32, n. 23, p. 1849-1860, 2015.

3. GONÇALVES DV, et al. Determinantes epidemiológicos do trauma cranioencefálico em crianças. Amadeus International Multidisciplinary Journal, 2019; 4(7): 232-244.

4. GUILHERI J, et al. "Brincadeira do desmaio": uma nova moda mortal entre crianças e adolescentes. Características psicofisiológicas, comportamentais e epidemiologia dos 'jogos de asfixia. Ciência e Saúde Coletiva, 2017; 22(3): 867-878.

5. SILVA GG, et al. A brincadeira das crianças como experiência social de elaboração de conhecimentos acerca do mundo físico na Educação Infantil, 2018; 20(38): 469-487. 
RESUMOS EXPANDIDOS: Revisão Bibliográfica

Título: Comparação dos efeitos da Síndrome de Burnout entre professores escolares e universitários no Brasil: uma revisão sistemática

Autor/coautores: Matheus Vinicius de Araújo Lucena; Felipe Rigatti de Souza; Geneci Lucas Lucena Lopes; Mariana Ribeiro Vanderley de Arruda; Bruno Marcello Mendonça Nascimento.

Instituição: Universidade Federal de Pernambuco, Recife-Pernambuco.

Palavras-chave: Burnout Syndrome, Faculty, School Teachers.

\section{INTRODUÇÃO}

A sociedade vivencia um período epidêmico de desgaste físico e mental que atinge os professores em geral, dessa forma, como esses são a base para a formação dos indivíduos, observam-se reflexos em toda população. Ademais, diante dessa responsabilidade social, eles sentem-se pressionados, o que favorece 0 surgimento de doenças psicológicas como a Síndrome de Burnout (SB), observada em pessoas que estão sujeitas ao estresse crônico (DA SILVA RJS, et al., 2018).

A SB apresenta-se de forma tridimensional e é caracterizada por elevada exaustão emocional, despersonalização e por fortes sentimentos de baixa realização pessoal (DA SILVA SMF, et al., 2017). Os professores sofrem com ela, pois passam constantemente pela necessidade de transformação quanto a forma de ensinar, além de lidarem com a obsolescência e desvalorização profissional, que conduzem ao aparecimento de doenças. Daí a necessidade de haver estudos sobre o tema, focando na análise da situação tanto no âmbito universitário, quanto dos ensinos fundamental e médio.

\section{OBJETIVO}

Revisar a literatura disponível sobre a incidência da Síndrome de Burnout em professores do ensino fundamental e médio e de universidades, a fim de analisar como essa síndrome se distribui em cada uma dessas categorias.

\section{MÉTODO}

Realizou-se revisão de literatura nas bases de dados eletrônicas: BVS, Google Acadêmico, e SciELO, cruzando-se os descritores, baseados no vocabulário Descritores em Ciências da Saúde (DeCS), "Burnout Syndrome"; "Faculty"; e "School Teachers". Foram encontradas 1201 publicações, no período de junho de 2015 a junho de 2020, sendo selecionadas 6, com base nos critérios de inclusão e exclusão.

Os critérios de inclusão foram: estudos com professores de ensino médio, fundamental ou de universidade; que utilizaram a escala Maslach Burnout Inventory (MBI) para avaliação; e que estavam relacionados apenas e diretamente com o docente. Foram excluídos: revisões; estudos relacionados a outros problemas comportamentais; e que não atingissem amostra populacional mínima de 50, para professores dos ensinos fundamental e médio, e de 160, para de universidades.

\section{REVISÃO BIBLIOGRÁFICA}

Três estudos utilizaram amostras de professores universitários: 1265 professores (pouco mais da metade do gênero masculino), concentrados na faixa de idade de 32 a 46 anos (FERREIRA PAP, 2016); 173 professores com idade média de aproximadamente 39 anos, a maioria mulheres (DA SILVA SMF, et al., 2017); e 161 professores (predomínio do gênero feminino), concentrados na faixa de 37 a 42 anos de idade (DA SILVA RJS, et al., 2018). 
Outros três utilizaram professores dos ensinos fundamental e médio: 52 professores (predomínio considerável de mulheres), a maioria acima dos 47 anos (DA SILVA JLL, et al., 2018); 220 professores com idade média aproximada de 42 anos e pouco mais da metade do sexo feminino (SOUZA S, et al., 2016); e 804 professores, maioria mulheres e 62,90\% com menos de 45 anos (KOGA GKC, et al., 2015).

Todos os estudos analisados abordaram a distribuição dos professores nas dimensões do questionário MBI, destacando os valores percentuais dos índices elevados de Exaustão Emocional (EE) e Despersonalização (DP) e reduzidos de Realização Profissional (RP).

Nos estudos, foram identificados, entre os professores universitários, altos índices de EE em 20,20\%; 29,50\%; e 54,70\%; de DP em 18,90\%; 34,70; e 41,60\%; e baixos índices de RP em 17,40\%; 41,00\%; e $13,00 \%$. Já entre os professores dos ensinos fundamental e médio, os índices foram altos para EE em 40,40\%; 34,09\%; 22,51\%; para DP em 28,80\%; 9,09\%; 22,63\%; e baixos para RP em $11,50 \%$; $15,45 \%$; $19,02 \%$.

Considerando-se uma amostra total, observa-se que entre os professores universitários ( $N=1599)$ os índices são altos para EE em $24,68 \%$, para DP em $22,90 \%$ e baixos para RP em $19,51 \%$. Já entre os professores do ensino fundamental e médio ( $N=1076)$, são, respectivamente, 22,74\%, 20,16\% e 17,93\% (Gráfico 1).

Gráfico 1 - Comparação da distribuição das dimensões do questionário MBI entre professores dos ensinos fundamental e médio e universitários.

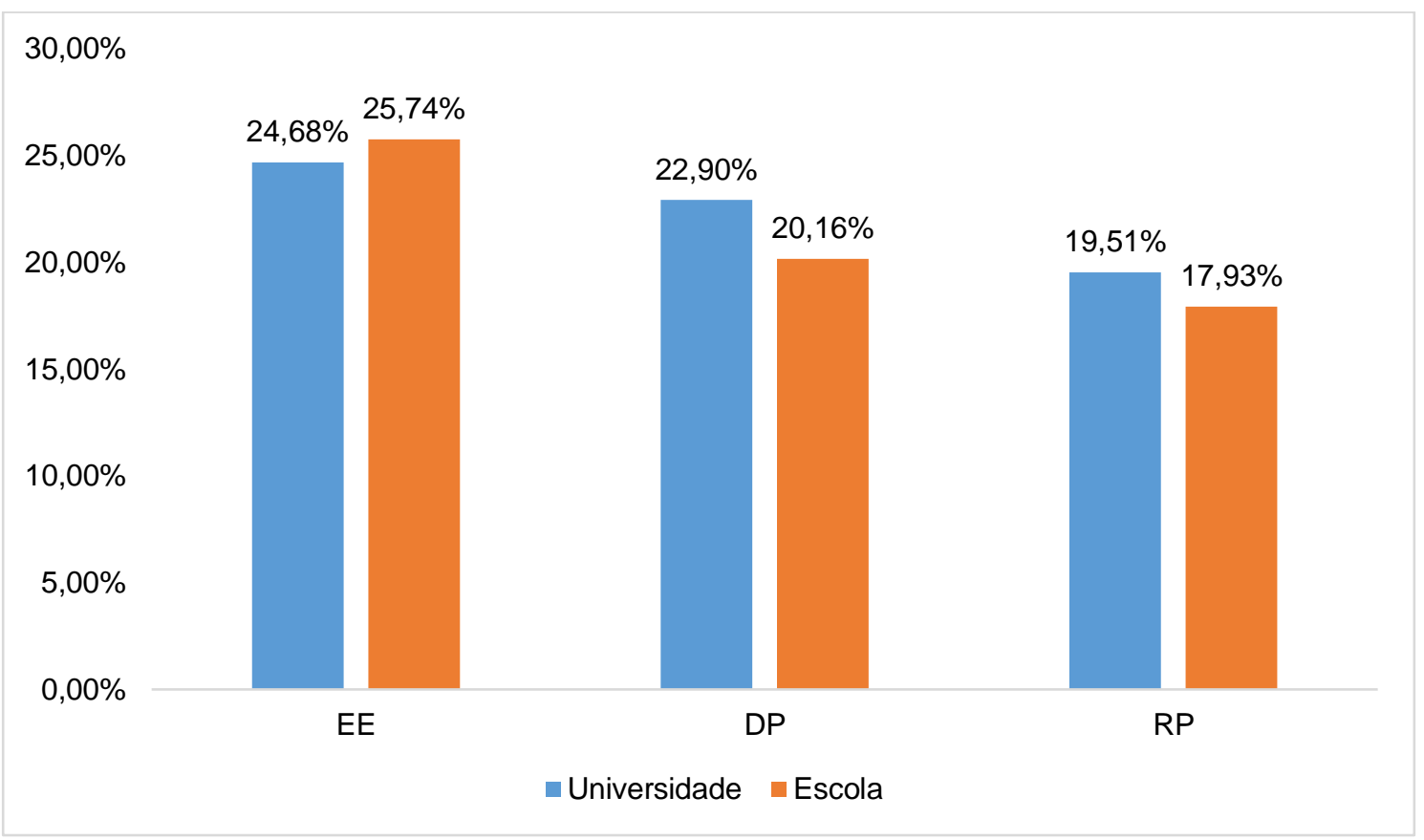

Fonte: LUCENA MVA, et al., 2020.

\section{DISCUSSÃO}

O esgotamento dos docentes do ensino fundamental e médio procede dos problemas intrínsecos da faixa etária dos discentes, além das cobranças dos responsáveis. Enquanto, o professor universitário vem lidando com a pressão por aumento da produção científica e competições acirradas (FERREIRA PAP, 2016). Essas problemáticas refletem nos expressivos índices da EE, DP e baixa RP, tanto no grupo dos professores universitários, quanto no dos escolares. 
Os dados da literatura demonstram que a prevalência da SB entre professores é expressiva (DA SILVA JLL, et al., 2018). Porém, os estudos não fornecem informações comparativas sobre prevalência da síndrome entre os professores escolares e universitários, o que demonstra a importância da realização de novos estudos, a fim de criar políticas públicas para reverter essa realidade.

\section{CONSIDERAÇÕES FINAIS}

Este estudo, ao comparar os dados das três dimensões da SB, evidencia que professores universitários (EE em $24,68 \%$, para DP em $22,90 \%$ e RP em 19,51\%) apresentam índices maiores em relação aos professores do ensino fundamental e médio (EE em $22,74 \%$, para DP em $20,16 \%$ e RP em $17,93 \%$ ); fato que não pode amenizar o sofrimento de ambos os docentes, mas sim fomentar a busca de novas ferramentas para sancionar os fatores que levam ao adoecimento psíquico do meio educacional.

\section{REFERÊNCIAS}

1. DA SILVA JLL, et al. Prevalência da síndrome de Burnout entre professores da Escola Estadual em Niterói, Brasil. Enfermería Actual de Costa Rica, 2018; (34): 14-25.

2. DA SILVA RJS, et al. Ocorrência da Síndrome de Burnout em professores do ensino superior em instituição privada. Fisioterapia Brasil, 2018; 19(4): 490-499.

3. DA SILVA SMF. Burnout em professores universitários do ensino particular: o impacto das percepções de suportes social no trabalho e organizacional. Dissertação (Mestrado em Psicologia) - Instituto de Psicologia. Universidade Federal de Uberlândia, Uberlândia, 2017; 93 p.

4. FERREIRA PAP. Burnout em Professores Universitários. Dissertação (Mestrado em Psicologia). Universidade Salgado de Oliveira, Niterói, 2016; 105 p.

5. KOGA GKC, et al. Fatores associados a piores níveis na escala de Burnout em professores da educação básica. Cadernos Saúde Coletiva, 2015; 23(3): 268-275.

6. SOUZA S, et al. Síndrome de burnout e valores humanos em professores da rede pública estadual da cidade de João Pessoa: Um estudo correlacional. Análise Psicológica, 2016; 34(2): 119-131. 
RESUMOS EXPANDIDO: Revisão Bibliográfica

Título: Avaliação Imagiológica em Pacientes com Suspeita de COVID-19

Autor/coautores: Ana Clara César Coelho; Andressa Silva Couto; Fernanda Aquino de Oliveira; Frederico Isolani; Andrade; Natália Caetano Alves Melo.

Instituição: Universidade de Itaúna (UIT), Itaúna - Minas Gerais.

Palavras-chave: COVID-19, Tomografia Computadorizada, Diagnóstico.

\section{INTRODUÇÃO}

A doença respiratória aguda causada pelo novo coronavírus (SARS-CoV-2) iniciou-se com um surto epidêmico na China, e foi se alastrando rapidamente pelos continentes, ocasionando uma pandemia. Corona Vírus Disease 2019 (COVID-19) é uma doença altamente contagiosa e de evolução ainda pouco conhecida. Devido à magnitude alcançada, o interesse científico por esta enfermidade também tem crescido na literatura global, incluindo suas manifestações nos exames de imagem, principlamente na Tomografia Computadorizada (TC) torácica (CHATE RC, et al., 2020).

Atualmente o método de escolha para o diagnóstico de COVID-19 se dá a partir da detecção do RNA do SARS-CoV-2 por reação em cadeia da polimerase com transcrição reversa (RT-PCR) em material biológico, colhido da orofaringe ou da nasofaringe. A RT-PCR permanece como padrão-ouro para o diagnóstico definitivo apesar dos relatos de resultados falso-negativos diante de achados imagiológicos positivos (ARAUJO-FILHO JAB, et al., 2020).

À fim de aumentar a acurácia diagnóstica, novos estudos apoiam o uso da TC de tórax na triagem de pacientes com características clínicas e epidemiológicas compatíveis com a infecção pelo novo coronavírus, principalmente quando o teste de RT-PCR é negativo (FANG Y, et al., 2020).

\section{OBJETIVO}

Avaliar a eficácia, a sensibilidade e a especificidade dos métodos de imagem, tais como a Tomografia Computadorizada e a Radiografia de Tórax, utilizados no diagnóstico e no seguimento de pacientes com suspeita de COVID-19.

\section{MÉTODO}

Este estudo constitui-se de uma revisão da literatura realizada nos bancos de dados Scielo, PubMed, Lilacs e Latindex, no período de maio à julho de 2020. Os descritores utilizados foram "coronavírus", "COVID-19", "diagnóstico", "imagem" e "tomografia computadorizada". Foram incluídos artigos científicos publicados no ano de 2020.

\section{REVISÃO BIBLIOGRÁFICA}

Até o presente momento, recomenda-se que o diagnóstico de COVID-19 seja feito através da RT-PCR em tempo real para o SARS-CoV-2 ou sequenciamento genético. Também os meios imagiológicos de diagnóstico, tais como a radiografia do tórax e a TC torácica têm sido muito utilizados na investigação de doentes com suspeita ou confirmação desta enfermidade. Todavia, ainda não é consensual o valor destas técnicas de imagem no diagnóstico e controle da doença (ESTEVÃO A, 2020).

Algumas instituições não recomendam a utilização de exames de imagem para o rastreamento da doença nem como teste de primeira linha para o diagnóstico de COVID-19. No entanto, múltiplos estudos científicos 
evidenciam os achados tomográficos dessa condição, mesmo em pacientes com resultado de RT-PCR negativo, despertando o interesse em relação ao papel da TC no cenário clínico atual (FANG Y, et al., 2020)

Em relação aos achados tomográficos mais frequentemente observados nos casos de COVID-19, encontram-se predominantemente alterações alveolares, como opacidades em vidro fosco e, ocasionalmente, consolidações focais e opacidades mistas, geralmente com acometimento bilateral e multifocal, distribuição periférica e predomínio nos campos pulmonares médios, inferiores e posteriores. Com a evolução da doença podem surgir espessamentos septais, padrão "em mosaico" e consolidação periférica e, em fases mais graves e avançadas, bronquiectasias de tração. São menos frequentes o acometimento central do parênquima ou a presença de nódulos, derrame pleural, cavidades ou linfonodomegalias (DE FARIAS LPG, et al., 2020).

Em relação à sensibilidade dos métodos diagnósticos de COVID-19 foi-se comprovada a superioridade da TC torácica em virtude da RT-PCR. Esses métodos apresentaram sensibilidade de $98 \%$ e $71 \%$, respectivamente (FANG Y, et al., 2020). Tais fatos subsidiam que o uso da TC de tórax pode ser útil como método padrão para o diagnóstico de COVID-19 e para otimizar o tratamento dos pacientes. Contudo, a TC ainda é limitada no que tange à identificação do vírus, apresentando especificidade de $25 \%$ (LI Y, XIA L. 2020).

\section{DISCUSSÃO}

Embora o uso da TC torácica como ferramenta de triagem ainda não esteja definido, estudos atuais têm demonstrado um papel central deste exame na detecção e gerenciamento precoces das manifestações pulmonares de COVID-19, com alta sensibilidade porém, com especificidade limitada (ESTEVÃO A, 2020).

Os métodos imagiológicos podem auxiliar no diagnóstico dessa doença, porém não podem isoladamente confirmá-lo. Os achados tomográficos da pneumonia por COVID-19 são inespecíficos, semelhantes aos de outras afecções pulmonares, devendo ser correlacionados com evidências clínicas e laboratoriais da infecção por COVID-19 (CHATE RC, et al., 2020).

Particularmente, a radiografia de tórax não tem sido recomendada como modalidade imagiológica de primeira escolha diante da suspeita de COVID-19, pois este método apresenta limitada sensibilidade na detecção de alterações como opacidades em vidro fosco e de outros achados pulmonares incipientes da infecção. Desta forma recomenda-se a sua utilização para excluir o diagnóstico da doença (ARAUJO-FILHO JAB, et al., 2020).

\section{CONSIDERAÇÕES FINAIS}

Por mais que os achados imagiológicos se sobreponham aos encontrados em infecções pulmonares causadas por outros agentes e que, atualmente, o diagnóstico definitivo deva ser realizado por meio da utilização da RT-PCR, é indiscutível a importância dos métodos de imagem, principlamente a TC de tórax, para avaliação do paciente com suspeita e confirmação de COVID-19. Portanto, até que novos estudos sobre o papel da TC na pneumonia por COVID-19 sejam publicados, uma análise integrada dos aspectos clínicos, imagiológicos e laboratoriais deve ser preconizada, objetivando o diagnóstico precoce da doença.

\section{REFERÊNCIAS}

1. ARAUJO-FILHO JAB, et al. Pneumonia por COVID-19: qual o papel da imagem no diagnóstico?. J Bras Pneumol, 2020; 46(2):e20200114.

2. CHATE RC, et al. Apresentação tomográfica da infecção pulmonar na COVID-19: experiência brasileira inicial. J Bras de Pneumol, 2020; 46(2):e20200121. 
3. DE FARIAS LPG, et al. O sinal do halo como apresentação tomográfica pulmonar na COVID-19. einstein (São Paulo), 2020; 18:eAl5742.

4. ESTEVÃO A. COVID-19. Acta Radiológica Portuguesa, 2020; 32(1): 5-6.

5. FANG Y, et al. Sensitivity of chest CT for COVID-19: comparison to RT-PCR. Radiology, 2020; 296:E115E117.

6. LI Y, XIA L. Coronavirus disease 2019 (COVID-19): role of chest CT in diagnosis and management. American Journal of Roentgenology, 2020; 214:1280-1286. 
RESUMOS EXPANDIDOS: Revisão Bibliográfica

Título: Saúde bucal da gestante e suas consequências embrionárias e fetais: uma prevenção e um tratamento interprofissional

Autor/coautores: Iasmyn Paranhos de Oliveira; Marcos Lorran Paranhos Leão; Thalia Thamyres Basilio Vieira; Débora Abreu Badaró.

Instituição: Universidade Federal de Juiz de Fora (UFJF), Governador Valadares - Minas Gerais. Universidade de Pernambuco (UPE), Recife - Pernambuco. Universidade Vale do Rio Doce (UNIVALE), Governador Valadares - Minas Gerais.

Palavras-chave: Saúde Bucal, Gravidez, Desenvolvimento embrionário e fetal.

\section{INTRODUÇÃO}

Desde as primeiras semanas de gestação, a mulher passa por alterações hormonais, anatômicas e psicológicas que a torna mais suscetível a doenças bucais. Ainda, há evidências de que a deficiente manutenção da saúde oral perinatal esteja associada a implicações significativas para a saúde materna, fetal e infantil. Portanto, faz-se necessário uma visão mais cuidadosa para essas pacientes, alterando o padrão de atendimento odontológico (GUPTA N e CHHETRY M, 2019; MARTINS WLL, 2019; SOARES ALF de H, et al., 2020).

Dessa forma, é imprescindível uma abordagem consciente e integral do pré natal, com todos os profissionais necessários, observando cada caso em sua particularidade. Infelizmente, há falta de informação sobre a importância desses cuidados bucais durante a gravidez, decorrentes de níveis socioeconômicos e/ou questões culturais. Vale ressaltar, que este é um período onde a gestante está receptiva a novos estilos de vida, devido a isso, este é o momento oportuno para abordagens de promoção em saúde bucal (SOARES ALF de H, et al., 2020; SILVA CC, 2020).

\section{OBJETIVO}

Analisar as produções científicas, dos últimos cinco anos, em diferentes repositórios de busca nacionais e internacionais, acerca da saúde bucal da gestante e suas repercussões para a formação e desenvolvimento embrionário e fetal.

\section{MÉTODO:}

Trata-se de um estudo qualitativo, do tipo revisão integrativa de literatura. A busca foi realizada nas bases de dados: Pubmed, Ebsco, Bireme, Scielo, Lilacs, Acervo mais e Google Acadêmico, com os Descritores em Ciência da Saúde: Oral Health, Pregnancy e Embryonic and Fetal Development. Foi filtrada por ano de publicação: 2016 a 2020, e língua: inglês, português e espanhol. Ainda, por se tratar de uma pesquisa que utiliza exclusivamente textos científicos para revisão da literatura científica, não precisa de prévia autorização em qualquer comitê de ética, respaldada pelo parágrafo único do Art $1^{\circ}$ da resolução $510 / 2016$, resolvida pela Comissão Nacional de Ética em Pesquisa (CONEP), do Conselho Nacional de Saúde (CNS).

\section{REVISÃO BIBLIOGRÁFICA}

A busca feita com os descritores, e filtrada com os requisitos pré-estabelecidos, resultou em uma amostragem de 18 artigos. É necessário destacar que alguns desses repositórios não apresentaram resultados satisfatório para a busca e pré-filtragem, seja por acervo antigo, anterior a 2016, ou por não possuir trabalho relacionado ao tema. 
Diversas alterações da saúde oral de gestantes foram frequentemente relatadas, como: mudanças nas glândulas salivares, hiperplasia gengival, granulomas piogênicos, gengivite, cárie dentária e doenças periodontais relacionadas (SILVA PA e QUEIROZ JAS, 2017) Contudo, algumas como: as cáries e possíveis doenças periodontais não estão totalmente relacionadas aos componentes fisiológicos da gestação, mas, principalmente, à má higiene oral, hábitos de alimentação inadequados, composta em sua maioria por carboidratos e doces, bem como a maior frequência das refeições, quadro comum na gestação (DELGADO $\mathrm{JA}$, et al.,2018). As demais mudanças como a hiperplasia, alterações morfológicas e funcionais ocorrem prioritariamente pela nova regulação hormonal e atuais necessidades corporais (PEREIRA RPAR, 2018).

Ainda, embora faltem evidências, resultados preliminares mostram que é possível que a doença periodontal, assim como outras alterações como as cáries dentárias, provoque prematuridade e baixo peso ao nascer através de bactérias que liberam mediadores inflamatórios locais e sistêmicos, que, de forma direta ou indireta, podem afetar o desenvolvimento de anexos embrionários e do embrião ou feto propriamente dito. Ainda, tem se mostrado que o melhor momento para possíveis intervenções odontológicas é o segundo trimestre, pois há menor risco de complicações maternas e para o concepto (PEREIRA RPAR, 2018; SILVA LG, et al., 2020).

Ademais, um olhar interprofissional tem sido relatado como um dos fatores de grande auxílio na epidemiologia dessas alterações. O correto acompanhamento pré-natal, médico e odontológico, foi relatado como um dos fatores que mais contribuem para um bom prognóstico (SILVA LG, et al., 2020).

Figura 1 - Alterações gestacionais e consequências fetais

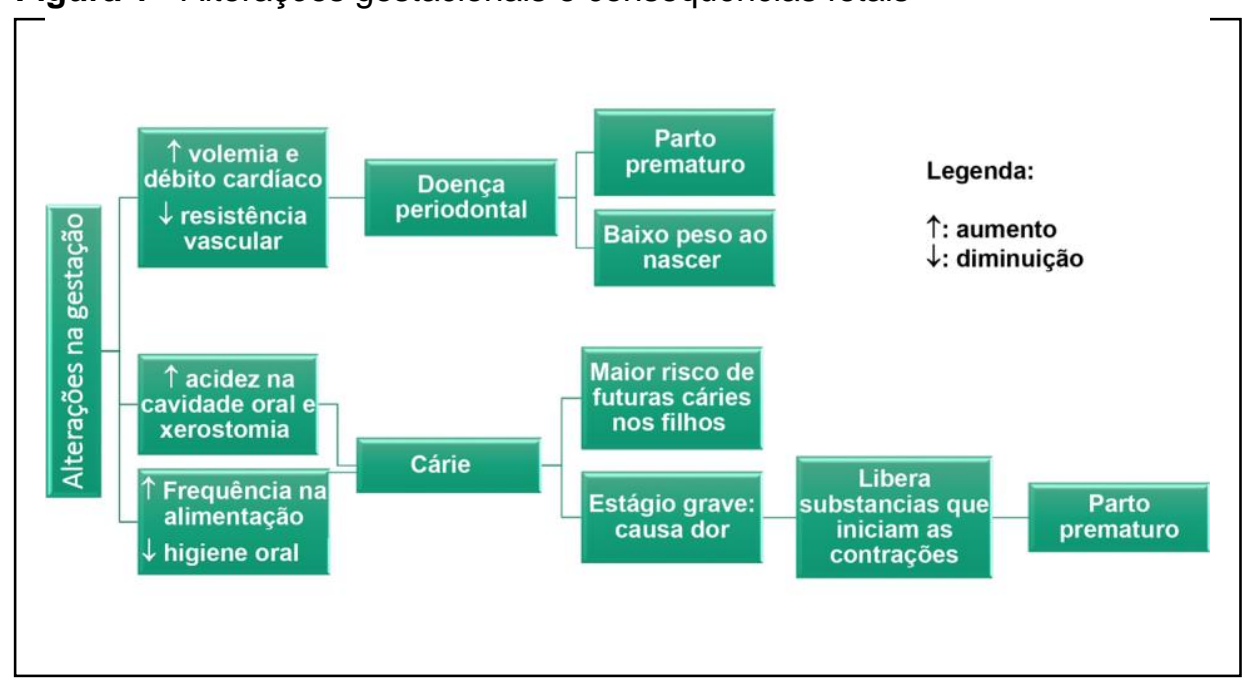

Fonte: OLIVEIRA IP, et al., 2020.

\section{DISCUSSÃO}

Na contemporaneidade, há mitos que envolvem a saúde bucal das gestantes. Devido a isso, muitas grávidas evitam procedimentos odontológicos por medo de gerar algum dano ao feto. Todavia, devido às alterações hormonais e fisiológicas que acompanham a gestação, a mulher fica mais suscetível às perturbações orais, tais como a periodontites. Logo, existem fortes evidências que relacionam a doença periodontal com prematuridade e baixo peso ao nascer, sendo assim, essencial a atenção odontológica na gravidez (MATSUBARA AS, DEMETRIO ATW, 2017).

Contudo, estudos apontam que as gestantes de consultórios particulares geralmente são mais orientadas a respeito desse processo do que as pertencentes ao Sistema Único de Saúde (SUS). Portanto, é indubitável que novas pesquisas sejam feitas a fim de desmistificar o tratamento odontológico na gestação. Ainda, 
equipes multiprofissionais, por meio de cartilhas e cartazes, devem viabilizar o acesso as informações ao grupo de gestantes pertencentes ao SUS (MARTINS WLL, et al., 2019).

\section{CONSIDERAÇÕES FINAIS}

São muitas as crenças errôneas enraizadas na população acerca da assistência odontológica na gravidez, embasadas na falta de informação. Devido a isso, concluímos que a desinformação é o principal empecilho para que as gestantes façam um pré natal odontológico e se previnam das possíveis consequências de uma má higiene oral. Por tudo, enfatizamos a importância de uma maior inserção de todo o corpo profissional de saúde bucal, nos trabalhos multi e interprofissional nos postos de saúde, trabalhando simultaneamente com o pré natal médico. Assim, essas mulheres terão um maior acesso às informações e possibilidades de prevenir possíveis agravos.

\section{REFERÊNCIAS}

1. DELGADO JA, et al. A relação da doença periodontal com o parto prematuro. Revista da AcBO, 2018; $8(1)$.

2. GUPTA N, CHHETRY M. Knowledge and Practices of Pregnant Women regarding Oral Health in a Tertiary Care Hospital in Nepal. Journal of the Nepal Medical Association, 2019; 57(217).

3. MATSUBARA AS, DEMETRIO ATW. Atendimento odontológico às gestantes: revisão da literatura. Revista Uningá Review, 2017; 29(2).

4. MARTINS WLL, et al. Conhecimentos de gestantes sobre sua saúde bucal e a do bebê. Revista Uningá, 2019; 56 (2): 22-33.

5. PEREIRA RPAR. Implicações da gravidez na cavidade oral: alterações salivares e correlação com a incidência de cárie dentária, 2018.

6. SILVA CCD, et al. Acesso e utilização de serviços odontológicos por gestantes: revisão integrativa de literatura. Revista Ciência \& Saúde Coletiva, 2020; 25(3): 827-835.

7. SILVA PA, QUEIROZ JAS. Percepções de gestantes sobre atenção odontológica durante a gravidez e cuidados com a saúde bucal, 2017. 
RESUMOS EXPANDIDOS: Revisão Bibliográfica

Título: A vulnerabilidade dos imigrantes venezuelanos em meio à pandemia da COVID-19 em Boa Vista-RR

Autor/coautores: Emanuelly Leite Soares; Mariana de Souza Oliveira; lara Leão Luna de Souza; lara de Melo Resende Veras; Bruno Rafael Moreira Gondim.

Instituição: Universidade Estadual de Roraima (UERR), Boa vista-Roraima/ Univerisdade Federal de Roraima (UFRR), Boa Vista-Roraima.

Palavras-chave: COVID-19, Venezuelanos, Vulnerabilidade.

\section{INTRODUÇÃO}

A nova variante do coronavírus SARS-CoV2, agente etiológico da COVID-19, tem sido destaque por conta dos elevados impactos que causa na saúde pública, além dos inúmeros casos quantificados em um curto período de tempo. A transmissão entre humanos acontece pela contaminação de secreções respiratórias, gotículas ou da presença do vírus em fômites, seguido pelo contato com as mucosas da boca, nariz ou olhos (PIMENTEL RMM, et al., 2020).

Uma das principais medidas de contenção da COVID-19 é a restrição de contato social. Entretanto, observa-se a dificuldade do isolamento social nas populações refugiadas. Assim, a situação dos venezuelanos que habitam abrigos lotados ou moradias improvisadas no estado de Roraima, aliadas às condições ruins de higiene são fatores que dificultam esse isolamento social, tornando-os ainda mais vulneráveis à pandemia causada pelo novo coronavírus. Apesar disso, a Agência da Organização das Nações Unidas (ONU) para Refugiados (ACNUR) juntamente com a Operação Acolhida desenvolveu políticas em Roraima com o objetivo de auxiliar na proteção dos imigrantes, especialmente durante a pandemia (ACNUR, 2020). Ademais, esse estado continua sendo um dos que menos está aderindo ao decreto de isolamento social, ressaltando a importância da discussão do tema que pode gerar inúmeras consequências à população local.

\section{OBJETIVO}

Revisar a situação de vulnerabilidade dos imigrantes venezuelanos em meio à pandemia do novo coronavírus na cidade de Boa Vista, e os planos traçados na tentativa de reduzir os impactos gerados pelo vírus.

\section{REVISÃO BIBLIOGRÁFICA}

Os fluxos migratórios sempre estiveram presentes no contexto mundial, e o Brasil, devido à localização geográfica e às oportunidades no mercado de trabalho, recebe, há anos, um número grande de estrangeiros, dificultando o isolamento social (PATARRA NL, FERNANDES D., 2011).

Em meio à pandemia, a Operação Acolhida, traçou um Plano Emergencial de Contingenciamento para a COVID-19 com o intuito de estabelecer normas gerais de ação para prevenção, controle e tratamento de infecções pelo novo coronavírus (BRASIL, 2020a).

Nesse plano, buscava-se a comunicação com a população assistida para que se combata a desinformação e negligência de possíveis casos suspeitos, ou seja, pessoas com sintomas de febre acima de $37,8^{\circ}$, tosse, dor de garganta e dificuldade de respiração, além de melhores condições sanitárias e hábitos de higiene. Ademais, o ACNUR juntamente com outras agências da ONU e a sociedade, que já desempenham atividades nos abrigos, trabalham para que se aumente a conscientização da população abrigada com relação ao 
autoisolamento, limitação de movimentos interno e externos, limpeza de áreas comuns e desinfecção das áreas de dormir diariamente (ACNUR, 2020).

Adicionalmente, a Operação Acolhida conta com o auxílio de trabalhadores venezuelanos e brasileiros na construção do hospital temporário para o tratamento contra a COVID-19 na capital de Roraima, Boa Vista e, muitos venezuelanos revelaram a satisfação em contribuir para ajudar os conterrâneos e os brasileiros que $o$ acolheram, além de ser fonte de renda em meio às incertezas econômicas decorrentes dessa pandemia. Essa construção de suporte hospitalar momentâneo se torna mais importante pelo atual cenário do Estado de Roraima que, mediante o boletim epidemiológico, até o dia 18 de junho de 2020, notificou 13.999 casos para a COVID-19. Destes casos, 7.650 foram confirmados dos quais 5.625 representam a população contaminada da capital Boa Vista (BRASIL, 2020b).

\section{DISCUSSÃO}

No contexto da pandemia causada pelo Sars-CoV-2, a transmissibilidade da COVID-19 se destaca ainda mais devido à quantidade de pessoas que vivem reunidas em abrigos e em outras ocupações não respeitando 0 isolamento social indicado pelas autoridades. Nesse cenário, destaca-se Roraima que se enquadra em situação de emergência devido às altas demandas nos serviços de saúde pelos imigrantes venezuelanos. Ressalta-se que ocorreu o fechamento inicial da fronteira com a Venezuela, atendendo ao pedido da Associação Médica Brasileira. No entanto, o pedido não levava em conta o bem estar dos migrantes e refugiados, conforme a Lei de Migração (Lei no 13.445/2017) (PÊGO B, et al., 2020).

A preservação da saúde pública frente ao coronavírus deve sempre conservar os Direitos Humanos dos refugiados. Nesse sentido, como estratégia viável mediante o combate a COVID-19, buscou-se a construção de um hospital de campanha na capital Boa Vista pela Operação Acolhida, atendendo também aos refugiados.

\section{CONSIDERAÇÕES FINAIS}

O momento vivenciado demonstrou que a falta de cuidados com a higiene e as aglomerações sociais, especificamente, no caso dos imigrantes venezuelanos, aparecem como os principais mecanismos que facilitam a disseminação do vírus e, portanto, necessitam de medidas urgentes. Logo, o plano contingencial desenvolvido pela Operação Acolhida e as ações conjuntas com a ACNUR foram benéficas não apenas para os imigrantes venezuelanos, mas para toda população roraimense. Por fim, nesse período pandêmico, a aliança entre as instituições, autoridades e a própria população são essenciais para que se reduza a transmissão e os impactos do novo conronavírus.

\section{REFERÊNCIAS}

1. AGÊNCIA DA ONU PARA REFUGIADOS (ACNUR), COVID-19: ACNUR e parceiros apoiam refugiados e comunidades de acolhida na emergência. 2020.

2. BRASIL. MINISTÉRIO DA SAÚDE. Operação Acolhida. Plano Emergencial de Contingenciamento para COVID-19. 2020a.

3. BRASIL. SECRETARIA DE ESTADO DA SAÚDE DE RORAIMA (SESAU). Boletim Epidemiológico no 138. 2020b.

4. PATARRA NL, FERNANDES D. Brasil: país da imigração?. Revista Internacional em Língua Portuguesa: Migrações, 2011; 3(24): 360-415.

5. PÊGO B, et al. Pandemia e fronteiras brasileiras: análise da evolução da COVID-19 e proposições. Nota técnica projeto "A política nacional de desenvolvimento regional (PNDR) e a faixa de fronteira" - Instituto de Pesquisa Econômica Aplicada (IPEA). Brasília: IPEA; 2020; n16: 68p.

6. PIMENTEL RMM, et al. A disseminação da covid-19: um papel expectante e preventivo na saúde global. Journal of Human Growth and Development. 2020; 30(1): 135 -140. 
RESUMOS EXPANDIDOS: Revisão Bibliográfica

Título: Acidente vascular cerebral como complicação em pacientes com covid-19: uma revisão da literatura

Autor/coautores: Isabela Bahia Ferreira; Aline Cordeiro Lins de Oliveira Costa; Ana Carla Araújo Paiva; Rodrigo Moreira Faleiro.

Instituição: Universidade Federal de Minas Gerais (UFMG) - Belo Horizonte - Minas Gerais.

Palavras-chave: AVC, COVID-19, SARS-CoV-2.

\section{INTRODUÇÃO}

Desde dezembro de 2019, a doença do novo Coronavírus (COVID-19), causada pelo vírus SARS-CoV-2, tornou-se uma importante preocupação mundial, impulsionando milhares de estudos científicos a fim de melhor elucidar os seus diferentes aspectos, bem como possíveis complicações para além do sistema respiratório. Nesse contexto, embora ainda haja muitas dúvidas acerca da ação do vírus e da sua patogênese, os efeitos sistêmicos da COVID-19 foram confirmados por estudos recentes que atestaram a presença do vírus em múltiplos órgãos, prejudicando a funcionalidade destes e do organismo como um todo (ZHAO Y, et al., 2020). Dessa maneira, uma possível complicação que tem sido notificada e estudada é a ocorrência do acidente vascular cerebral (AVC) em pacientes infectados pelo SARS-CoV-2. Esta e outras diferentes manifestações da doença são um desafio atual para os médicos e para a comunidade científica no mapeamento dos riscos de cada paciente e na busca por soluções preventivas e terapêuticas deste quadro clínico.

\section{OBJETIVO}

Realizar uma revisão da literatura acerca dos efeitos do novo coronavírus na geração de danos ao endotélio e de fenômenos protrombóticos, estabelecendo uma relação entre estes quadros e a ocorrência de AVC em pacientes infectados pelo vírus.

\section{MÉTODO}

Para conduzir esta revisão foram usadas as strings de busca a seguir: acidente vascular cerebral, coronavírus, COVID-19, coagulopatia e SARS-CoV-2. Estas palavras-chaves foram definidas utilizando o método PICO, sendo assim foram selecionadas e analisadas cinco referências para a pesquisa de evidências e a realização de uma revisão sistemática da literatura de maneira imparcial e criteriosa. Esta revisão da literatura foi realizada a partir das bases de dados online como PubMed, Nature, ResearchGate e BMJ Journals. As fontes selecionadas seguiram os seguintes critérios: foram publicadas no ano de 2020 , sendo que todas são estudos de origem internacional.

\section{REVISÃO BIBLIOGRÁFICA}

Com os muitos estudos que estão sendo realizados sobre o Sars-CoV-2, diversas descobertas essenciais foram obtidas, permitindo um melhor entendimento sobre esse vírus. Um dos aspectos elucidados foi o seu meio de entrada no organismo, por onde a sua proteína de ligação se conecta, que foi descoberto como sendo a enzima conversora de angiotensina 2 (ECA2) expressa nos pulmões, o que permite a invasão das células epiteliais alveolares e resulta nos sintomas respiratórios LAN J, et al. (2020). Tal relação com a ECA2 explica como o SARS-CoV-2 pode gerar complicações não apenas respiratórias, mas também sistêmicas, uma vez que a enzima pode ser encontrada nas células endoteliais de artérias e veias e em células musculares lisas de múltiplos órgãos (ZHAO Y, et al. (2020). 
Um estudo retrospectivo (TANG N, et al. 2020) observou que pacientes com COVID-19 não sobreviventes apresentavam altos níveis de D-dímero e de produtos de degradação de fibrina (PDF), associados ainda a elevados tempos de protrombina e de trombroplastina parcial ativada, configurando o quadro de coagulação intravascular disseminada (CID) em $71,4 \%$ dos que foram a óbito. Já nos sobreviventes, o estudo mostrou que apenas um deles $(0,6 \%)$ apresentou CID durante a permanência no hospital, sugerindo uma relação entre parâmetros anormais de coagulação a um pior prognóstico.

Foi possível, ainda, observar relação da COVID-19 com o desenvolvimento de complicações vasculares e neurológicas, em que, de 214 pacientes com COVID-19 analisados, 36,4\% (78) apresentaram sintomas que incluíam cefaleia, distúrbios de consciência e acidente vascular cerebral (AVC) (MAO L, et al. 2020).

Corroboram-se, ainda, altos níveis de proteína C reativa e de D-dímero, indicando um estado próinflamatório e anormalidades na cascata de coagulação, que podem atuar na fisiopatologia do AVC associado ao COVID-19, visto que parte dos pacientes evoluem com AVC isquêmico e hemorragia intracerebral (LI Y, et al. 2020).

\section{DISCUSSÃo}

Nesse contexto, a associação do vírus com receptores de ECA2 (LAN J, et al., 2020) mostra-se importante para relacionar a COVID-19 com efeitos sistêmicos. Trata-se de uma enzima amplamente presente no miocárdio e nas células epiteliais dos vasos sanguíneos (ZHAO Y, et al., 2020), onde o vírus invade causando inflamação e lesão miocárdica, predispondo à ocorrência de trombogênese e AVC (LI Y, et al., 2020).

Os resultados observados (TANG N, et al., 2020) corroboram a CID, confirmando a disfunção endotelial vascular e coagulopatias em pacientes infectados com SARS-CoV-2.

Todo este quadro gera um cenário favorável à formação de êmbolos que, quando alojados em artérias cerebrais, causam AVC, podendo desencadear sequelas neurológicas e até óbito.

Apesar de ser possível estabelecer relação entre a infecção pelo novo coronavírus e fenômenos protrombóticos que corroboram AVC, ainda são necessários mais estudos com escopo de melhor elucidar o mecanismo pelo qual o vírus gera CID.

\section{CONSIDERAÇÕES FINAIS}

Em suma, deve-se considerar o AVC como uma possível complicação da COVID-19, haja vista o quadro de disfunção endotelial e inflamação vascular e miocárdica gerados pelo vírus por meio da ECA2. Tais fatores podem, assim, desencadear coagulação intravascular disseminada, fator predisponente à formação de trombos e êmbolos passíveis de ocluírem artérias cerebrais, causando o AVC (TANG N, et al., 2020). Nesse sentido, é essencial que o médico em questão esteja atento a cada caso individualmente, avaliando comorbidades preexistentes e o processo de desenvolvimento da doença no paciente.

\section{REFERÊNCIAS}

1. LAN J, et al. Structure of the SARS-CoV-2 spike receptor-binding domain bound to the ACE2 receptor. Nature 2020; 581, 215-220.

2. LI Y, et al. Acute cerebrovascular disease following COVID-19: a single center, retrospective, observational study. Stroke \& Vascular Neurology, 2020; svn-2020-000431.

3. MAO L et al. Neurological manifestations of hospitalized patients with covid-19 in wuhan, china: a retrospective case series study. JAMA Neurology, 2020;77(6):683-690. 
4. TANG N, et al. Abnormal coagulation parameters are associated with poor prognosis in patients with novel coronavirus pneumonia. Journal of Thrombosis and Haemostasis, 2020;18:844-847.

5. ZHAO Y, et al. Single-cell RNA expression profiling of ACE2, the putative receptor of Wuhan 2019-nCov. bioRxiv. 2020. Preprint. 
RESUMOS EXPANDIDOS: Relato de Experiência

Título: Prevenção de Trauma Cranioencefálico e Raquimedular entre crianças de 8 a 14 anos em escolas públicas municipais

Autor/coautores: Daniel Meira Nóbrega de Lima; Kamilla Priscila Coelho da Costa; Natalia Paiva Lima; Renata Maria Santos de Freitas; Maurus Marques de Almeida Holanda.

Instituição: Universidade Federal da Paraíba, João Pessoa - Pernambuco.

Palavras-chave: Extensão comunitária, Prevenção de acidentes, Trauma.

\section{INTRODUÇÃO}

Sabe-se que o trauma é uma das principais causas de morte e de lesões permanentes em crianças e adolescentes no mundo. No Brasil, constitui-se a principal causa de morte em crianças acima de cinco anos de idade e responsável por mais de 50\% dos óbitos na adolescência (MAGALHÃES AL, et al., 2017).

O traumatismo cranioencefálico (TCE) eo raquimedular (TRM) estão presentes na maioria das crianças vítimas de trauma e é responsável por mais de $75 \%$ das mortes na infância. Crianças que sofrem TCE ou TRM grave necessitam de internação prolongada e monitorização de sinais vitais realizada em Centros de Terapia Intensiva (CTI), com alta mortalidade e morbidade, além de gerar um elevado custo financeiro (TEHERAN AA, et al., 2016).

Dessa forma, visando a redução dos traumas, deve-se atuar sobre os fatores de risco, além de melhorar a qualidade de vida dos que já passaram pela afecção. O que traz benefícios a população e resulta em menos custos e comorbidades tanto para o indivíduo com para o sistema de saúde (ACCIOLY MA, et al., 2017).

\section{OBJETIVO}

Informar sobre a prevenção do Trauma Cranioencefálico (TCE) e Trauma Raquimedular (TRM), bem como instruir acerca das suas principais causas, mecanismos fisiopatológicos e biomecânicos, inseridos dentro do contexto vivenciado pelos participantes.

\section{RELATO DE EXPERIÊNCIA}

Após o consentimento, foram aplicados questionários com os alunos e profissionais da escola, a fim de compreender o grau de informação sobre o tema, bem como, as peculiaridades da patologia nesse território. A partir das situações elencadas da faixa etária, do contexto socioeconômico e cultural, construímos os pilares da prevenção em TCE e TRM.

Os universitários participantes do projeto conseguiram assimilar os conceitos básicos referentes à trauma cranioencefálico e raquimedular. Além disso, os extensionistas, durante o convívio com os alunos da rede pública, observaram e compreenderam os determinantes em saúde associados aos eventos traumáticos.

Percebeu-se também a conquista de ferramentas linguísticas e didáticas adequadas à comunicação efetiva com a faixa etária pediátrica. Assim, verificou-se através dos discursos obtidos em reuniões, que os estudantes universitários desenvolveram conhecimentos acerca do tema central do projeto, mas também acerca de práticas de observação e interação com a população em geral.

Notou-se uma subestimação entre a população pelas medidas simples e condutas rotineiras, como o uso do cinto de segurança no trânsito e do celular ao volante; assim como a perpetuação de atitude de risco. Compreende-se que essas ações possuem alto impacto e relevância, ademais contribuem no crescente número de acidentes com repercussões neurológicas. 
Aferiu-se uma ampliação do conhecimento da população acerca dos fatores de risco, das principais causas e como evita-las, atingindo não só os estudantes participantes, como também familiares, vizinhança, alcançando de forma mais ampla a escola, a comunidade.

Ademais, percebeu-se uma maior co-responsabilização e autonomia dos participantes para com suas atitudes, repercutindo em suas ações na escola, casa e ambientes recreativos.

\section{DISCUSSÃO}

A conscientização e o oferecimento de aparato informativo à indivíduos, desde a infância, é de vital importância para que se firme uma comunidade envolvida e co-responsável na segurança e bem-estar geral. Em se tratando de saúde, apresentar temas à população - no presente projeto, a população pediátrica - pode envolver determinado nível de complexidade, principalmente ao serem levados em conta aspectos socioeconômicos e culturais (SILVA KL, et al., 2018). Apesar de não conseguirmos estatisticamente, mensurar o real impacto na diminuição dos acidentes, incentivamos a continuação da intervenção, a realização de estudos prospectivos que possam averiguar o impacto nessa comunidade. Foi relatado a continuidade da abordagem desses temas pelos profissionais e educadores dessas escolas, uma vez a necessidade da construção contínua de responsabilização e conscientização das medidas acerca dessas afecções, permitindo um diálogo entre os extensionistas com os profissionais da escola e uma reverberação do conhecimento, como demonstrado por outros estudos (ACCIOLY MA, et al., 2017).

\section{CONSIDERAÇÕES FINAIS}

A conscientização e o oferecimento de aparato informativo à indivíduos, desde a infância, é de vital importância para que se firme uma comunidade envolvida e co-responsável na segurança e bem-estar geral. Em se tratando de saúde, apresentar temas à população - no presente projeto, a população pediátrica - pode envolver determinado nível de complexidade, principalmente ao serem levados em conta aspectos socioeconômicos e culturais.

Dessa forma, entendemos a necessidade de continuar esse projeto e assim, uma conscientização de toda uma geração, objetivando adultos mais responsáveis, além de impedir o processo de adoecimento.

\section{REFERÊNCIAS}

1. ACCIOLY M., et al. Neurotrauma: prevenção realizada pelo Núcleo de Estudos Acadêmicos em Neurocirurgia. Revista Ciência em Extensão, 2017; 13(3): 64-76.

2. MAGALHÃES A., et al. Epidemiologia do Traumatismo Cranioencefálico no Brasil. Revista Brasileira Neurologia, 2017; 53(2): 15-22.

3. SILVA K., et al. Projeto Neurotrauma: Educar para prevenir - o melhor tratamento. Revista Ciência em Extensão, 2018; 14(1): 70-82.

4. TEHERAN A., et al. Incidencia y características del trauma raquimedular em um hospital de III nível, Bogotá 2011-2014. Panam. J. Traum. Crit. Care Emerg. Cir., 2016; 5(3): 140-147. 
RESUMO EXPANDIDO: Revisão Bibliográfica

Título: Como Conduzir o Primeiro Atendimento aos Pacientes Vítimas de Queimaduras

Autor/Coautores: Letícia Aparecida da Silva; Luiza Helena Santos Giorni; Juliana Aparecida Rezende; Gustavo Henrique Pedroso; Poliana Aparecida Ferreira.

Instituição: Centro Universitário Atenas (UniAtenas), Paracatu-Minas Gerais.

Financiamento: Não Possui.

Palavras-chave: Queimadura, Primeiro Atendimento.

\section{INTRODUÇÃO}

Queimaduras são lesões de tecidos orgânicos produzidas, principalmente, por traumas de origem térmica, podendo também ser causadas por outras etiologias como: radiação, eletricidade e compostos químicos. A gravidade do ferimento é influenciada diretamente pela profundidade da lesão e do número de camadas acometidas da pele e de outras estruturas subjacentes (DIAS LDF, et al., 2015).

Avalia-se que no Brasil aconteça em torno de um milhão de incidentes envolvendo queimaduras ao ano, sendo que apenas cem mil pacientes buscam atendimento hospitalar e, deste valor, cerca de dois mil e quinhentos irão a óbito por razão direta ou indireta em função de lesões (BRASIL, 2017).

As queimaduras são consideradas um importante problema de saúde pública por gerarem inúmeras complicações físicas aos indivíduos, sendo capazes de levar o paciente a danos de ordem psicológica e social, podendo ainda ocasionar a morte. Além dos cuidados imediatos, as queimaduras geralmente requerem tratamento em longo prazo com inúmeras visitas ambulatoriais, múltiplos procedimentos cirúrgicos reconstrutivos e longas internações hospitalares.

\section{OBJETIVO}

Revisar como deve ser feito os primeiros atendimentos aos pacientes queimados, a fim de reduzir possíveis complicações e sequelas, além de melhorar a qualidade de vida desses indivíduos. Concomitante a isso, objetiva-se analisar os melhores e mais recentes tratamentos para as queimaduras.

\section{MÉTODO}

Trata-se de um trabalho de revisão literária sistemática constituída com base em artigos científicos acerca da temática "primeira assistência ao paciente queimado". Para isso, utilizaram-se como fonte de pesquisa as bases de dados: PubMed, Medline e SciELO. Os critérios de inclusão foram artigos publicados em português e inglês dos últimos cinco anos que abordassem a temática.

\section{REVISÃO BIBLIOGRÁFICA}

$\mathrm{Na}$ contemporaneidade, entende-se que o primeiro atendimento ao paciente queimado deve ser rápido e dinâmico a fim de evitar sequelas e, para isso, faz-se necessário a assistência de uma equipe preparada e a presença de insumos hospitalares. Para a realização do primeiro atendimento ao paciente queimado, devese analisar a aplicação de cinco pilares.

O primeiro pilar do primeiro atendimento ao paciente queimado consiste na aplicação de curativos que são capazes de promover a revitalização e prevenir a infecção, além de evitar a perda de água e calor para o meio, mantendo a ferida sempre úmida. 
Por conseguinte, deve-se realizar o controle da infecção objetivando prevenir a sepse, responsável pela causa mais prevalente de morte após lesão por queimadura, correspondendo entre 75 e $85 \%$ dos óbitos. É comprovado que se os pacientes sobreviverem às primeiras 72 horas após lesão por queimadura, a causa mais comum de morte são as infecções, sendo a pneumonia associada ao ventilador a mais prevalente delas (LIU HF, et al., 2017).

O terceiro item é a ressuscitação de fluídos. À medida que o tamanho da queimadura se aproxima de 15 a $20 \%$ do acometimento da superficial corporal, o choque hipovolêmico é extremamente comum (LIU HF, et al., 2017).

O quarto ponto a ser considerado é a possibilidade de excisão da área queimada, uma prática benéfica para a redução da mortalidade em pacientes que não tiveram lesão por inalação.

O último pilar diz respeito ao uso de substitutos de pele para a reconstrução da área lesada, um método que além de restaurar o local da lesão, é também de extrema importância para conservar a saúde mental do paciente, uma vez que o indivíduo se sente mais confiante ao visualizar a presença da reconstrução na área queimada (LIU HF, et al., 2017).

\section{DISCUSSÃO}

Baseado na realização dos cinco pilares, um estudo transversal exploratório descritivo mostrou que as maiores dificuldades encontradas pelos internos de medicina no momento do atendimento inicial ao paciente queimado são cálculo do volume de hidratação e forma de distribuição do volume de hidratação em 24 horas. Esse mesmo estudo revelou 48,12\% acertaram o item sobre correta prescrição de antibioticoprofilaxia sistêmica (CUNHA LVT, et al., 2016). Outro estudo realizado na Unidade de Tratamento de Queimaduras do Hospital São Paulo observou um total de 114 procedimentos cirúrgicos em vítimas de queimaduras do segundo grau entre os anos de 2009 e 2012 (DIAS LDF, et al., 2015). Contudo, percebe-se que o número de estudos acerca do manejo do paciente vítima de queimaduras ainda é pequeno. Dessa forma, é notório a necessidade estudos observacionais a fim de nortear profissionais de saúde sobre como conduzi-los da melhor maneira.

\section{CONSIDERAÇÕES FINAIS}

As queimaduras estão entre os traumas de maior gravidade. Além dos problemas físicos que podem evoluir até à morte do paciente, ela é também capaz de acarretar outros problemas de ordem psicológica e social. No Brasil, os dados estatísticos sobre as lesões por queimaduras ainda são escassos. Contudo, esses dados são importantes para que se possa compreender a magnitude do problema e identificar as populações mais atingidas, assim como as circunstâncias nas quais as queimaduras ocorrem, de forma que seja possível implementar programas de prevenção.

\section{REFERÊNCIAS}

1. CUNHA LVT, et al. Atendimento inicial ao paciente queimado: avaliação do conhecimento de alunos do internato do curso de medicina. Revista Brasileira de Queimaduras, 2016; 15(2):80-6.

2. DIAS LDF, et al. Burn Care Unit of São Paulo Federal University: an epidemiological profile. Rev. Bras. Cir. Plást, 2015; 30(1):86-92.

3. LIU HF, et al. History and Advancement of Burn Treatments. Anaals of Plastic Surgery, 2017; 78(1):5258.

4. BRASIL. MINISTÉRIO DA SAÚDE. Queimados. 2017.

5. SMOLLE C, et al. Recent Trends in Burn Epidemiology Worldwide: A Systematic Review. Burns, 2017; 43(2): 249-257. 
RESUMOS EXPANDIDOS: Revisão Bibliográfica

Título: Panorama da violência contra as mulheres: Uma revisão da literatura

Autor/coautores: Milena Amaral Melo; Brenda de Brito Peito; Gabriela Lamego; Rafael Andrés Patino.

Instituição: Universidade Federal do Sul da Bahia - UFSB, Teixeira de Freita - Bahia; Universidade Federal da Bahia - UFBA, Salvador - Bahia

Palavras-chave: Violência, Mulheres, Gênero.

\section{INTRODUÇÃO}

Partimos do entendimento de violência contra a mulher como qualquer ação ou conduta, baseada no gênero, que cause morte, dano/sofrimento físico, sexual ou psicológico ao outro (que aqui, será restrito às pessoas que se identificam como mulheres), tanto no âmbito público como no privado (SILVA CR, 2018). Dessa forma, compreendendo a magnitude dessa problemática, o Brasil é signatário de convenções internacionais que a reconhece como uma violação dos direitos humanos, assumindo assim o compromisso perante a comunidade internacional de criar mecanismos capazes de coibir a discriminação e a violência que as mulheres são vítimas. Entretanto, este cenário ainda parece distante, visto que o Brasil foi considerado no ranking mundial, $05^{\circ}$ lugar onde mais mulheres são assassinadas, de acordo com o mapa da violência de 2015. Neste mesmo período, houve um aumento nas taxas de violências, e esse crescimento resultou em $22 \%$ da mortalidade de mulheres negras (IPEA,2015). Esses dados apontam que apesar da compreensão que a violência contra as mulheres se faz presente em todas as classes sociais, é importante ressaltar que existem grupos sociais/raciais mais vulneráveis.

\section{OBJETIVO}

Revisar as principais produções para a compreensão do panorama da violência contra as mulheres no Brasil e suas diferentes expressões a partir da naturalização estrutural e relações desiguais de gênero.

\section{MÉTODO}

Foi realizada uma revisão da literatura em torno da temática no Portal de Periódicos da CAPES. A busca, foi realizada a partir dos descritores: trauma social, violência de gênero, violência contra mulher, abuso contra mulher e sofrimento psíquico; sendo utilizado o operador booleano AND. Diante dos resultados, foram estabelecidos critérios de inclusão, sendo eles: artigos científicos disponíveis eletronicamente e na íntegra no idioma português, que tratassem de aspectos relacionados à temática abordada; e critérios de exclusão: estudos que não atendiam aos critérios de inclusão estabelecidos e repetições. A partir disso, foram selecionados 20 artigos que, após a leitura dos resumos e artigo completo, passaram a constituir o corpus deste estudo.

\section{REVISÃO BIBLIOGRÁFICA}

No Brasil, uma pesquisa constatou que $43 \%$ das mulheres já sofreram algum tipo de violência sexual, sendo que mais de $50 \%$ não pediram ajuda e, em $53 \%$ dos casos, os maridos e parceiros foram os agressores. $O$ estudo aponta, ainda, que uma em cada cinco brasileiras declara espontaneamente já ter sofrido algum tipo de violência masculina e que a cada 15 segundos, uma mulher é espancada (BRILHANTE AVM, et al., 2016). Pesquisa realizada em Salvador, a partir da análise de 326 boletins de ocorrência, identificou que a média de idade das denunciantes é 30 anos e que são majoritariamente pardas, residentes em bairros populares e baixa escolaridade. Além disso, evidenciou a face como local de maior incidência de lesões provocadas pelos agressores, o que poderia indicar uma forma de demonstração de poder sob o corpo feminino. Um ponto 
destacado foi que essa análise se deu apenas com mulheres que recorreram à instituição para denúncia, podendo ser indicativo que o número é maior diante do grupo de mulheres que estão em situação de violência e não realizam denúncia (DOURADO SZ e NORONHA SV, 2015).

Alguns motivos para mulheres permanecerem no relacionamento violento foram identificados, como: vulnerabilidade social, baixa escolaridade, vida adulta precoce e reforço de estereótipos (DOURADO SZ e NORONHA SV, 2015). Para além disso, a falta de apoio e segurança, por parte dos equipamentos de proteção social, suficientes para mantê-la longe do agressor, pode dificultar o acesso dessas mulheres aos serviços impedindo que estratégias para o enfrentamento dessas violências sejam elaborados.

\section{DISCUSSÃO}

A violência contra as mulheres possui diferentes tipificações e adquire desdobramentos e implicações teóricas e práticas em função das condições e situações específicas. Nesse sentido, se apresenta como uma forma de legitimação de poder do homem sobre o corpo feminino (NETTO LA, et al., 2017). A dependência e rompimento de vínculos externos, afeta a subjetividade das mulheres em situação de violência, onde sua interação social é restrita atingindo as relações sociais. De modo geral, essa forma de controle masculino na sociedade atual reduzindo a autonomia feminina.

Este fenômeno constitui um problema relevante de saúde pública, uma vez que interfere diretamente na saúde física, mental e sexual das mulheres. As repercussões também afetam as esferas socioeconômica e nos judiciários (ACOSTA DF, et al., 2015). Sendo assim, o enfrentamento da violência contra as mulheres, demanda de esforços intersetoriais, constituindo-se um problema complexo devida fragmentação da rede de apoio e a não qualificação desses profissionais.

\section{CONSIDERAÇÕES FINAIS}

A violência e vulnerabilidade vivida pelas mulheres resultam em efeitos negativos em sua saúde física e psicológica. Sendo assim, o enfrentamento da violência demanda esforços coordenados e sistematizados de diversos setores governamentais, segmentos sociais e da sociedade civil. A mulher em situação de violência se encontra vulnerável por não possuir apoio e segurança social suficientes para garantir a sua integridade o que, por vezes, pode provocar ainda maiores dificuldades de acesso dessas mulheres aos serviços e impedir estratégias para o enfrentamento dessas violências sejam produzidas.

\section{REFERÊNCIAS}

1. ACOSTA DL, et al. Violence against women commited by intimate partners: (in)visibility of the problem. Rev. Texto \& Contexto - Enfermagem, 2015; 24: e1590.

2. BRILHANTE AVM, et al. Um estudo bibliométrico sobre a violência de gênero. Saúde Soc, 2016;3:e1290.

3. DOURADO SM; NORONHA CV. Marcas visíveis e invisíveis: danos ao rosto feminino em episódio de violência conjugal. Ciência e Saúde Coletiva, 2015; 9: e1413.

4. NETTO LA, et al. Isolation of women in situation of violence by intimate partner: a social network condition. Escola Anna Nery - Revista de Enfermagem, 2017;1:e1414.

5. SILVA CR. Violência de Gênero no Brasil e na América Latina: Um enfoque psicanalítico, a produção de conhecimento e perspectivas de enfrentamento. Rev. Bras. Psico. e Educ, 2018; 1: e30715. 
RESUMOS EXPANDIDOS: Relato de Experiência

Título: Determinantes em saúde na faixa pediátrica: um relato de experiência em escolas públicas

Autor/coautores: Daniel Meira Nóbrega de Lima; Natalia Paiva Lima; Renata Maria Santos de Freitas; Kamilla Priscila Coelho da Costa; Maurus Marques de Almeida Holanda.

Instituição: Universidade Federal da Paraíba, João Pessoa - Paraíba.

Palavras-chave: Extensão comunitária, Prevenção de acidentes, Trauma.

\section{INTRODUÇÃO}

Em um passado recente, outras intervenções sob o modelo de projetos de extensão têm sido realizadas em um número de instituições de ensino superior público com o objetivo de transmitir informações, promover mudança comportamental e conscientização de risco para a prevenção de traumatismo cranioencefálico (TCE) e trauma raquimedular (TRM) (GONÇALVES DV, et al., 2019). Como exemplo, há de se mencionar extensões realizadas pela Universidade Federal do Ceará (UFC) e pela Universidade Federal dos Vales do Jequitinhonha e Mucuri (UFVJM), nos anos de 2017 e 2018, respectivamente (ACCIOLY MA, et al., 2017; SILVA KL, et al., 2018).

A primeira, teve sua realização viabilizada por parceria com a Sociedade Brasileira de Neurocirurgia (SBN) e com o Departamento Estadual de Trânsito (DETRAN) do estado em questão, realizando campanhas para reduzir índices de acidentes automobilísticos; a segunda promoveu de forma bastante similar ao presente projeto de extensão, ações educativas tendo como população-alvo alunos de escolas públicas do município.

De modo comparativo, todos os projetos previamente mencionados tiveram como base, fundamentalmente, a conscientização de indivíduos acerca de riscos diários que normalmente não são levados em conta, ou mesmo, deixam de ser informados a eles.

\section{OBJETIVO}

Discutir com a comunidade, fatores de risco e determinantes em saúde, bem como fornecer ferramentas de proteção e prevenção, visando inserir o praticante como protagonista do seu cuidado. Dessa forma, participantes terão autonomia e serão co-responsáveis.

\section{RELATO DE EXPERIÊNCIA}

Alguns dos resultados obtidos nas extensões mencionadas anteriormente dizem respeito à subestimação que a população faz de medidas simples e condutas rotineiras, como o uso do cinto de segurança no trânsito e do celular ao volante; e, a perpetuação de atitude de risco é, sabidamente, um dos mais importantes e impactantes fatores que influenciam e contribuem no crescente número de acidentes com repercussões neurológicas.

A conscientização e o oferecimento de aparato informativo à indivíduos, desde a infância, é de vital importância para que se firme uma comunidade envolvida e co-responsável na segurança e bem-estar geral. Em se tratando de saúde, apresentar temas à população - no presente projeto, a população pediátrica - pode envolver determinado nível de complexidade, principalmente ao serem levados em conta aspectos socioeconômicos e culturais.

Por conseguinte, faz-se necessário uma abordagem realizada de forma clara, precisa e com uso de linguagem amplamente conhecida, utilizando recursos didáticos para tanto. Não obstante, é imprescindível manter um discurso com base em evidências científicas e dados de credibilidade. 
Em outras palavras, no foco do presente projeto esteve como constante a orientação e solução de dúvidas das crianças e profissionais da escola envolvidos, de modo que os universitários participantes do projeto como extensionistas solidificaram o conhecimento de que a conduta absoluta em termos de evitar TCE e TRM, é a prevenção da comunidade - promovendo autoproteção e agindo diretamente nos fatores mutáveis relacionados ao neurotrauma.

Além disso, foi possível realizar reuniões com os pais e mobilizar um evento, como uma caminhada, em prol, da conscientização da comunidade.

\section{DISCUSSÃO}

Observou-se que outros estudos obtiveram resultados semelhantes. $O$ alto indice de eventos traumáticos na infancia e adolescência, sendo evidenciado a porcentagem de $39,8 \%$ relacionados a traumas cranioencefálicos e $8 \%$ a traumas raquimedulares. Verificou-se também que os dados da literatura estão subestimados (AMORIM ES, et al., 2017), sendo necessário estudos coorte para averiguar a real associação dos fatores de risco e a incidência desses eventos, bem como estudos transversais visando determinar a prevalência do TCE e TRM na faixa pediátrica (ACCIOLY MA, et al., 2017). Os projetos de extensão devem ser estimulados, uma vez que os estudantes adquirem ferramentes neurolinguísticas e afetivas, assim como tornam-se influenciadores e disseminadores de conhecimento científico. Ademais, percebe-se uma transferência e contratransferência entre os estudantes do ensino fundamental e os estudantes universitários, pela identificação de suas realidades.

\section{CONSIDERAÇÕES FINAIS}

Conclusivamente, através de orientações comportamentais em cada uma das vivências, e, levando em conta fatores culturais, socioeconômicos e de faixa etária, modificar fatores de risco populacionais. Como resultado final, foi obtido não somente o desenvolvimento de aprendizado mútuo entre as partes envolvidas, mas também de conquistas das mais diversas competências relacionadas ao processo didático e comportamento preventivo.

\section{REFERÊNCIAS}

1. ACCIOLY MA, et al. Neurotrauma: prevenção realizada pelo Núcleo de Estudos Acadêmicos em Neurocirurgia. Revista Ciência em Extensão, 2017; 13(3): 64-76.

2. AMORIM ES, et al. Perfil epidemiológico de vítimas infantis de trauma cranioencefálico. Revista de Enfermagem da UFPE, 2017; 11(supl. 10): 4150-4156.

3. GONÇALVES DV, et al. Determinantes epidemiológicos do trauma cranioencefálico em crianças. Amadeus International Multidisciplinary Journal, 2019; 4(7): 232-244.

4. SILVA KL, et al. Projeto Neurotrauma: Educar para prevenir - o melhor tratamento. Revista Ciência em Extensão, 2018; 14(1): 70-82. 


\section{Simples}

RESUMOS SIMPLES: Estudo Original

Título: Análise da mortalidade por sepse em pacientes com doença falciforme

Autor/coautores: Rodrigo De Martin Almeida; Tássia Mariana Moreira da Paz; Thais Sette Espósito; Olivia Franco dos Santos; Daniela de Oliveira Werneck Rodrigues.

Instituição: Faculdade de Ciências Médicas e da Saúde de Juiz de Fora - SUPREMA - Minas Gerais; Universidade Presidente Antônio Carlos - FAME UNIPAC - Juiz de Fora - Minas Gerais; Universidade Federal de Juiz de Fora - UFJF - Minas Gerais; Fundação Hemominas - Juiz de Fora - Minas Gerais.

Financiamento: Fundação Hemominas, Fundação de Amparo à Pesquisa do Estado de Minas Gerais (Fapemig) e National Institutes of Health (NIH).

Palavras-chave: Mortalidade, Doença Falciforme, Sepse.

\section{INTRODUÇÃO}

A Doença Falciforme (DF) é uma doença hemolítica hereditária crônica grave com alterações inflamatórias sistêmicas (CARNEIRO-PROIETTI ABF, et al., 2018). A DF cursa com alterações do sistema imunológico, acarretando múltiplos episódios infecciosos com elevada mortalidade, incluindo choque séptico (KNISELY MR, et al., 2020). Dentre as causas de óbito na DF a infecção grave tem uma prevalência significativa, principalmente na Anemia Falciforme (AF). As medidas de antibioticoprofilaxia na infância, com imunização estendida, são medidas importantes para a redução da morbimortalidade. Entretanto, a letalidade entre adultos com DF persiste elevada (NADER E, et al., 2020).

\section{OBJETIVO}

Quantificar o número de óbitos e analisar os óbitos por sepse entre os pacientes com DF do estudo intitulado Recipient Epidemiology and Donor Evaluation Study III (REDS III Doença Falciforme).

\section{MÉTODO}

Estudo tipo coorte com 275 pacientes diagnosticados com DF acompanhados em um Hemocentro de Minas Gerais entre novembro/2013 a dezembro/2019. As informações e dados foram extraídos no sistema http://data.ime.xxx.br/REDSIII-SMS. As variáveis estudadas foram: óbito, sexo, idade e tipo de DF. A análise estatística foi realizada com o teste $Q$ quadrado. A pesquisa foi aprovada pelo Comitê de Ética em Pesquisa (CEP), sendo registrada pelo CAAE: 02790812.0.2002.5118 e Plataforma Brasil (no 419.415/2013).

\section{RESULTADOS}

Ocorreram 23 óbitos entre os pacientes da coorte, com uma mortalidade de $8,36 \%$. O quadro séptico foi responsável por $52,17 \%$ dos óbitos $(p<0,03)$. Quanto ao foco primário de infecção, $66,7 \%$ dos casos decorreram de Síndrome Torácica Aguda, em 16,7\% não foi possível estabelecer o sítio infeccioso primário e houve um óbito por dengue grave. Em relação ao sexo, 83,35\% dos óbitos ocorreram no sexo feminino $(p<0,05)$ e em $100 \%$ dos casos houve a indicação de suporte hemoterápico. A análise do tipo de DF x óbito por sepse evidenciou que $91,6 \%$ dos casos ocorreram em pacientes com $A F(p<0,01)$ e a idade média dos que evoluíram a óbito foi 30,7 anos. 


\section{CONSIDERAÇÕES FINAIS}

Pacientes com DF exigem atenção individualizada além de protocolos específicos para o tratamento de quadros sépticos, devido à alta letalidade nesta população. O estudo de coorte REDSIII DF busca gerar conhecimento sobre DF para implementação de programas para aumentar a sobrevida destes pacientes e reduzir a mortalidade, principalmente por sepse.

\section{REFERÊNCIAS}

1. CARNEIRO-PROIETTI ABF, et al. Clinical and genetic ancestry profile of a large multi-centre sickle cell disease cohort in Brazil. British Journal of Haematology, 2018.

2. KNISELY MR, et al. Patient-reported Outcomes in Sickle Cell Disease and Association with Clinical and Psychosocial Factors: Report from the Sickle Cell Disease Implementation Consortium. American Journal of Hematology, 2020.

3. NADER E, et al. The Red Blood Cell-Inflammation Vicious Circle in Sickle Cell Disease. Frontiers in Immunology, 2020; 11: 454. 
RESUMOS SIMPLES: Revisão Bibliográfica

Título: Análise do gene APC no contexto da oncogenética: uma revisão sistemática

Autor/coautores: Maria Clara Rocha Elias Dib; João Paulo Pires Caixêta; Mercielle Ferreira Silva Martinelle; Luiza Ferro Marques Moraes; Antonio Márcio Teodoro Cordeiro Silva.

Instituição: Pontifícia Universidade Católica de Goiás (PUC Goiás), Goiânia-Goiás.

Palavras-chave: PAF, Câncer, Teste genético.

\section{INTRODUÇÃO}

A oncogenética é direcionada para indivíduos com suspeita de síndrome de predisposição ao câncer. É importante essa identificação para acompanhamento mais adequado de pacientes e familiares que também podem estar em risco (PALMERO El, et al., 2016). Nessa perspectiva, há a incorporação de painéis genéticos de diferentes tipos de câncer à prática clínica (MARCOS IE, et al., 2019). Os testes genéticos para rastreamento de mutações germinativas devem ter cobertura dos planos de saúde privados nacionais. O teste para análise do gene adenomatous polyposis coli $(A P C)$ é utilizado, por exemplo, para diagnóstico de polipose adenomatosa familiar, desde 2015 (SALES LAP e LAJUS TBP, et al., 2018).

\section{OBJETIVO}

Discutir a importância da oncogenética na avaliação do gene $A P C$, em e familiares no contexto com aconselhamento genético e da medicina de precisão.

\section{MÉTODO}

Trata-se de revisão sistemática da literatura, realizada na base de dados PubMed. Foram utilizados os descritores "oncogenetics" e "APC". Os filtros aplicados para inclusão dos artigos nessa pesquisa foram: "in the last 10 years" e "humans". A busca resultou em 21 artigos, dos quais foram considerados elegíveis 10 artigos de acordo com a temática em questão.

\section{REVISÃO BIBLIOGRÁFICA}

Variantes patogênicas do gene $A P C$ estão associadas a pólipos intestinais, o que pode aumentar probabilidade de desenvolvimento de adenomas ou indicar a necessidade de cirurgias (KARIV R, et al., 2019). A identificação dessas mutações pode contribuir na tomada de decisões cirúrgicas e na realização de endoscopia em paciente com polipose adenomatosa familiar (SOURROUILLE I, et al., 2017). Ademais, a análise da correlação genótipo-fenótipo e dos locais das variantes patogênicas do $A P C$ são relevantes na caracterização, monitoramento e tratamento dos membros das famílias afetadas pela síndrome genética em questão e, nesse sentido, um estudo mostrou que, em brasileiros, a correlação genótipo-fenótipo pode apresentar achados específicos ainda não relatados, demonstrando que o conhecimento dessas variáveis é importantes para o manejo clínico de indivíduos de diferentes populações (DE OLIVEIRA JC, et al., 2019). Um artigo concluiu que inibidores da $A P C / C$ podem ser promissores agentes terapêuticos (DE LANGE J, et al., 2015). Adicionalmente, um artigo analisou que pacientes com polipose esporádica devem ser considerados com possíveis portadores de mosaicismo do gene APC (MONGIN C, et al., 2012).

\section{CONSIDERAÇÕES FINAIS}

Nota-se que o estudo da oncogenética, na análise dos genes $A P C$, é necessário, principalmente, no que tange à tomada decisões clínicas e no manejo do paciente e da família que apresenta variantes patogênicas 
do gene APC. Assim, a identificação precoce dessas mutações e a análise da correlação genótipo-fenótipo podem contribuir tanto na prevenção quanto na terapêutica individualizada e no prognóstico desses pacientes.

\section{REFERÊNCIAS}

1. MARCOS IE, et al. Aplicación clínica de los paneles de genes de susceptibilidad al cáncer: caracterización de variantes en genes de riesgo e impacto psicológico. Universitat Autònoma de Barcelona, 2019; 1.

2. PALMERO El, et al. Serviço oncogenético e sistema público de saúde brasileiro: a experiência de um hospital de referência em cancer. Genetics and Molecular Biology, 2016; 39: 2.

3. SALES LAP, LAJUS TBP. Aconselhamento genético em oncologia no Brasil: realidade e perspectiva. Revista de Medicina, 2018; 5: e97. 
RESUMOS SIMPLES: Revisão Bibliográfica

Título: Diagnósticos diferenciais da leucocoria e o papel da atenção básica no seu rastreio

Autor/coautores: Andressa Marcolino Campos; Luiza Helena Santos Giorni; Laura Couto Cunha; Larissa Aparecida Guimarães Oliveira; Tábata Passos Ferreira Mariano.

Instituição: Centro Universitário Atenas (UniAtenas) - Paracatu, Minas Gerais.

Palavras-chave: Retinoblastoma; Catarata; Atenção Básica.

\section{INTRODUÇÃO}

Leucocoria é uma palavra de origem grega, derivada de leuco (=branco) e coria (=pupila), representando a pupila branca. É um achado clínico no qual há um reflexo pupilar anormal, secundário a uma opacidade no cristalino e/ou segmento posterior do olho. O teste de Brückner ou do Reflexo Vermelho é o principal teste de triagem indicado para a sua detecção precoce. Esse é, também, conhecido como Teste do Olhinho e deve ser realizado na maternidade e, pelo menos, duas a três vezes/ano nos três primeiros anos de vida (BRASIL, 2016).

\section{OBJETIVO}

Discutir os principais diagnósticos diferenciais da leucocoria - uveítes, retinoblastoma e catarata congênita - e abordar o papel da Atenção Básica (AB), que apresenta uma extrema importância no rastreio e diagnóstico precoce dessa enfermidade.

\section{MÉTODO}

Realizou-se uma revisão da literatura, na qual os dados foram obtidos a partir de meios eletrônicos como Google Acadêmico e a Diretriz de Atenção à Saúde Ocular na Infância. Foram selecionados apenas trabalhos que se encaixavam nos critérios de inclusão: estudos realizados entre 2015-2020, escritos no português ou espanhol.

\section{REVISÃO BIBLIOGRÁFICA}

As uveítes se caracterizam pela inflamação da íris, corpo ciliar ou coroide, podendo alcançar a retina e o nervo óptico. Estão comumente associadas a quadros infecciosos, sendo a toxocaríase um dos principais diagnósticos diferenciais a serem investigados como causa de leucocoria. A leucocoria, também, constitui o principal sinal do retinoblastoma. Este é considerado o tumor maligno intraocular mais frequentemente encontrado na população pediátrica (BEZERRA DS, et al., 2017). O diagnóstico tardio relaciona-se a perda da função visual, do globo ocular e potencialmente da vida da criança. A catarata congênita pode se apresentar na forma unilateral ou bilateral, sendo essa última a mais frequente, e tem como característica típica a presença de "pupila branca" (URIBE-CAMPOS L, et al., 2018). Tais patologias apresentadas são passíveis de serem rastreadas pelo Teste do Olhinho, disponível na AB. O diagnóstico precoce da leucocoria é fundamental na prevenção da ambliopia, que consiste em uma baixa acuidade visual secundária a falta de estímulo adequado durante o período do desenvolvimento visual.

\section{CONSIDERAÇÕES FINAIS}

Diante do exposto, entende-se a importância da atenção básica no seguimento da criança e na identificação e diagnóstico precoce da leucocoria. Faz-se, portanto, fundamental a criação de políticas públicas que incentivem a puericultura e a realização do teste do reflexo vermelho na atenção primária, além do pronto encaminhamento ao oftalmologista, uma vez detectada a leucocoria, para a investigação e esclarecimento diagnóstico. 


\section{REFERÊNCIAS}

1. BEZERRA DS, et al. Retinoblastoma: contextualização dos principais achados literários retinoblastoma. Temas em Saúde, 2017; 17(3):284-292.

2. BRASIL. MINISTÉRIO DA SAÚDE. Diretrizes de Atenção à Saúde Ocular na Infância: detecção e intervenção precoce para prevenção de deficiências visuais. 2016.

3. URIBE-CAMPOS L, et al. Catarata congénita bilateral: ambliopía por deprivación y su relación con el desarrollo. Revista Mexicana de Oftalmologia, 2018; 92. 
RESUMOS SIMPLES: Revisão Bibliográfica

Título: Diagnóstico diferencial entre Mutismo Seletivo e Autismo: uma revisão bibliográfica

Autor/coautores: Ana Caroline Ribeiro de Carvalho; Nyvea Rubbya Viana e Silva; Mariana Nunes Soares; Jordão Duarte de Almeida; Rodrigo Pinheiro Neiva Jordão.

Instituição: Centro Universitário Atenas (UniAtenas), Paracatu - Minas Gerais.

Palavras-chave: Mutismo, Mutismo Seletivo, Transtorno do Espectro Autista.

\section{INTRODUÇÃO}

Mutismo seletivo (MS) refere-se a um transtorno de ansiedade e caracteriza-se pela incapacidade de falar em situações de interação social, apesar de fazê-lo em outros contextos. Os afetados ficam gradualmente mais ansiosos à medida que as situações exigem mais comunicação e, com isso, o desenvolvimento psicossocial pode estagnar (ROGOLL J, et al., 2018). O Transtorno do Espectro Autista (TEA) é um distúrbio do neurodesenvolvimento persistente e heterogêneo e, dentre os sintomas essenciais, também há deficiência na comunicação e interação social (GONZÁLEZ MC, et al., 2019). Apesar das disparidades no curso, há fatores confusionais que limitam e atrasam o diagnóstico desses transtornos.

\section{OBJETIVO}

Revisar sistematicamente publicações nacionais e internacionais a respeito do diagnostico diferencial entre mutismo seletivo e transtorno do espectro autista em crianças na busca de ferramentas para o diagnostico diferencial entre ambas.

\section{MÉTODO}

Os dados foram coletados nas bases SciELO, PUBmed e Lilacs, com os descritores "mutismo", "mutismo seletivo" e "transtorno do espectro autista". Critérios de inclusão: artigos primários que abordassem o MS e o TEA, publicações no período de 2017 a 2020. Foram excluídos aqueles que não se enquadravam nesses critérios.

\section{REVISÃO BIBLIOGRÁFICA}

MS e TEA são transtornos que se manifestam durante a primeira infância e a detecção precoce é crucial para evitar um impacto negativo no funcionamento educacional e social (PEIXOTO ACA, et al., 2017). Assim, atribui-se à fase pré-escolar particular relevância para o reconhecimento de comportamentos ansiosos e introspetivos. Apesar de ambos se apresentarem com dificuldades de comunicação e de interação social, na criança com MS essas funções estão apropriadas em algumas circunstâncias e os comportamentos restritivos e repetitivos típicos do TEA estão ausentes. Um diagnóstico abrangente inclui cuidadores, professores e profissionais envolvidos para obter informações suficientes sobre hábitos e repertório comunicativo da criança (ROGOLL J, et al., 2018). Apesar do Diagnóstico de Transtornos Mentais V (DSM-V) descrever os critérios, ainda é complexo avaliar um quadro que especifique o MS, devido às diferentes formas de manifestação. Dentre as ferramentas encontradas para auxílio diagnóstico, o teste ADOS (Autism Diagnostic Observation Schedule) é o mais utilizado (GONZALES MC, et al., 2019).

\section{CONSIDERAÇÕES FINAIS}

A presente revisão demonstra que a apresentação clínica é o principal meio para se chegar ao diagnóstico. Testes específicos têm sido cada vez mais aprimorados para melhorar a capacidade diagnóstica do TEA e sua diferenciação com outras condições. Todavia, permanece como padrão ouro para diagnóstico a avaliação formal realizada por uma equipe multidisciplinar. 


\section{REFERÊNCIAS}

1. PEIXOTO ACA, et al. Selective Mutism: a case study with interdisciplinary treatment. Revista Brasileira de Terapias Cognitivas, 2017; 13(1); 591-602.

2. ROGOLL J, et al. Selektiver Mutismus. Der Nervenarzt, 2018; 89 (5); 5-11.

3. GONZÁLEZ MC, et al. Trastorno del espectro autista: Diagnóstico clínico y test ADOS. Revista Chilena de Pediatria, 2019; 90(5); 485-491. 
RESUMOS SIMPLES: Revisão bibliográfica

Título: O uso de inibidores de SGLT2 em DM1 e o risco de cetoacidose diabética

Autor/coautores: Susana de Miranda Gomes; Júlia Carvalho Garcia de Assis; Mylena Varela Santos Oliveira; Tayla Figuieredo Lacerda; Lízia Baruque Baylão.

Instituição: Universidade de Rio Verde Rio Verde - Goiás

Palavras-chave: SGLT2i, DM1, Cetoacidose Diabética.

\section{INTRODUÇÃO}

O interesse em tratamentos adjuvantes para pacientes com diabetes mellitus tipo1 (DM1), está relacionado a importância de testes em busca de medicações com menos efeitos adversos para esses pacientes e uma eficácia segura comprovada. Estudos do Comitê Consultivo em Medicamentos Endocrinológicos e Metabólicos denotam que a utilização dos inibidores do co-transportador sódio-glicose2 (SGLT2i) foi expressiva no DM1 trazendo resultados positivos, incongruentes aos riscos vitais de cetoacidose diabética (CAD) (ADA, 2019).

\section{OBJETIVO}

Analisar o risco à cetoacidose diabética (CD) com ênfase no uso dos SGLT2, como um medicamento adjuvante à insulina no paciente diabetes mellitus tipo 1 e a melhor abordagem para essa prática.

\section{MÉTODO}

Trata-se de uma revisão bibliográfica, na qual foram consultadas as bibliotecas virtuais: SciELO e PubMed, Sociedade Brasileira de Diabetes (SBD) e American Diabetes Association (ADA), na data de março de 2015 a junho de 2019. Um Estudo de Centro de Controle e Prevenção de Doenças foi analizado. Os termos utilizados: "SGLT2i" "DM1" "cetoacidose diabética". Artigos os quais observou-se além do tema estudado foram excluídos.

\section{REVISÃO BIBLIOGRÁFICA}

Os SGLT2i são medicamentos antidiabéticos orais não hipoglicêmicos que reduzem a hemoglobina glicada, a pressão arterial e o peso corporal (DANNE T, et al., 2019). Com a frequência de prescrição off-label do SGLT2i no tratamento do DM1 foram realizados estudos específicos sobre o risco de CAD. A presença de níveis glicêmicos normais ou hiperglicemia leve, incomum ao quadro de CAD, complica o diagnóstico e retarda o tratamento, caracterizando o quadro como uma falta de alerta vital no paciente (ADA, 2019). Reviu-se assim, uma nova aplicação de medicamentos para o uso de SGLT2i no DM1. Os pacientes foram orientados por protocolos, mediadores para triagem de cetona, instruídos a detectar e tratar a cetose e assim avaliou-se 0 perfil de risco-benefício do SGLT2i. Resultados sugeriram que doses menores do SGLT2i podem ajudar a minimizar o risco de CAD em DM1 (ROSENSTOCK J, et al., 2018).

\section{CONSIDERAÇÕES FINAIS}

Para a segurança do paciente é de suma importância o esclarecimento da necessidade do controle ao portador de DM1, com a medição da cetona aos sintomas da CAD, tais como mal-estar, fadiga, náusea ou vômito, mudanças de dieta e dose de insulina, infecções, desidratação, cirurgia, oclusão da cânula de infusão, mau funcionamento da bomba ou estresse, para garantir uma administração do SGLT2i no DM1 segura e preventiva à CAD. 


\section{REFERÊNCIAS}

1. ROSENSTOCK J, et al. Empagliflozin as Adjunctive to Insulin Therapy in Type 1 Diabetes: The EASE Trials. Diabetes Care 2018; dc181749.

2. INTERNATIONAL DIABETES FEDERATION. IDF Diabetes Atlas, 8th edition. International Diabetes Foundation; 2017.

3. DANNE T, et al. Consenso Internacional sobre Gerenciamento de Riscos da Cetoacidose Diabética em Pacientes com Diabetes Tipo 1 Tratados com Inibidores do Cotransportador de Glicose de Sódio (SGLT). Diabetes Care 2019; dc182316. 
RESUMOS SIMPLES: Revisão Bibliográfica

Título: Uso de células-tronco mesenquimais no tratamento de pneumonia por COVID-19

Autor/coautores: Talita Carenzio Azevedo; Larissa Fernandes Amaral; Fernanda Pereira Alvarenga; lury Camargos Nery Ferreira.

Instituição: Centro Universitário Atenas (UniAtenas), Paracatu - Minas Gerais.

Palavras-chave: Células-tronco mesenquimais, Pneumonia, COVID-19.

\section{INTRODUÇÃO}

A nova patologia causada pelo coronavírus SARS-CoV-2 tornou-se uma emergência global, trazendo um número crescente de pacientes infectados a cada dia (LENG Z, et al., 2020). Em março de 2020, essa doença foi considerada uma pandemia pela Organização Mundial da Saúde, o que levou estudiosos de diversas áreas a procurarem medidas ou tratamentos que controlem esse recente surto (GOLCHIN A, et al., 2020). Atualmente a ciência não apresenta nenhuma terapia eficaz para a cura do coronavírus, entretanto, foi descoberto que as células-tronco mesenquimais (CTMs), através da sua função imunomodeladora melhoram a resistência biológica do paciente e sua função pulmonar. Sendo então, introduzida como uma abordagem terapêutica (METCALFE SM, 2020).

\section{OBJETIVO}

Avaliar por meio desta revisão a eficácia do transplante de CTMs no tratamento de pneumonia em pacientes infectados com o vírus SARS-CoV-2, destacando suas funções e resultados no organismo humano.

\section{MÉTODO}

Este trabalho foi elaborado através de uma revisão de literatura na base de dados Pubmed, utilizando os descritores COVID-19 e sinônimo, SARS-CoV-2, células-tronco mesenquimais e pneumonia. Foram selecionados artigos publicados nos últimos 5 anos relacionados ao tema.

\section{REVISÃO BIBLIOGRÁFICA}

Pacientes positivados com COVID-19, variando entre estados criticamente grave, graves e tipo comum foram submetidos ao transplante de CTMs, que através de suas propriedades imunomoduladoras possuem capacidade de mutação e impedem a falência do tecido pulmonar, por meio da neutralização das citocinas e renovação de tecidos danificados. Os resultados obtidos pós transplante foram positivos, pois anteriormente ao uso da nova terapia, os pacientes analisados apresentavam febre alta, astenia, dispneia e baixa saturação de oxigênio (METCALFE SM, 2020). Assim sendo, 2 a 4 dias após o transplante, todos os sintomas desapareceram nos pacientes. Além disso, ocorreu um aumento dos linfócitos e ativação de células imunes secretoras de citocinas, alívio da sintomatologia causada pela pneumonia e estabilização dos sinais vitais (LENG Z, et al., 2020). Observou-se também que as células-tronco mesenquimais estão livres de serem infectadas por esse vírus, sendo então, seguras e eficazes como terapia em pacientes com pneumonia por COVID 19 (GOLCHIN A, et al., 2020).

\section{CONSIDERAÇÕES FINAIS}

As propriedades imunomodeladoras das CTMs no tratamento de pneumonia por COVID-19, mostraram resultados positivos e uma opção para diminuir a mortalidade dos pacientes infectados. Entretanto, novas 
pesquisas precisam ser feitas na área, avaliando um número maior de pacientes, efeitos a longo prazo e complicações pós-transplante.

\section{REFERÊNCIAS}

1. GOLCHIN A, et al. Mesenchymal stem cell therapy for COVID-19: present or future. Stem Cell Rev Rep, 2020; 13: 1-7.

2. LENG, et al.Transplantation of ACE2(-) mesenchymal stem cells improves the outcome of patients with COVID-19 pneumonia. Aging Dis, 2020; 11 (2):216-228.

3. METCALFE SM. Mesenchymal stem cells and management of COVID-19 pneumonia. Med Drug Discov, 2020. 5:100019. 
RESUMOS SIMPLES: Relato de experiência

Título: Planejamento Familiar e sexualidade na escola: relato de experiência de uma ação educativa com foco na escuta

Autor/coautores: Ana Carla Franklin Braga; Anna Luísa Dias Bastos de Moura; Bruna Ribeiro Lajes; Izadora Lopez Solla Karl; Ana Paula Borges Carrijo.

Instituição: Universidade de Brasília (UnB), Brasília - Distrito Federal.

Palavras-chave: Planejamento familiar, Sexualidade, Atividade educativa.

\section{INTRODUÇÃO}

Conciliar educação e saúde desenvolve saberes, promovendo bem-estar individual e comunitário. A escola, cenário plural representante de desigualdades, é espaço fundamental de atuação da Estratégia de Saúde da Família (ESF) (PAES CCDC e PAIXÃO ANP, 2016). Um eixo importante é a saúde sexual e reprodutiva na adolescência, fase de transformações biopsicossociais. $O$ acesso a informações possibilita formação de consciência crítica, autonomia e responsabilidade social sobre suas práticas (PAES CCDC e PAIXÃO ANP, 2016; QUEIROZ MVO, et al., 2016). Este relato aborda dinâmicas sobre sexualidade e planejamento familiar no Distrito Federal, com alunos do $8^{\circ}$ e $9^{\circ}$ anos, realizada por extensionistas do primeiro ano de medicina da Universidade de Brasília.

\section{OBJETIVO}

Discutir o acesso à informação em saúde sexual, prevenção de infecções sexualmente transmissíveis (ISTs) e planejamento familiar no ambiente escolar e suas possíveis repercussões na adolescência, com foco na escuta dos alunos.

\section{RELATO DE EXPERIÊNCIA}

Discutimos planejamento familiar e sexualidade com profissionais da Unidade Básica de Saúde (UBS) adscrito na área da escola, estimulando a construção coletiva desses conceitos. Além das dúvidas, a atividade suscitou comentários preconceituosos por parte dos alunos, o que foi acolhido e problematizado pelo grupo. É fundamental mostrar a importância desse tema para o autocuidado, assim como promover prevenção de doenças desde a adolescência. No segundo momento, a turma realizou uma dinâmica de perguntas e respostas. Observamos diferentes saberes e experiências a respeito dos métodos contraceptivos, além do desconhecimento do papel das UBS no acompanhamento integral da saúde. Ressaltou-se ainda a importância da formação de vínculo com a equipe e da confidencialidade das informações trocadas entre profissionais e comunidade. Posteriormente, abordamos os métodos contraceptivos disponíveis e reforçamos o uso dos preservativos como única forma efetiva de prevenção de ISTs. Finalizamos com esclarecimento de dúvidas e exposição de vivências, como: uso indevido de contraceptivos orais e de emergência, realização de coito interrompido para prevenção de gravidez indesejada e dúvidas quanto a prevenção de ISTs em relações homoafetivas.

\section{CONSIDERAÇÕES FINAIS}

O cenário escolar reflete a realidade social brasileira: a omissão da discussão sobre sexualidade, de forma clara e natural, gera um ambiente hostil para as inúmeras questões que emergem na adolescência. Assim, a realização de atividades na escola, uma parceria entre a universidade e a ESF, torna-se fundamental para 
permitir um espaço de escuta às demandas dos alunos, o acesso à informação e o esclarecimento de dúvidas.

\section{REFERÊNCIAS}

1. PAES CCDC, PAIXÃO ANP. A importância da abordagem da educação em saúde. Revista de Educação da Universidade Federal do Vale do São Francisco, 2016; 6(11).

2. QUEIROZ MVO, et al. Participação de adolescentes em ações educativas sobre saúde sexual e contracepção. Revista Brasileira em Promoção da Saúde, 2016; 29: 58-65. 
RESUMOS SIMPLES: Revisão Bibliográfica

Título: Terapia nutricional na queimadura em crianças: uma revisão literária

Autor/coautores: Juliana Cavalcanti de Andrade Silva; Caroline Sampaio Portugal Andrade.

Instituição: Centro Universitário Faculdade de Tecnologia e Ciências (UniFTC), Salvador - Bahia.

Palavras-chave: Queimadura, Pediatria, Terapia nutricional.

\section{INTRODUÇÃO}

As queimaduras são importantes causas de hospitalizações e mortes não intencionais em crianças no Brasil (VALENTINI M, et al., 2018). São lesões teciduais por trauma térmico, elétrico, químico, radioativo, por atrito ou friç̧ão. Queimaduras de $2^{\circ}$ e $3^{\circ}$ graus são graves pela ocorrência de complicações, como infecções, perda de eletrólitos, reações metabólicas, e óbito (ALMEIDA MEMSB, 2018). O hipermetabolismo altera as concentrações de lipídios, carboidratos, proteínas e ácidos graxos. Crianças apresentam necessidades metabólicas basais maiores, iniciando a nutrição mais precocemente. Repor nutrientes reduz complicações, tempo de internamento e mortalidade (LIMA MN, et al., 2019). Contudo, não existe um programa nutricional ideal para auxiliar no tratamento e recuperação desses pacientes.

\section{OBJETIVO}

Revisar as particularidades da terapia nutricional e resposta metabólica ao trauma nos pacientes pediátricos queimados, e descrever a importância da nutrição para reestabelecer o quadro clínico desses pacientes.

\section{MÉTODO}

Revisão literária sobre a terapia nutricional em crianças queimadas. Foram incluídos trabalhos dos últimos 20 anos, em português, inglês ou espanhol. 26 artigos científicos foram selecionados no Google Acadêmico, SciELO, MEDLINE e UpToDate, entre maio/2019 e julho/2020. Descritores: queimaduras, terapia nutricional e pediatria.

\section{REVISÃO BIBLIOGRÁFICA}

Observou-se nos dados dos artigos referenciados que o suporte nutricional deve ser iniciado precocemente; porém, não foi especificado o momento de início da terapia nem o tempo médio para atingir a meta energética. Deve administrar por via enteral para atingir as necessidades energéticas do paciente, prevenir infecções ao modular a resposta imuno-inflamatória, reduzir o tempo de internação e aumentar a sobrevida (LIMA MN, et al., 2019). As principais queimaduras nas crianças foram por escaldamento nos menores de 7 anos e por chama dos 8 aos 12 anos, causas que poderiam ser evitadas com cuidados básicos em casa. A incidência foi maior em meninos com 2 a 10\% da superfície corporal queimada (ALMEIDA MEMSB, 2018). A mortalidade não apresentou diferença para nutrição precoce ou tardia (VALENTINI M, et al., 2018). Faz-se necessário mais pesquisas sobre tal nutrição, a fim de desvendar suas especificidades e produzir um programa de terapia nutricional ideal para, assim, reduzir a mortalidade por queimaduras graves na pediatria.

\section{CONSIDERAÇÕES FINAIS}

Evidenciou-se que é recomendada a terapia nutricional por via enteral precocemente, principalmente na pediatria. Entretanto, faltam pesquisas que consolidem o tempo ideal de início e permanência da terapia, para 
que o aporte nutricional seja adequado, com consequente redução de complicações, tempo de internamento, e melhora na recuperação do paciente.

\section{REFERÊNCIAS}

1. ALMEIDA MEMSB. Vítimas de queimaduras: perfil sócio demográfico e principais causas na região metropolitana de Salvador - Bahia, 2018.

2. LIMA MN, et al. Conduta nutricional no tratamento de pessoas que sofreram queimaduras graves. Revista Saúde, 2019; 13(1).

3. VALENTINI M, et al. Terapia nutricional enteral pediátrica para vítimas de queimaduras: quando iniciar? Revista Brasileira de Terapia Intensiva, 2019; 31(3). 
RESUMOS SIMPLES: Relato de Experiência

Título: A telessaúde em tempos de pandemia: o contato entre acadêmicos de medicina do segundo ano e idosos em distanciamento social

Autor/coautores: Isadora Lima do Prado; Jordana Oliveira Silva; Maria Eduarda Diniz Antônio; Monarko Nunes Azevedo.

Instituição: Centro Universitário de Anápolis - UniEVANGÉLICA, Anápolis-Goiás

Palavras-chave: Telemedicina, Acadêmicos de medicina, Idosos.

\section{INTRODUÇÃO}

A educação médica brasileira requer a constante união entre teoria e aplicação prática, para isso, nos últimos anos, diversas alternativas, como aplicativos, projetos de realidade virtual e e-Cursos, já vinham ganhando espaço como auxiliadores do processo de aprendizagem (SANTOS CSS e SANTOS MC, 2015). Contudo, com o advento da pandemia de COVID-19 em 2020, a realidade médica e também educacional foi completamente modificada e recursos, a exemplo do contato virtual e teleconsultas, tornaram-se fundamentais devido ao seu benefício de reduzir o risco de contaminação de pessoas e manter contato direto com os pacientes (CAETANO R, et al.,2020).

\section{OBJETIVO}

Descrever a experiência de estudantes do segundo ano do curso de Medicina em contato com a telemedicina como alternativa de comunicação com pacientes idosos em distanciamento social durante pandemia de COVID-19.

\section{RELATO DE EXPERIÊNCIA}

A atividade em questão foi proposta pela disciplina de Medicina de Família e Comunidade a todos os alunos do quarto período do curso de Medicina do Centro Universitário de Anápolis - UniEVANGÉLICA, na forma de projeto de Saúde Coletiva. Inicialmente os professores responsáveis entraram em contato com os idosos selecionados, explicando a proposta e pedindo seu consentimento em participar. Depois disso, os estudantes receberam orientações, materiais de apoio e foram separados em duplas para execução do projeto, que utilizou como embasamento teórico o Arco de Maguerez, a Caderneta de Saúde da Pessoa Idosa e a Política Nacional da Pessoa Idosa (PNSPI). O desenvolvimento foi dividido em etapas semanais: 1) Observação da realidade; 2) Levantamento dos postos-chaves; 3) Teorização e 4) Proposta de intervenção. Semanalmente, os acadêmicos eram responsáveis por realizar ao menos uma ligação, na forma de vídeo ou apenas áudio, para o idoso, coletar seus dados pessoais e preencher a parte da Caderneta requerida pelo professor orientador, devendo também entregar relatórios a cada etapa. Além disso, o momento da ligação foi uma forma de acolhimento e apoio aos idosos que, em muitos casos, encontravam-se distantes de seus familiares e amigos devido aos riscos inerentes à COVID-19. O projeto teve duração de três semanas e, ao final, cada dupla passou uma devolutiva, na forma de animação, texto, folheto ou vídeo, para o idoso em questão.

\section{CONSIDERAÇÕES FINAIS}

Acadêmicos de medicina, professores e idosos mostram-se bastante satisfeitos com o projeto. Aos estudantes foi enriquecedora a oportunidade de aprender novas formas de realizar sua futura profissão, adequando-se aos desafios atuais e tendo o prazer de acompanhar idosos que logo tornaram-se também especiais. 


\section{REFERÊNCIAS}

1. CAETANO R, et al. Desafios e oportunidades para telessaúde em tempos da pandemia pela COVID-19: uma reflexão sobre os espaços e iniciativas no contexto brasileiro. Cadernos de Saúde Pública, 2020; 36(5).

2. SANTOS CSS, SANTOS MC. Telemedicina: o uso das tecnologias interativas para o ensino da Medicina. Revista de Iniciação Científica, Tecnológica e Artística, 2015; 5(4). 
RESUMOS SIMPLES: Revisão Bibliográfica

Título: A influência dos fatores neuronais e do ambiente obesogênico no desenvolvimento da obesidade

Autor/coautores: Daniel Lopes Marques de Araújo; Luana Soares Vargas; Márden Estêvão Mattos Júnior.

Instituição: Centro Universitário Atenas (UniAtenas), Paracatu - Minas Gerais.

Palavras-chave: Obesidade, Ambiente obesogênico, Mecanismos neurobiológicos.

\section{INTRODUÇÃO}

De acordo com o Ministério da Saúde, quase $20 \%$ da população adulta brasileira está obesa e cerca de $55 \%$ está com excesso de peso. A obesidade é uma doença crônica de caráter multifatorial. Tal patologia leva a inúmeras complicações como hipertensão arterial, dislipidemia, doenças cardiovasculares, diabetes mellitus tipo 2, dentre outras. A rapidez e a modernidade da era contemporânea têm contribuído de forma decisiva para o acúmulo de gordura corporal (URIBE-CERDA S, et al., 2018). Sob essa ótica, o ambiente obesogênico e os mecanismos neurobiológicos mostram-se fundamentais no desenvolvimento da obesidade e do sobrepeso (LEE PC e DIXON JB, 2017).

\section{OBJETIVO}

Revisar os mecanismos neuronais que contribuem para o desenvolvimento da obesidade e analisar 0 ambiente obesogênico como um fator predisponente e crucial para o excesso de peso nos indivíduos.

\section{MÉTODO}

Realizou-se pesquisa documental e bibliográfica, utilizando-se os termos "obesidade", "ambiente obesogênico" e "mecanismos neurobiológicos". Foram selecionados artigos publicados na base Pubmed, nos últimos 5 anos, em língua inglesa. Estudos não relacionados ao tema foram excluídos.

\section{REVISÃO BIBLIOGRÁFICA}

A alimentação deixou de ser um fator homeostático para ser uma alternativa hedônica, consequentemente, envolvendo fatores cognitivos e emocionais. Áreas córtico-límbicas, como o Núcleo Accumbens, estão relacionadas ao comportamento de recompensa quando estimuladas pelo hipofuncionamento do sistema dopaminérgico de indivíduos obesos. Assim, os alimentos palatáveis acarretam um retorno temporário nos níveis normais de dopamina, causando uma melhora no humor. Por outro lado, o Hipotálamo Lateral contém diferentes subpopulações neuronais que regulam vários aspectos da alimentação. Através do neurotransmissor GABA, a compulsão por sacarose e a aprendizagem alimentar são induzidas por projeções monossinápticas da área Tegmentar Ventral, que regula o apetite (URIBE-CERDA S, et al., 2018). Além disso, o ambiente obesogênico induz comportamentos não saudáveis e sedentários. A indústria alimentícia oferta e comercializa produtos com maior conteúdo em gorduras, açúcares e de baixa qualidade nutricional, com alto poder de saciedade, sabor agradável e baixo custo. Ainda, a mecanização do trabalho, melhores comunicações e transportes, reduzem o gasto de energia associado à falta de tempo para atividades físicas, contribuindo para um aumento da gordura corpórea (RENDINA D, et al., 2019).

\section{CONSIDERAÇÕES FINAIS}

O desenvolvimento da obesidade na população possui causas multifatoriais. Dentre elas, a influência do ambiente obesogênico, que induz o consumo de alimentos industrializados e a redução da atividade física, e 
os mecanismos neurobiológicos que influenciam no apetite, humor, alimentação e no comportamento de recompensa em indivíduos obesos.

\section{REFERÊNCIAS}

1. LEE PC, DIXON JB. Food for thought: reward mechanisms and hedonic overeating in obesity. Current obesity reports, 2017; Rep 6, 353-361.

2. RENDINA D, et al. Methodological approach to the assessment of the obesogenic environment in children and adolescents: A review of the literature. Nutrition, Metabolism \& Cardiovascular Diseases, 2019; 29:561-571.

3. URIBE-CERDA S, et al. Updates on the neurobiology of food reward and their relation to the obesogenic environment. Current Opinion in Endocrinology, Diabetes and Obesity, 2018; 25:292-297. 
RESUMOS SIMPLES: Relato de experiência

Título: Impactos da intervenção em saúde na escola na graduação médica: um relato de experiência

Autor/coautores: Catarina Epichin Amin; Daniel Prado dos Santos; Ana Cecília Alves Arrivabeni; Elisa Smith Barbiero Medeiros; Francine Alves Gratival Raposo.

Instituição: Escola Superior de Ciências da Santa Casa de Misericórdia de Vitória (EMESCAM), Vitória Espírito Santo.

Palavras-chave: Programa Saúde na Escola (PSE), Território, Educação em Saúde.

\section{INTRODUÇÃO}

No contexto da formação acadêmica da Medicina pautada no Método Clínico Centrado na Pessoa, a inserção dos acadêmicos no território é primordial para construção de uma visão ampla dos determinantes no processo saúde-doença. A busca pela humanização da medicina amplia suas áreas de inserção, alcançando o contexto escolar, visto como local de informações confiáveis e propício ao empoderamento acerca de temas necessários (CHARD AN, et al., 2018). Diante disso, a Educação em Saúde surge como ferramenta para estabelecer a confluência desses setores com o saber popular, para melhorias nas condições de vida e no autocuidado (CARVALHO FFB, 2015).

\section{OBJETIVO}

Relatar a experiência realizada por acadêmicos de Medicina para empoderamento de alunos do $1^{\circ}$ ao $3^{\circ}$ ano de uma escola da rede pública municipal de Ensino Fundamental no Espírito Santo.

\section{RELATO DE EXPERIÊNCIA}

O primeiro contato com a escola foi através de uma visita objetivando um diagnóstico observacional, que fundamentou a elaboração de projeto de intervenção pela ótica da Educação em Saúde. As atividades desenvolvidas foram norteadas pelas demandas apresentadas acerca de hábitos de higiene insuficientes, falta de autocuidado com o corpo. Considerando o nível de maturidade e cognição dos alunos, a intervenção buscou integrar e articular os preceitos do Programa de Saúde na Escola, através de metodologia lúdica e ativa. Anteriormente às práticas, foram feitas orientações aos alunos sobre hábitos de higiene. Em relação à saúde bucal, foi realizada escovação correta com dentes feitos de garrafas pets e restos de alimentos e cáries feitos com massinha. Sobre a higiene corporal, foi simulada a retirada de microrganismos de um cartaz utilizando água, sabão e esponjas. Para a lavagem das mãos, utilizou-se tinta solúvel mostrando a técnica de higienização ideal. Para pediculose, desenvolveu-se um teatro com fantoches abordando formas de contágio, prevenção e eliminação dos piolhos. A ação foi eficaz para melhoria da problemática e proporcionou aos alunos serem protagonistas de seu próprio aprendizado.

\section{CONSIDERAÇÕES FINAIS}

A experiência permitiu aos graduandos enxergar a importância de ações de promoção de saúde e seus impactos na comunidade. A intervenção aprimorou o conhecimento teórico-prático dos acadêmicos e a sua qualificação para atuarem na prestação de serviços de saúde com aplicabilidade na Atenção Primária à Saúde. A visão ampla dos determinantes no processo saúde-doença possibilitou um aprendizado com ênfase em uma visão holística da prática médica, urgente atualmente. 


\section{REFERÊNCIAS}

1. CARVALHO FFB. A saúde vai à escola: a promoção da saúde em práticas pedagógicas. Rio de Janeiro. Revista de Saúde Coletiva, 2015; 25(4).

2. CHARD AN, et al. The impact of school water, sanitation, and hygiene improvements on infectious disease using serum antibody detection. PLOS Neglected Tropical Diseases, 2018; 12(4): e0006418.

3. PEDROSO RT, et al. A educação baseada na comunidade no ensino médico na Uniceplac (2016) e os desafios para o futuro. Revista brasileira de educação médica, 2019; 43 (4). 
RESUMOS SIMPLES: Revisão Bibliográfica

Título: Abordagem da lombalgia crônica inespecífica em adultos: aspectos clínicos e terapêuticos

Autor/coautores: Leandro Sávio Nunes; Ingridy Thaís Holanda de Almeida; Raíza de Albuquerque Félix; Rodrigo Araújo Alencar; José Rebberty Rodrigo de Holanda.

Instituição: Universidade Potiguar (UNP), Natal- Rio Grande do Norte; Universidade Federal do Rio Grande do Norte (UFRN), Natal-Rio Grande do Norte.

Palavras-chave: Lombalgia, Medicina do trabalho, Qualidade de vida.

\section{INTRODUÇÃO}

Lombalgia é definida como uma dor localizada entre a margem inferior das últimas costelas e as nádegas, podendo vir ou não acompanhada de dor nos membros inferiores (MARSHALL PWM, et al., 2017). Estimase que até $84 \%$ dos adultos tenham lombalgia em algum momento de suas vidas e é, depois da cefaleia, a causa mais comum de dor, representando cerca de $5 \%$ das consultas em serviços de emergência (NIJS J, et al., 2020). Para muitos indivíduos, os episódios de dor são autolimitados. A avaliação clínica da lombalgia inclui anamnese e exame físico direcionados para avaliar se há necessidade de exame de imagem ou avaliação adicional (BODES PG, et al., 2018).

\section{OBJETIVO}

Descrever e identificar as principais manifestações clínicas, fatores causais, consequências e terapêutica adequada no paciente com lombalgia crônica inespecífica para um melhor prognóstico e contribuindo assim na qualidade de vida do indivíduo.

\section{MÉTODO}

Trata-se de uma revisão de literatura, realizada a partir da busca de artigos científicos em bases de dados online, como Scielo e UptoDate, no período compreendido entre Junho e Julho de 2020. Os descritores utilizados foram: lombalgia, medicina do trabalho e qualidade de vida. Foi encontrado um total de 9 artigos considerados relevantes ao tema e foram incluídos aqueles que abordavam a temática de forma satisfatória nos últimos 3 anos.

\section{REVISÃO BIBLIOGRÁFICA}

Os fatores biofísicos, psicológicos e sociais interferem na dor lombar e no seu impacto, como idade, sexo feminino, obesidade, tabagismo, trabalho extenuante, sedentarismo, insatisfação no trabalho, desordem de somatização, ansiedade e depressão. Afeta principalmente a população economicamente ativa, podendo ser altamente incapacitante, além de causar grande impacto na qualidade de vida do indivíduo. É importante na investigação da dor caracterizar localização, duração, gravidade, detalhes de qualquer dor lombar anterior e sua evolução. O tratamento é individualizado incluindo analgesia com uso de relaxantes musculares, tricíclicos ou inibidor seletivo da receptação de serotonina (ISRS), reabilitação por meio de fisioterapia e atividade física, podendo incluir também outras terapias como acupuntura e psicoterapia.

\section{CONSIDERAÇÕES FINAIS}

A utilização de uma combinação de terapias de exercício, intervenções psicológicas, terapia farmacológica e outros tratamentos é mister para gerenciar a dor, aumentar a função e maximizar as habilidades de enfrentamento. Fatores a serem considerados na escolha entre as terapias disponíveis incluem resposta 
prévia a tratamentos, custos, conveniência e disponibilidade local. Além disso, é imprescindível orientações sobre o autocuidado, como posição de dormir, postura ao sentar e evitar cintas abdominais.

\section{REFERÊNCIAS}

1. BODES PG, et al. Educação em Neurofisiologia da Dor e Exercício Terapêutico para Pacientes com Dor Lombar Crônica: Um Estudo Controlado Randomizado de Um Cego. Arch Phys Med Rehabil 2018; 99: e338.

2. MARSHALL PWM, et al. Atividade física e o efeito mediador do medo, depressão, ansiedade e catastrofização na incapacidade relacionada à dor em pessoas com dor lombar crônica. Rev. Assoc. Med. Bras. 2017; 12: e0180788.

3. NIJS J, et al. Integrando a entrevista motivacional na educação em neurociência da dor para pessoas com dor crônica: um guia prático para clínicos. Phys Ther 2020; 100: e846. 
RESUMOS SIMPLES: Revisão Bibliográfica

Título: A relação entre o foco restrito/interesse intenso na síndrome de Asperger e o desenvolvimento de alta habilidade

Autor/coautores: Larissa da Silveira Mattos; Nicole Ribeiro Cardozo; Ligia Aurelio Vieira Pianta Tavares; Dayanne Cristina Mendes Ferreira Tomaz.

Instituição: Centro Universitário Serra dos Órgãos (UNIFESO), Teresópolis-Rio de Janeiro.

Palavras-chave: Transtorno do Espectro Autista, Síndrome de Asperger, Criança expecional.

\section{INTRODUÇÃO}

Desde 2014, a Síndrome de Asperger (SA) é compreendida como um Transtorno do Espectro Autista (TEA) de nível leve (VILARINHO-REZENDE D, et al., 2016). Com isso, é possível caracterizar o SA por comprometimento da interação social recíproca e comportamentos padronizados e repetitivos, além de excelente memória, gama de interesses excepcionalmente limitada e muito absorvente, interferindo no aprendizado de outras habilidades e ajustes sociais (SILVA SCF e RANGNI RA, 2019). Diante disso, é cabível ressaltar que um dos atributos mais curiosos de quem possui a SA é a dupla excepcionalidade que envolve esta síndrome e a alta habilidade especial desenvolvida em virtude do interesse intenso e foco restrito em algo.

\section{OBJETIVO}

Analisar a relação da alta habilidade desenvolvida associada às características de foco limitado e interesse em demasia das pessoas diagnosticadas com a Síndrome de Asperger.

\section{MÉTODO}

O método utilizado foi a revisão bibliográfica em bases de dados, como artigos já publicados em Scientific Eletronic Library Online (SciELO) e Periódicos, do período de 2017 a 2019, através dos seguintes descritores: "Transtorno do Espectro Autista", "Síndrome de Asperger" e "criança excepcional". Nesse sentido, procurouse abranger a população com TEA, diagnosticadas com SA e que possuem características específicas para o desenvolvimento da consequente alta habilidade apresentada pelos mesmos.

\section{REVISÃO BIBLIOGRÁFICA}

Os resultados preliminares obtidos na revisão bibliográfica datam que indivíduos nascidos dentro do TEA, e que principalmente possuam SA, desenvolvem altas habilidades dentro de suas áreas de interesse por apresentarem especificidades neurais, demonstrando padrão elevado de aprimoramento de habilidades, que os permitem ter foco único e restrito sobre determinado assunto, estimulado por um fascínio pessoal que intensifica o aprendizado (VILARINHO-REZENDE D, et al., 2016). Diante disso, apesar da concomitância da desordem psíquica com esses aspectos, a descrição inicial de Asperger previu um desfecho positivo para muitos de seus pacientes que eram capazes de utilizar seus talentos especiais para auxiliar desde o bom desempenho na escola e, futuramente, obter emprego e vidas autossustentadas.

\section{CONSIDERAÇÕES FINAIS}

Em vista dos argumentos apresentados e analisados, o indivíduo com Síndrome de Asperger tem desenvolvimento precoce habilidades especiais e na comunicação, alguns autores ainda consideram a SA, 
como um autismo de alto funcionamento. Dessa forma, ressalta-se que apesar das dificuldades associadas 'a SA, casos especiais acontecem revelando os aspectos positivos da síndrome, levando o portador da mesma a ter um desempenho impressionante em seus assuntos de interesse.

\section{REFERÊNCIAS}

1. VILARINHO-REZENDE D, et al. Desafios no diagnóstico de dupla excepcionalidade: um estudo de caso. Revista de Psicología (Lima), 2016; 34(1).

2. SILVA SCF, RANGNI RA. Indicadores de altas habilidades/superdotação em aluno com síndrome de asperger: um estudo de caso. EccoS - Revista Científica, 2019; 51: e8334. 
RESUMOS SIMPLES: Revisão Bibliográfica

Título: COVID-19: coagulação intravascular disseminada e o uso de anticoagulante como tromboprofilaxia

Autor/coautores: Lorena Cota Noronha; Flávio Romão Silva de Oliveira; Luana Soares Vargas; Ana Carolina Albernaz Barbosa.

Instituição: Centro Universitário Atenas (UniAtenas), Paracatu - Minas Gerais.

Palavras-chave: COVID-19, Coagulopatia, Coagulação Intravascular disseminada.

\section{INTRODUÇÃO}

O Coronavírus 2 da Síndrome Respiratória Aguda Grave (SARS-CoV-2), foi denominada pela Organização Mundial de Saúde (OMS) como COVID-19 (OLIVEIRA ES e MORAIS ACLN, 2020). A transmissão ocorre por contato e por gotículas de saliva de indivíduos assintomáticos e sintomáticos. Os sintomas cursam com uma síndrome gripal aguda com febre de início súbito, tosse, dispneia e mialgia (SOBREIRA ML e MARQUES MA, 2020). Pode desenvolver diversas complicações, como a coagulação intravascular disseminada (CIVD), caracterizada pela ativação difusa da coagulação intravascular, que forma e deposita fibrina na microvasculatura, e possui como alternativa profilática o uso de anticoagulantes (ORSINI MA, et al., 2020).

\section{OBJETIVO}

Revisar sobre o desenvolvimento da coagulação intravascular disseminada, a qual pode evoluir para uma sepse e morte, e o uso de anticoagulantes de maneira profilática, como a heparina, que podem evitar a complicação nos casos mais graves da COVID-19.

\section{MÉTODO}

Realizou-se pesquisa documental e bibliográfica, utilizando-se os termos "COVID-19", "Coagulopatia" e "Coagulação Intravascular disseminada". Foram selecionados artigos publicados na base Pubmed e Google Acadêmico, do atual ano, em língua inglesa e portuguesa. Artigos não relacionados ao tema foram excluídos.

\section{REVISÃO BIBLIOGRÁFICA}

A coagulação intravascular disseminada está associada a doenças infecciosas que levam a quadros de septicemia, sendo essa a principal causa de mortes em $70 \%$ dos pacientes que cursam para uma síndrome respiratória aguda grave, causada pelo coronavírus, em leitos de terapia intensiva. Desse modo, a coagulação é uma resposta do hospedeiro ao vírus, causando uma coagulopatia induzida pela sepse e/ou dímero-D em níveis aumentados. Esse processo leva à um aumento na geração da trombina, na degradação de fibrina e na deficiência da fibrinólise, que indicam um estado hipercoagulável. Assim, a tromboprofilaxia farmacológica com heparina de baixo peso molecular tem sido eficaz na CIVD podendo ser utilizada, na maioria dos pacientes internados com a COVID-19 que não possuem contraindicações. Mas, aqueles em que os anticoagulantes são contraindicados, tem sido usada a tromboprofilaxia mecânica, como os dispositivos de compressão pneumática, demonstrando eficácia (ORSINI MA, et al., 2020).

\section{CONSIDERAÇÕES FINAIS}

A pandemia do novo coronavírus ainda é um desafio para a ciência, sendo escassos os dados na literatura sobre o uso de anticoagulantes de maneira profilática na gravidade da doença. Desse modo, o risco da 
tromboprofilaxia deverá ser sempre revisado de acordo com cada caso, levando em consideração o risco elevado de eventos trombóticos em micro e macrocirculação causados pelo COVID-19.

\section{REFERÊNCIAS}

1. OLIVEIRA ES, MORAIS ACLN. COVID-19: uma pandemia que alerta à população. InterAm J Med Health 2020;3: e202003008.

2. ORSINI MA, et al. Coagulação intravascular disseminada e COVID-19: mecanismos fisiopatológicos. Revista de Saúde. 2020 Jan./Jun.; 11 (1): 87-90.

3. SOBREIRA ML, MARQUES MA. A panaceia dos anticoagulantes na infecção pela COVID-19. J Vasc Bras. 2020;19: e20200063. 
RESUMOS SIMPLES: Revisão Bibliográfica

Título: Isoflavona de soja como terapia não-hormonal do climatério

Autor/coautores: Ana Cristina de Lima Pimentel; Lucas Neves Coelho Filho; Alessandra Cassano Fonseca; Andressa Benhame Fonseca; Thayane Carvalho Lourenço.

Instituição: Universidade Federal de São João del Rei, campus Dom Bosco (UFSJ), São João del Rei-Minas Gerais.

Palavras-chave: Climatério, Fitoterápicos, Glycine max.

\section{INTRODUÇÃO}

Diante dos efeitos colaterais que os hormônios sintéticos podem causar, interroga-se os riscos, benefícios e eficácia do uso de fitoterápicos para o manejo de sintomas no climatério. O Protocolo de Saúde da Mulher (BRASIL, 2016) recomenda os seguintes fitoterápicos para manejo dos sintomas transitórios do climatério: Isoflavona de soja; Trevo vermelho; Cimicífuga; Hipérico; Valeriana e Melissa. Dentre esses, apenas a isoflavona de soja encontra-se na Relação Nacional de Medicamentos Essenciais 2020 (RENAME), sendo disponibilizada pelo SUS. Contudo, seu uso ainda é controverso na sociedade médica devido à falta de estudos que comprovem ou não sua eficácia.

\section{OBJETIVO}

Verificar os efeitos benéficos e adversos da isoflavona de soja como terapia alternativa não hormonal sobre os sintomas transitórios do climatério através de revisão bibliográfica integrativa no contexto médico atual.

\section{MÉTODO}

Realizou-se uma revisão bibliográfica integrativa, usando os descritores "climatério", "fitoterápicos", "Glycine max" nas bases de dados PubMed e Google Scholar. O critério de inclusão foi a abordagem dos artigos pelos descritores e publicação entre 2015 a 2020. Já o de exclusão foi o não enquadramento nos critérios acima.

\section{REVISÃO BIBLIOGRÁFICA}

A isoflavona de soja, obtida por meio da Glycine max, possui ação estrogênio-símile e está associada ao tratamento alternativo não-hormonal dos sintomas do climatério (BRASIL, 2016). Apesar de não ser consenso médico, os efeitos benéficos dessa terapia parecem reduzir os sintomas vasomotores, melhorar o perfil lipídico e atenuar a perda de massa óssea. Os possíveis efeitos colaterais incluem alergia, má absorção de minerais, constipação, flatulências, náuseas e irritação gástrica (BRASIL, 2016). Alguns estudos apontaram a inexistência de evidências suficientes na redução das ondas de calor, porém, satisfatoriamente, não foram relatados efeitos estrogênicos no endométrio ou na vagina (DIETZ BM, et al., 2016). A variável biodisponibilidade de genisteína e daidzeína nos compostos de isoflavona pode explicar a inconstante eficácia e os efeitos relativamente modestos sobre os sintomas climatéricos (RODRíGUEZ-MORATÓ J, et al., 2015). Assim, explica-se a divergência entre os estudos, interrogando-se a aplicabilidade da isoflavona.

\section{CONSIDERAÇÕES FINAIS}

Apesar de ser utilizada em alguns países como uma alternativa fitoterápica à $T R H$, a Isoflavona de soja carece de estudos clínicos para avaliar riscos, benefícios e eficácia da terapia. Tal carência manifesta-se no 
Brasil, que realiza escassos estudos na área e apresenta pouca literatura sobre a fitoterapia no que diz respeito à qualidade de vida da mulher no climatério.

\section{REFERÊNCIAS}

1. BRASIL. MINISTÉRIO DA SAÚDE. Protocolos da Atenção Básica: Saúde das Mulheres. 2016.

2. DIETZ BM, et al. Botanicals and their bioactive phytochemicals for women's health. Pharmacological reviews, 2016; 68(4): 1026-1073.

3. RODRÍGUEZ-MORATÓ J, et al. Pharmacokinetic comparison of soy isoflavone extracts in human plasma. Journal of agricultural and food chemistry, 2015; 63(31): 6946-6953. 
RESUMOS SIMPLES: Revisão Bibliográfica

Título: Utilização de drogas vasoativas no choque distributivo: uma revisão sistemática

Autor/coautores: Joaquim Ferreira Fernandes; Bárbara Custódio Rodrigues da Silva; Camila de Assunção Martins; Paula Pacheco Katopodis; Antonio Márcio Teodoro Cordeiro Silva;

Instituição: Pontifícia Universidade Católica de Goiás (PUC Goiás), Goiânia-Goiás.

Palavras-chave: AIDS, HIV, Imunodeficiência.

\section{INTRODUÇÃO}

O choque é causado pela incapacidade do sistema circulatório em suprir a demanda celular de oxigênio. O choque distributivo é o tipo mais comum, caracterizado por vasodilatação periférica, com redução da précarga e da pós-carga (SMITH N, et al, 2020). Se o choque distributivo se perpetua, a falência do coração pode ocorrer, possibilitando a redução do débito cardíaco e vasoconstrição periférica, na tentativa de manter a pressão arterial. Pacientes com choque são tratados por meio de reposição volêmica; caso não seja eficaz, são utilizadas drogas vasoativas, para otimizar o débito cardíaco e o tônus vascular da circulação sistêmica e pulmonar, e, assim, reestabelecer o fluxo sanguíneo nos órgãos vitais durante o choque (BISTAS EE e SANGHAVI D, 2020).

\section{OBJETIVO}

Analisar os benefícios e os riscos proporcionados pela utilização das drogas vasoativas, noradrenalina, vasopressina, angiotensina II (AT2) e azul de metileno (AM); e estabelecer suas relações frente ao tratamento do choque distributivo.

\section{MÉTODO}

Trata-se de revisão sistemática da literatura, utilizando as bases de dados SciELO, Cochrane e PubMed. Foram selecionados 27 artigos, publicados no ano de 2020, com o descritor em saúde: "distributive shock", sem o uso de filtros para o idioma do artigo. Foram considerados elegíveis, oito artigos, que se enquadravam nos critérios de inclusão, ou seja, que tratavam de drogas utilizadas no contexto do choque distributivo.

\section{REVISÃO BIBLIOGRÁFICA}

A noraepinefrina é a droga de primeira linha nos casos de choque distributivo. Os artigos defendem o uso da vasopressina e da AT2 como agentes secundários para pacientes que mantêm a hipotensão decorrente do quadro. Entretanto, todos os artigos demostraram que esses vasopressores associados à catecolamina não possuem efeitos elucidados. Em comparação entre a vasopressina e a noraepinefrina, a vasopressina tem menor tempo de reversão distributiva do choque em análise não ajustada, porém falhou em manter tal diferença na análise com variáveis. Já o azul de metileno tem limitada eficácia para choque distributivo refratário e não tem resposta hemodinâmica, quando há hipóxia tecidual profunda, com alto grau de metabolismo aeróbico.

\section{CONSIDERAÇÕES FINAIS}

A noradrenalina apresenta maior benefício contra o choque distributivo e a utilização de vasopressina e AT2 não está clara, porém o uso dessas drogas como agentes secundários é indicado. O azul de metileno é eficiente quando a noradrenalina tem ação refratária. Portanto, as evidências sobre os vasopressores são 
baixas, o que torna imprescindível estabelecer novos estudos para definir o melhor tratamento voltado para o choque distributivo.

\section{REFERÊNCIAS}

1. BISTAS EE, SANGHAVI D. Methylene Blue. Treasure Island: StatPearls Publishing, 2020.

2. SMITH N, et al. Distributive Shock. Treasure Island: StatPearls Publishing, 2020. 
RESUMOS SIMPLES: Estudo de Caso

Título: Manifestação hemorrágica de cavernoma mesencefálico associado a outras malformações vasculares ocultas em paciente jovem

Autor/coautores: Carolina Mibielli de Souza; Joanna Campos Robson; Larissa Rocha Alipio Duarte; Sarah Camargo dos Santos; Pedro Lobo Alcântara Neves.

Instituição: Centro Universitário de Belo Horizonte (UniBH). Belo Horizonte - Minas Gerais.

Palavras-chave: Hemorragia, Cavernoma, Malformações Vasculares Ocultas.

\section{INTRODUÇÃO}

A malformação cavernosa (MC) representa cerca de 10 a $20 \%$ de todas as malformações vasculares intracranianas (MVI), com 20\% dos casos cursando com múltiplas lesões (AKERS A, et al., 2017). A MC é definida como um conjunto de canais vasculares sinusoidais dilatados de forma anormal, bem delimitados e localizados principalmente em hemisférios cerebrais, cerebelo e medula espinhal (GANMORE I e ACHIRON $A, 2017)$. Clinicamente, predominam as crises convulsivas $(35-70 \%)$, seguidas por hemorragias intracranianas e sintomas neurológicos focais, enquanto $20-50 \%$ dos casos são assintomáticos. A hemorragia intracraniana é a principal complicação da $M C$ que demanda tratamento neurocirúrgico, que, no entanto, pode ser dificultada em razão da localidade anatômica (STAPLETON CJ e BARKER FG, 2018).

\section{OBJETIVO}

Relatar o caso de uma paciente com alterações visuais, previamente diagnosticada com migrânea, sendo posteriormente detectada hemorragia compatível com MC mesencefálica associada a outras MVI ocultas à ressonância magnética $(\mathrm{RM})$.

\section{ESTUDO DE CASO}

Caso cedido por B.A.S, feminino, 38 anos, mediante Termo de Consentimento Livre e Esclarecido. Em 2007, iniciou com cefaleia intensa $(\mathrm{Cl})$, em faixa e queimação, com predomínio frontal, associada à perda de campo visual. Diagnosticada com migrânea, sendo realizada profilaxia semestral com topiramato. Posteriormente, ressonância magnética $(\mathrm{RM})$ detectou anomalia de retorno venoso localizada nas profundezas do tálamo esquerdo (E). Em 2016, Cl rescindiu com duração de 2 dias e evoluiu com visão turva bilateral por 2 meses. Exame oftalmológico sem alterações. RM identificou MVI ocultas: cavernomas no tálamo direito (D) e pedúnculo cerebral $E$; telangiectasias no lobo frontal $D$ e parassagital à $D$ na base da ponte e anomalia de desenvolvimento venoso no tálamo E. Após 1 mês, nova RM mostrou regressão do volume da lesão hemorrágica no pedúnculo cerebral E. Exame neurológico sem alterações. Paciente realiza exame de acompanhamento a cada 2 anos. Desde o episódio de 2016, foi orientada a restringir o consumo de bebidas alcoólicas, cafeína, realizar atividade física e não ter ganho excessivo de peso.

\section{CONSIDERAÇÕES FINAIS}

Em razão de proximidade anatômica entre o pedúnculo cerebral e o trato óptico, supõe-se que a hemorragia pode ter causado acometimento do nervo óptico, levando às alterações visuais. Ademais, ainda que haja passagem das fibras do trato corticoespinhal pelo pedúnculo cerebral, inesperadamente não houve nenhuma alteração motora. Ressalta-se a importância do caso devido ao desconhecimento da $\mathrm{MC}$ e das suas complicações, embora seja uma patologia comum ( $0,5 \%$ da população). 


\section{REFERÊNCIAS}

1. AKERS A, et al. Synopsis of Guidelines for the Clinical Management of Cerebral Cavernous Malformations: Consensus Recommendations Based on Systematic Literature Review by the Angioma Alliance Scientific Advisory Board Clinical Experts Panel. Neurosurgery, 2017; 5(80): 665-680.

2. GANMORE I, ACHIRON A. Cerebral Cavernous Malformations. New England Journal of Medicine, 2017; 377(1): 71-80.

3. STAPLETON CJ, BARKERII FG. Cranial Cavernous Malformations: Natural History and Treatment. Stroke: American Heart Association. Boston, 2018; 49(4): 1029-1035. 
RESUMOS SIMPLES: Revisão Bibliográfica

Título: Staphylococcus aureus resistente à meticilina: um estudo sobre a pravalência de infecções nosocomiais

Autor/coautores: Joana Vitória Cardoso Marold; Daniel Aguiar Pires; Leonardo Germano da Silva; Luiza Helena Santos Giorni; Gabrielly Borges Machado.

Instituição: Centro Universitário Atenas (UniAtenas) - Paracatu, Minas Gerais.

Palavras-chave: MRSA, Prevalência, Infecções.

\section{INTRODUÇÃO}

As infecções nosocomiais constituem consideráveis problemáticas no que tange à Saúde Pública, devido a frequência com que ocorrem. Com relação a prevalência das infecções por MRSA, nota-se um aumento significativo de casos no cenário hospitalar. Staphylococcus aureus (SA) é uma bactéria gram positiva, coexistindo na microbiota da nasofaringe ou da pele humana. Entretanto, quando há ruptura da barreira de proteção, ela pode invadir tecidos, causando infecções com graves repercussões clínicas (LEE SA, et al., 2018). No decorrer dos anos, através de processos mutacionais, essas bactérias desenvolveram mecanismos de resistência aos antibióticos da classe dos beta-lactâmicos, principalmente à ação da Meticilina, que era amplamente empregada (HASSOUN A, et al., 2017).

\section{OBJETIVO}

Revisar o principal mecanismo mutacional pelo qual a SA se tornou uma bactéria resistente à ação dos betalactâmicos, além de expor a epidemiologia relacionada a infecção por MRSA e sua problemática quando em cenário nosocomial.

\section{REVISÃO BIBLIOGRÁFICA}

Por meio de mutações a SA adquiriu um cromossomo denominado mec que permite a síntese de uma proteína de baixa afinidade a beta lactâmicos tornando-a resistente a uma vasta quantidade de medicamentos e dessa forma levando a um tratamento restrito (HASSOUN A, et al., 2017). Salgado et al. afirma que 1,3\% da população geral é colonizada pela MRSA. Outros estudos apontam que aproximadamente $15 \%$ da população são considerados portadores persistentes da bactéria e $70 \%$ portadores intermitentes (são infectados diversas vezes mas conseguem se recuperar espontaneamente da infecção). Ademais, observase que ser portador de MRSA em ambiente hospitalar aumenta em 9,5 vezes o risco de desenvolver infecções se comparado a não portadores (LEE SA, et al., 2018). No caso dos pacientes que estão hospitalizados percebe-se que a infecção pela MRSA é prolongada principalmente pela existência de lesões crônicas de pele como úlceras de decúbito, além de outras comorbidades como diabetes e doença renal crônica. Nota-se também dificuldade no diagnostico precoce da infecçao o que dificulta o tratamento.

\section{CONSIDERAÇÕES FINAIS}

Devido ao aumento da resistência do MSRA, a prevalência das infecções nosocomiais apresentou uma elevação considerável, ademais, pacientes hospitalizados apresentarem infecção mais duradoura em decorrência da presença de comorbidades. Diante disso, são necessarios mais estudos e investimentos a fim de obter-se o controle do MSRA, além de novas pesquisas e medidas preventivas inovadoras. 


\section{REFERÊNCIAS}

1. LEE SA, et al. Methicillin-resistant Staphylococcus aureus. Nature Reviews, 2018; 4(18033):1-23.

2. HASSOUN A, et al. Incidence, prevalence, and management of MRSA bacteremia across patiente populations - a review of recent developments in MRSA management and treatment. Critical Care, 2017; 21(211):1-10.

3. SALGADO CD, et al. Community - Acquired Methicillin- Resistant Staphlococcus aureus: a meta-anaysis of prevalence and risk factors. Clinical Infectious Diseases, 2003; 36(2):131-139. 
RESUMOS SIMPLES: Revisão Bibliográfica

Título: Principais consequências da prática de automedicação em idosos: uma revisão integrativa

Autor/coautores: Thamara Riana de Aguiar Barbosa Interaminense Guerra; Ana Roberta Negromonte da Silva; Maria Isabelle Barbosa da Silva Brito.

Instituição: Universidade Católica de Pernambuco, UNICAP, Recife, Pernambuco, Brasil; Universidade de Pernambuco, UPE, Recife, Pernambuco, Brasil; Instituto Aggeu Magalhães, Fiocruz/PE, Recife, Pernambuco, Brasil.

Palavras-chave: Automedicação, Uso de Medicamentos, Idoso.

\section{INTRODUÇÃO}

A automedicação tem como um de seus conceitos o uso de medicamentos sem a devida prescrição, tornando-se um ato que, associado ao uso indiscriminado, acarreta riscos ao organismo (FERNANDES WS e CEMBRANELLI JC, 2015). Quando se enfatiza a população idosa, observa-se que há fatores predisponentes que intensificam o risco dessa prática, muito embora, a automedicação seja ainda pouco estudada nesse grupo etário (OLIVEIRA MA, et al., 2012). Dessa forma, o uso de medicação de forma indevida e sem uma avaliação prudente do profissional habilitado, pode acarretar reações adversas, aparecimento de sintomatologia inespecífica e piora da condição de saúde (SECOLI SR, et al., 2018).

\section{OBJETIVO}

Identificar as principais consequências da prática de automedicação em idosos a partir da descrição dos fatores responsáveis pelo uso de medicamentos sem prescrição, da sintomatologia apresentada e dos grupos de medicamentos mais utilizados.

\section{MÉTODO}

Trata-se de uma revisão integrativa, realizada de abril a junho de 2020, através da base de dados da Biblioteca Virtual em Saúde. Foi utilizado o intervalo dos últimos cinco anos, a combinação de descritores "Automedicação", "Uso de Medicamentos" e "Idoso", e o operador "AND". A inclusão dos estudos teve como base a pergunta condutora: Quais as principais consequências da prática de automedicação em idosos? Resultando numa amostra de 17 artigos.

\section{REVISÃO BIBLIOGRÁFICA}

Os principais fatores responsáveis pela automedicação nos idosos são: reutilização de receituários ou sobras de drogas antigas, facilidade de aquisição e influência por parte de amigos e familiares (FERNANDES WS e CEMBRANELLI JC, 2015). Buscam principalmente os anti-inflamatórios não esteroides (AINES), relaxantes musculares, anti-histamínicos, antipiréticos, analgésicos e polivitamínicos (GUSMÃO EC, et al., 2019). As principais razões para automedicação são: minimizar a dor e suplementação, que podem estar atreladas a uma doença crônica, sendo necessário um tratamento específico. As interações medicamentosas podem acarretar efeitos adversos como sangramentos e úlceras gastrointestinais pelo uso de AINES; fraturas ósseas advindas de quedas, como consequência dos relaxantes musculares, dentre outros (SECOLI SR, et al., 2018).

\section{CONSIDERAÇÕES FINAIS}

Observa-se a automedicação como prática presente nessa população, tendo como cerne o incentivo por outros e o livre acesso aos medicamentos, usufruindo tanto de fármacos isentos de prescrição como aqueles 
potencialmente inapropriados, com seu uso apresentando significativas consequências maléficas, principalmente para os senescentes, graças às alterações fisiológicas inerentes da idade. Assim, mostra-se a relevância de uma maior atenção a esclarecimentos sobre os malefícios dessa prática e necessidade de constante monitorização.

\section{REFERÊNCIAS}

1. FERNANDES WS; CEMBRANELLI JC. Automedicação e o uso racional de medicamentos: o papel do profissional farmacêutico no combate a essas práticas. Revista Univap, 2015; 21 (37): 5-12.

2. OLIVEIRA MA, et al. Automedicação em idosos residentes em Campinas, São Paulo, Brasil: prevalência e fatores associados. Caderno de Saúde Pública, 2012; 28(2): 335-45.

3. SECOLI SR, et al. Tendência da prática de automedicação entre idosos brasileiros entre 2006 e 2010: Estudo SABE. Revista Brasileira de Epidemiologia, 2018; 21 (2): e180007. 